\title{
Mesenchymal Igf2 is a major paracrine regulator of pancreatic growth and function
}

Constanze M. Hammerle ${ }^{1,2, \oint_{1} *}$, Ionel Sandovici ${ }^{1,2,3, *}$, Gemma V. Brierley $^{1}$, Nicola M. Smith ${ }^{1,2}$, Warren E. Zimmer ${ }^{4}$, Ilona Zvetkova ${ }^{1}$, Haydn M. Prosser ${ }^{5, \S \S}$, Yoichi Sekita ${ }^{1, \S \S \$}$, Brian Y.H. Lam ${ }^{1}$, Marcella Ma ${ }^{1}$, Wendy N. Cooper ${ }^{1,2}$, Antonio Vidal-Puig ${ }^{1}$, Susan E. Ozanne ${ }^{1}$, Gema Medina-Gómez $^{6}$ \& Miguel Constância ${ }^{1,2,3}$

${ }^{1}$ University of Cambridge Metabolic Research Laboratories and MRC Metabolic Diseases Unit, Institute of Metabolic Science, Addenbrookes Hospital, Cambridge CB2 0QQ

${ }^{2}$ Department of Obstetrics and Gynaecology and National Institute for Health Research Cambridge Biomedical Research Centre, Cambridge CB2 OSW, United Kingdom

${ }^{3}$ Centre for Trophoblast Research, Department of Physiology, Development and Neuroscience, University of Cambridge, Cambridge CB2 3EG, United Kingdom

${ }^{4}$ Department of Medical Physiology, Texas A\&M Health Science Center, College Station, Texas, United States of America

${ }^{5}$ The Wellcome Trust Sanger Institute, Genome Campus, Hinxton, CB10 1SA, United Kingdom

6 Área de Bioquímica y Biología Molecular, Departamento de Ciencias Básicas de la Salud, Universidad Rey Juan Carlos, 28922-Alcorcón, Madrid, Spain

$\S$ Present address: Novo Nordisk A/S, DK-2880 Bagsværd, Denmark

$\S \S$ Present address: Cambridge Institute of Therapeutic Immunology \& Infectious Disease. Jeffrey Cheah Biomedical Centre, Cambridge Biomedical Campus, University of Cambridge, CB2 OAW, United Kingdom

$\S \S \$$ Present address: Laboratory of Stem Cell Biology, Department of Biosciences, Kitasato University School of Science, Kanagawa 252-0373, Japan

* These authors contributed equally to this work.

Correspondence and requests for materials should be addressed to M.C. (email: imasmc2@cam.ac.uk). 


\begin{abstract}
The genetic mechanisms that determine the size of the adult pancreas are poorly understood. Here we demonstrate that many imprinted genes are highly expressed in the pancreatic mesenchyme, and explore the role of Igf2 in-vivo. Mesenchyme-specific Igf2 deletion results in acinar and beta-cell hypoplasia, postnatal whole-body growth restriction and maternal glucose intolerance during pregnancy. Surprisingly, mesenchymal mass is unaffected, suggesting that the mesenchyme is a developmental reservoir of IGF2 used for paracrine signalling. The unique actions of mesenchymal IGF2 are demonstrated by the absence of phenotypes upon lgf 2 deletion in the developing pancreatic epithelium. Furthermore, increased IGF2 activity specifically in the mesenchyme, through lgf2 loss-of-imprinting or $\operatorname{lgf} 2 \mathrm{r}$ deletion, leads to pancreatic acinar overgrowth. Ex-vivo exposure of primary acinar cells to exogenous IGF2 increases cell proliferation and amylase production through AKT signalling. We propose that mesenchymal lgf2, and perhaps other imprinted genes, are key developmental regulators of adult pancreas size and function.
\end{abstract}

\title{
Introduction
}

The mammalian pancreas plays a central role in energy homeostasis, which is achieved by functionally and morphologically distinct exocrine and endocrine components. Optimal pancreatic function requires a match between pancreas size and the physiological demands of the host organism. However, the genetic determinants of organ size, and the mechanisms that achieve adequate relative organ size, are poorly understood. The size of the pancreas is thought to be fixed early in development, limited by the size of the progenitor cell pool that is set-aside in the developing pancreatic bud ${ }^{1}$. In addition to autonomous cues in the epithelium, pancreatic development is also dictated by non-autonomous signals from the mesenchyme. Mesenchymal cells overlie the developing pancreatic bud and provide critical signals for the expansion of both precursors and differentiated endocrine and exocrine cells ${ }^{2}$. These cells are present throughout pancreas organogenesis but the relative proportion of mesenchyme to epithelium shifts, with a dramatic reduction over time, as the epithelial cells expand. Recent elegant genetic manipulation approaches have shown that mesenchymal cells regulate pancreatic growth and branching at both early and late in utero developmental stages ${ }^{2,3}$. However, many of the mesenchymal signals that control these processes remain un-identified. Moreover, the factors required for cell fate decisions that specify individual pancreas cell type subsets are fairly well established but less is known about signalling pathways involved in proliferation and survival of cell types.

Insulin-like growth factors (IGF1 and IGF2) are small mitogenic polypeptides ( 7KDa) with structural homology to pro-insulin. Although IGFs expression is ubiquitous in many cell types, they are most 
abundant in the cells and tissues of mesodermal origin, and form important components of stem cell niches $s^{4,5,6,7,8,9}$. lgf2 transcription is regulated by genomic imprinting ${ }^{10}$, an epigenetic process that causes a subset of genes in the genome to be transcribed according to parental origin. Imprinted genes regulate key aspects of mammalian physiology, from growth to energy homeostasis ${ }^{11}$. In most mouse and human tissues, lgf2 is only transcribed from the paternally inherited allele, with the maternal allele being repressed by a methylation sensitive CTCF-dependent boundary that restricts the access of downstream enhancers to the $\lg f 2$ gene promoters ${ }^{12}$. In humans, reduced $\lg 2$ expression contributes to the intra-uterine growth restriction in patients with Silver-Russell syndrome $^{13}$. Conversely, bialellic lgf2 expression caused by loss of lgf2 imprinting is observed in Beckwith-Wiedemann patients ${ }^{14}$, a syndrome characterized by somatic overgrowth, neonatal hypoglycaemia with variable penetrance and increased predisposition to tumours. In mice, increased supply of embryonic lgf2 above biallelic expression can result in disproportionate overgrowth associated with heart enlargement, oedema and fetal death ${ }^{15}$. Igf2 null mice are viable, depending on the genetic background, with almost half the adult body weight ${ }^{15}$.

Key questions about how IGF2-mediated growth effects are developmentally programmed and how IGF2 contributes to organ growth control in-vivo remain unanswered. The normal timing, location and duration of IGF2 supply at the organ level are likely to be crucially important. The pancreas serves as an interesting model for the study of these processes, as it requires tight spatial and temporal regulation of proliferation, differentiation and morphogenesis. Very little is known about the main sites of lgf2 expression and imprinting during pancreas development. Moreover, most mouse transgenic studies conducted so far have been directed to the beta-cells, in which lgf2 is overexpressed $^{16,17}$ or knocked-out ${ }^{18}$, or focused on mice that overexpress $\lg f 2^{19,20}$ or lack lgf1 and Igf2 constitutively ${ }^{21}$.

Here we describe the generation of a conditional knock-out allele for Igf2 and perform systematic analyses of cell-type specific deletions that target the developing pancreatic mesenchyme (Nkx3.2Cre), epithelium (Ptf1a-Cre) or beta-cell (RIP-Cre), with the overall aim of defining the paracrine and autocrine roles of IGF2 in pancreatic growth. We demonstrate that the mesenchyme is a developmental reservoir of IGF2 that acts as an essential signal for exocrine and endocrine pancreas growth. We found little evidence for autocrine or paracrine growth effects of IGF2 from the developing epithelium, which is consistent with the low levels of expression seen in the epithelium when compared to the mesenchyme. Our findings show that the pancreatic hypoplasia caused by Igf2 deletion from the mesenchyme is associated with reduced whole-body weight around weaning and onwards. To our knowledge, this constitutes the first evidence that organ-specific lgf2 expression in fetal life can program the growth trajectory of the entire organism in post-natal/adult 
life. Furthermore, we show that glucose homeostasis is impaired in pregnant females that lack pancreatic mesenchymal Igf2. Together, these results uncover previously unanticipated roles for mesenchymal lgf2 in controlling the normal development and function of the pancreas, with important consequences for energy homeostasis regulation.

\section{Results}

\section{Generation of $\operatorname{lgf} 2^{+/ f f}$ mice and pancreas cell-type specific lgf2 knockouts}

Mice containing a floxed $\lg f 2$ allele $\left(\lg f 2^{+/ f 1}\right)$ were generated (see Methods and Supplementary Fig. 1) and crossed with transgenic strains that express Cre recombinase in the main cell types of the developing pancreas, i.e. Nkx3.2-Cre: mesenchyme; Ptf1a-Cre: epithelium, i.e. exocrine, endocrine and ducts; RIP-Cre: beta-cells. Recombination between the two loxP sites led to inactivation of the Igf2 gene via deletion of all coding exons (Supplementary Fig. 2). To confirm the efficiency of the Cre transgenics, we used a recombinase inducible YFP reporter under the control of the Rosa26 locus $\left(\right.$ Rosa26YFP-stop $\left.{ }^{\mathrm{fl} / f l}\right)$. This reporter was bred into the $\operatorname{lgf} 2^{+/ f l}$ background to generate an $\operatorname{lgf} 2^{+/ f l}$; Rosa26YFP-stop ${ }^{f / f l}$ strain. In these mice, Cre expression causes inactivation of $/ g f 2$, as well as expression of YFP, which can be identified by immunofluorescence and/or flow cytometry. Using these methods, we confirmed the specificity of each Cre line, showed that lgf2 is inactivated efficiently and that $I g f 2$ is mainly expressed from the paternal allele in the diverse pancreatic cell types (Supplementary Figs. 3 and 4). All genetic crosses used throughout, unless otherwise stated, refer to paternal transmission of the $/ g f 2$ floxed allele $\left(I g f 2^{+/ f l}\right)$ with maternal transmission of a Cre allele (Nkx3.2 $2^{\mathrm{Cre} /+} ;$ Ptf $1 a^{\mathrm{Cre} /+}$ or $\left.R I P^{\mathrm{Cre} /+}\right)$.

\section{The mesenchyme is the main source of Igf 2 in the developing pancreas}

We first sought to establish which major cell types within the developing mouse pancreas express lgf2 transcripts and to determine their relative levels using fluorescence activated cell sorting (FACS).

An expression timeline analysis, from E16 to adult, revealed that mesenchymal cells express the highest levels of Igf2 mRNA when compared to beta-cells or non-mesenchyme (which is comprised of exocrine, endocrine, ductal and endothelial cells) (Fig. 1a). At E16, mesenchyme cells express 380 fold more Igf2 than beta-cells and 1.5 fold more than non-mesenchyme cells. At P14, the difference between mesenchyme and non-mesenchyme is greatest, with mesenchymal cells expressing 700 fold more lgf 2 than non-mesenchyme cells. The levels of lgf2 in mesenchyme remain high in the neonatal period until the weaning period (at P21 levels are 3.2 fold reduced compared to E16, followed by a steep decline in adulthood) (Fig. 1a). Interestingly, both non-mesenchyme cells and the beta-cells decrease their Igf2 expression levels after E16. In situ hybridization analysis at P5 
shows that lgf2 transcripts are localized in mesenchymal structures surrounding vessels and ducts, with low to undetectable expression in beta and acinar cells (Fig. 1b).

To measure more precisely the contribution of the various cell types to overall pancreatic lgf2 levels, cell-type specific lgf2 knockouts were analysed at the neonatal stage P2. The mesenchyme contributes approximately $10 \%$ of the pancreatic tissue at this time point, as measured by stereology (Fig. 1c). Notably, deletion of Igf2 from those cells reduced total $\lg f 2$ pancreatic levels to $16 \%$ of normal (Fig. 1d). Ptf1a-Cre mediated deletion of Igf2 in exocrine, endocrine and ductal cells showed no discernible changes in whole pancreas Igf2 mRNA, which is consistent with the in situ hybridisation data shown in Fig. 1b. Deletion of Igf2 from endothelial cells (mediated by Tek-Cre) reduced Igf2 mRNA to approximately $75-80 \%$ of control levels (Fig. 1d).

Mesenchyme-specific lgf2 signalling controls the growth of exocrine and endocrine pancreas, but has no autocrine actions

To assess whether mesenchymal lgf2 plays a role in the programming of early growth of the pancreas, Igf $2^{+/ f l} ; N_{k \times 3.2} 2^{\text {Cre/+ }}$ knockout mice were first analysed at the neonatal stage P2 (Fig. 2a,b). Mice with deletion of the paternal lgf2 allele have normal body weight, but significantly lighter pancreases compared to littermate controls (69\% of normal; Fig. $2 \mathrm{c}$ and Supplementary Fig. 5a). Deletion of the maternal Igf2 allele has no phenotypic effects, which is consistent with findings that the maternal allele is transcriptionally inactive due to imprinting (Supplementary Figs. 5b,c). Importantly, Nkx3.2-Cre or Igf2 floxed carrier mice are indistinguishable from wild-type littermates (Supplementary Figs. 5a,b). We next measured the number of cell nuclei in DAPI-stained paraffin sections to establish if the loss of pancreas weight was due to hypoplasia. We found that the number of cell nuclei was significantly reduced in mutants compared to controls ( $74 \%$ of normal - Fig. $2 \mathrm{~d}$ ). This finding suggests that mutant pancreases are smaller due a reduction in cell numbers, which is in agreement with the well-established role for IGF2 in the control of cell proliferation and survival. Stereological analysis revealed that loss of $\lg f 2$ in pancreatic mesenchyme leads to decreases in acinar and beta cell mass, in line with the overall pancreas weight deficit (Fig. 2e). Also consistent with the decrease in acinar mass, mutant pancreases contained lower amounts of lipase (Fig. 2f). Interestingly, mesenchyme mass was not altered in mutants compared to controls, suggesting lack of autocrine actions of mesenchyme-derived IGF2 (Fig. 2e). To explore this hypothesis further, we performed a mesenchyme-specific deletion of the receptor that mediates the classic IGF2 actions on cell growth and survival ${ }^{15}$, the IGF type I receptor (IGF1R) (Supplementary Fig. 6a). Mutant pancreas weights at P2, as well as total body weights, were similar to littermate controls (Supplementary Fig. $6 b)$. Thus, our data reveals that mesenchyme-derived IGF2 is likely to control acinar and beta cell 
growth through paracrine signalling from the mesenchyme, rather than via autocrine effects leading to loss of mesenchymal mass.

\section{Growth effects caused by Igf 2 conditional inactivation are $m i R-483$ independent}

The microRNA miR-483 is located within the intron 4 of $\lg f 2$, which is deleted alongside the $\lg 2$ coding exons 4-6 upon Cre-mediated recombination. To rule out a contributory role of this microRNA to the phenotype, we analysed pancreases of mice carrying a miR-483 deletion ${ }^{22}$, and found that it does not alter pancreas weight at P2 (Supplementary Fig. 7). Furthermore, mir-483 knockout mice are normal sized, viable and show no evidence of impaired glucose homeostasis defects or other discernible phenotypes (Sekita et al. unpublished). We therefore conclude that the growth phenotype in the Igf $2^{+/ f l} ; N k \times 3.2^{\text {Cre/+ }}$ knockout mice can be attributed solely to IGF2 signalling actions.

\section{Mesenchyme-specific Igf2 loss-of-imprinting or $\operatorname{lgf} 2 r$ deletion result in pancreatic acinar overgrowth}

We used a well-established mouse model of lgf2 loss-of-imprinting - the H19DMD conditional knockout $^{23}$ - to overexpress /gf2 specifically in the pancreatic mesenchyme (H19DMD ${ }^{\mathrm{f} / /+} ; \mathrm{Nk} \times 3.2^{+/ \mathrm{cre}}$ ) and investigated the effects on acinar growth (Fig. 3a). As expected, deletion of the imprinting control region (DMD) from the maternal allele resulted in increased lgf2 and decreased H19 mRNA levels $(160 \%$ and $18 \%$ of controls, respectively - Fig. $3 b)$ and was associated with a $29 \%$ increase in pancreas weight, with similar body weights between genotypes at P2 (Fig. 3c). The acinar cell mass was increased by $34 \%$, in line with the overall pancreas weight increase (Fig. 3d). We then used an Igf2 gain-of-function model that does not lead to transcriptional changes in Igf2 or H19 but instead results in increased IGF2 protein. Accordingly, we deleted the IGF-type II receptor that is required for recycling IGF2 via lysosome degradation ${ }^{24}$, specifically in the pancreatic mesenchyme $\left(/ g f 2 \mathrm{fl}^{\mathrm{fl} /+}\right.$; $N k \times 3.2^{+/ / \mathrm{Cre}}$ ) (Fig. 3e). Reduced lgf2r mRNA levels in the mesenchyme cells ( $25 \%$ of controls - Fig. 3f), was associated with a $20 \%$ increase in pancreas weight, with similar body weights between genotypes at P2 (Fig. 3g). The acinar cell mass was also increased by $33 \%$ in this model (Fig. $3 \mathrm{~h}$ ). Therefore, the two gain-of-function genetic models further demonstrate that IGF2 produced by the pancreatic mesenchyme cells controls the growth of the acinar cells.

The neonatal pancreatic mesenchyme is enriched in genes related to IGF signalling and imprinted genes 
To investigate further the role of IGF2 signalling in the mesenchyme and its paracrine effects, we first performed genome wide-transcriptional profiling by RNA-seq in mesenchymal and nonmesenchymal cells isolated by FACS from P2 wild-type pancreata. 4,114 genes were found differentially expressed (fold change $>1.5$; FDR adjusted $p$ value $<0.05$ ) between the mesenchyme and non-mesenchyme cells in wild-type $/ g f 2^{+/+}$pancreas (Supplementary Data 1 ). A number of these genes were validated by qRT-PCR in biological replicates (Supplementary Fig. 8a). Genes highly enriched in mesenchyme include several which have been shown to be expressed in embryonic pancreatic mesenchyme at E11.5 ${ }^{2,3}$ (e.g. Hgf, Sfrp1, Tgfb3, Tgfb2) (Fig. 4a). Using DAVID functional annotation (see Methods) we identified over 20 significantly enriched GO terms (FDR adjusted $p$ value $<0.05$ ) (Fig. 4b), which included biological processes known be involved in pancreatic mesenchyme function (e.g. Wnt signalling), early pancreas development (e.g. retinoic acid and SMAD signalling) and epithelial-mesenchymal interactions (integrin-mediated signalling, cell adhesion, collagen catabolism). This analysis also highlighted unexpected pathways, such as semaphorin-plexin and insulin-like growth factor receptor signalling (Fig. 4b). Several gene members of the IGF signalling family are highly enriched in mesenchyme versus non-mesenchyme (Fig. 4c), with lgf2 being the highest expressed gene in pancreatic mesenchyme (Fig. 4d) and one of the most enriched compared to non-mesenchyme (53 fold; Fig. 4a and Supplementary Data 1). Interestingly, imprinted genes with known roles in growth control make up almost one third of the top 30 genes expressed in the pancreatic mesenchyme (Fig. 4 d).

As expected, the non-mesenchyme $\lg \mathrm{f}^{+/+}$fraction is highly enriched for genes expressed by different endocrine cell types, such as Ins1 (90 fold enriched), $P d \times 1$ (126 fold), Gcg (116 fold) and Sst (123 fold) and genes encoding digestive enzyme such as Amy2b (83 fold), Pnliprp1 (69 fold), Cela1 (49 fold) and Try10 (42 fold), (Fig. 4a and Supplementary Data 1). Supplementary Fig. 8b shows the top 30 expressed genes in the non-mesenchyme fraction.

\section{Mesenchymal lgf2 loss-of-function leads to widespread transcriptional changes in the pancreatic epithelium}

To investigate the molecular signatures associated with paracrine effects, we performed genome wide-transcriptional profiling by RNA-seq in both fractions of $1 \mathrm{gf2} 2^{+/ f l} ; \mathrm{Nk} \times 3.2^{\mathrm{Cre} /+}$ mutants (i.e. mesenchyme cells with Igf2 deleted and the corresponding non-mesenchyme fraction), compared to mesenchyme and non-mesenchyme cells isolated from controls, at the neonatal P2 stage. We found that transcriptional changes are far more widespread in the non-mesenchyme fraction (498 differentially expressed genes with $>1.5$-fold change and FDR-adjusted $p$ value $<0.05$ ) (Fig. 5a and Supplementary Data 2) than the Igf2-deficient mesenchyme itself (151 differentially expressed 
genes; Fig. 5a and Supplementary Data 3). DAVID functional annotation identified 15 enriched GO terms in the non-mesenchyme fraction (Fig. $5 \mathrm{~b}$ and Supplementary Data 2 ) but only 2 in the Igf2deficient mesenchyme fraction (namely, actin binding and inflammatory response, Supplementary Data 3). These findings are in agreement with the stereological analyses showing that loss of Igf2 from the mesenchyme impacts on the growth/function of the non-mesenchymal fraction through a paracrine effect, but not the growth of the mesenchyme itself. The top biological processes in the non-mesenchyme fraction enriched in genes up-regulated in mutants were related to digestion, inflammation/immune responses, apoptosis and ERK1/2 signalling, and biological processes enriched in genes down-regulated in mutants were related to tRNA methylation and erythrocyte development (Fig. 5c and Supplementary Data 2).

\section{Mesenchymal cells secrete IGF2 and acinar cells respond functionally to exogenous IGF2 ex-vivo}

To provide evidence that mesenchyme-derived IGF2 acts on acinar cells in a paracrine manner, we isolated primary mesenchyme and acinar cells from P2 pancreata (see Methods) (Fig. 6a,b). Mesenchymal cells secreted higher levels of IGF2 into the conditioned media compared to acinar cells (Fig. 6c), a finding that is consistent with higher levels of lgf2 mRNA expression in the mesenchyme in-vitro and in-vivo (Fig. $6 \mathrm{~b}$ and Fig. 1a,b). We then tested the effect of exogenous IGF2 treatment on acinar cells cultured ex-vivo. Isolated acinar cells treated with recombinant mouse IGF2 showed increasing levels of AKT phosphorylation (S473) in a concentration-dependent manner (Fig. 6d). Additionally, treatment of acinar cells with $50 \mathrm{ng} / \mathrm{ml} \mathrm{IGF2} \mathrm{stimulated} \mathrm{their} \mathrm{proliferation} \mathrm{and}$ led to a modest, but significant increase in amylase production (Fig. 6e). Altogether, the ex-vivo data shows that mesenchyme cells are capable of secreting IGF2 and that exogenous IGF2 induces intracellular signalling in acinar cells, associated with increased enzymatic output.

\section{Post-weaning growth and glucose homeostasis analyses in lgf2 pancreas-cell type specific knockouts}

To investigate the impact of lgf2 loss-of-function from the developing mesenchyme and/or epithelium on post-weaning growth and glucose homeostasis, single and double Nkx3.2-Cre and Ptf1a-Cre lgf2 knockouts, as well as beta-cell specific RIP-Cre lgf2 knockouts, were analysed (Fig. 7a). The pancreas weight deficit observed in single $/ g f 2^{+/ f l} ; N k \times 3.2^{\text {Cre/+ }}$ knockouts at P2 is maintained at weaning (Supplementary Fig. 9a) and is also observed at 9 weeks of age in single $\operatorname{lgf} 2^{+/ f l} ; N k \times 3.2^{\text {Cre/ } /+}$ knockout males and females (Fig. 7b). However, in contrast to the P2 time point, body weights are now reduced, by approximately $12 \%$ at P21 (Supplementary Fig. $9 \mathrm{~b}$ ), and by $5 \%$ and $10 \%$ for females and males, respectively, at 9 weeks of age (Fig. 7c). After normalization for body weight, the mutant 
pancreases remain disproportionately smaller at both P21 and 9 weeks time points (Supplementary Fig. 9a and Fig. 7b).

Double $\operatorname{lgf2} 2^{+/ f l} ; N k \times 3.2^{\mathrm{Cre} /+} ; \operatorname{Ptf1} a^{\mathrm{Cre} /+}$ knockouts show similar pancreatic weights and body weight reductions to the single $\operatorname{lgf} 2^{+/ f 1} ; N k \times 3.2^{\text {Cre/t }}$ knockout (Fig. $7 \mathrm{~b}, \mathrm{C}$ ), thus suggesting that IGF2 produced by the endocrine and exocrine pancreas does not play major autocrine or paracrine growth roles that alter pancreas size. Consistent with this hypothesis, single $\operatorname{lgf} 2^{+/ f l} ;$ Ptf $1 a^{\text {Cre/+ }}$ knockouts have normal pancreas sizes and body weights (Fig. $7 \mathrm{~b}, \mathrm{c}$ ).

Glucose homeostasis, assessed by oral glucose tolerance tests (OGTT), was unaltered in single

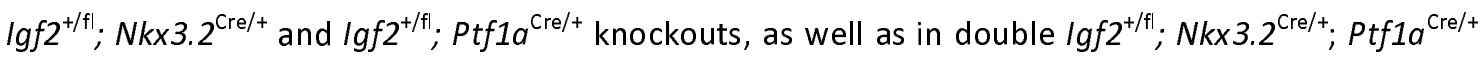
knockouts compared to $/ g \mathrm{f}^{+/ f 1}$ controls at 8 weeks of age (Supplementary Fig. 10a,b). Likewise, body weights and glucose tolerance were similar in beta-cell specific $/ g f 2^{+/ f l} ; R I P^{C r e /+}$ knockouts compared to $\operatorname{lgf2^{+/+}}$; RIP $P^{\text {Cre/+ }}$ controls at 8 weeks (Supplementary Figs. $10 \mathrm{c}, \mathrm{d}, \mathrm{e}$ ). We next assessed glucose homeostasis regulation during pregnancy (representing a naturally occurring metabolic stress state) at $\mathrm{E} 15$ in 8 weeks old $/ g f 2^{+/ f l} ; N k \times 3.2^{\mathrm{Cre} /+}$ and $\operatorname{lgf} 2^{+/ f \mathrm{l}} ; R I P^{\mathrm{Cre} /+}$ knockout females. Pregnant $\operatorname{lgf} 2^{+/ f \mathrm{fl}}$; $N k \times 3.2^{\text {Cre/+ }}$ knockout females are glucose intolerant compared to pregnant $/ g f 2^{+/ f 1}$ littermate controls (Fig. 7d). However, no differences in glucose tolerance were observed between pregnant $/ g f 2^{+/ f l}$; $R I P^{\text {Cre/+ }}$ knockout females and pregnant $I g f 2^{+/+} ; R I P^{\text {Cre/+ }}$ littermate controls (Fig. 7e).

\section{Discussion}

This study uncovers novel roles for IGF signalling in the developmental regulation of adult pancreas size, with consequences for energy homeostasis and post-natal whole body-growth. We first observed that gene members of the IGF signalling pathway, which include IGF2 and IGF1 ligands, are highly enriched in the neonatal mesenchyme compared to the non-mesenchyme cells. Moreover, IGF2 is the top expressed gene in the mesenchyme, as revealed by RNA-seq profiling at Postnatal day 2 (P2). Mesenchymal cells express the highest levels of Igf2 mRNA compared to all other pancreatic cell types from E16 to postnatal 8 weeks. At P2 we estimate, based on conditional deletions of Igf2 from the diverse cell types, that $84-86 \%$ of total $\lg f 2$ in the pancreas is expressed by the mesenchyme, $\sim 15 \%$ by the endothelium and less than $1 \%$ is derived from the epithelium. These conditional deletion studies also show that lgf2 is robustly imprinted (paternally expressed) in all cell types. Therefore, we hypothesized that mesenchymal IGF2/IGF signalling may play previously unanticipated roles in pancreatic development, and generated conditional specific mouse models mainly targeting levels in mesenchyme.

We found that mesenchymal IGF2 is principally required for normal growth of the exocrine pancreas. Deletion of Igf2 from the mesenchyme cells from E9.5 leads to severe hypoplasia of the postnatal 
pancreas ( $\sim 69 \% \mathrm{~N}$ at $\mathrm{P} 2, \sim 67 \% \mathrm{~N}$ at $\mathrm{P} 21$ and $\sim 79-83 \% \mathrm{~N}$ at 9 weeks of age). The acinar mass is mostly affected and is reduced, in line with the overall loss in pancreatic weight. This finding is in agreement with the reports of reduced exocrine mass in mice that lack both IGF ligands, i.e. mice lacking both $\operatorname{lgf1}$ and Igf2 in all cells of the body, or their receptors, i.e. mice constitutively lacking both Insr and $\lg f \mathrm{r}^{21}$. However, the contribution of the individual ligands or receptors to the loss of exocrine mass has remained unclear, mainly because Insr or Igf1r single total knockouts result in either normal or increased exocrine mass, respectively, and single $\lg 1$ or $\lg 2$ total knockouts were not studied for pancreatic phenotypes. Our work now demonstrates that IGF2 is a key promoter factor of acinar growth during development. Crucially, we have ruled out a role for IGF2 expressed in the developing epithelium, which includes IGF2 expressed in acinar cells, as a determinant of exocrine pancreas growth. Accordingly, deletion of lgf2 using Ptf1a-Cre, results in normal pancreatic growth. We therefore conclude that the effect of IGF2 on pancreas growth is restricted to either autocrine and/or paracrine roles in the mesenchyme.

We next addressed the question of how mesenchymal IGF2 regulates pancreas size. We propose that this is mainly achieved through secretion of IGF2 from the mesenchyme and signalling to the neighbouring cells types in a paracrine manner (see model in Fig. 8). This hypothesis is based on the following findings: first, IGF2 does not act in an autocrine manner in the mesenchyme, since its deletion does not lead to a loss of mesenchymal mass. In addition, we found very few transcriptomic changes in the Igf2-deficient mesenchyme. The absence of an autocrine role is further supported by the genetic manipulation of IGF type I receptor, the main receptor mediating cell proliferation effects of IGF ligands. We show that a mesenchyme specific deletion of Igf1r does not affect pancreas growth. We therefore conclude that the effect of lgf2 is not caused by major morphological or functional changes to the mesenchyme that could indirectly affect the growth and development of neighbouring cells. Second, IGF2 regulates acinar growth in a paracrine manner. We used primary cell cultures to show that mesenchyme secretes IGF2 into the culture media, and that exogenous IGF2 promotes proliferation of acinar cells and increased enzymatic output through AKT signalling. In vivo, increased IGF2 activity specifically in the mesenchyme led to significant hyperplasia of the exocrine pancreas, as shown in two distinct genetic models (H19DMD ${ }^{\mathrm{fl} /+}$; $N k \times 3.2^{+/ C r e}$, and $\left.\operatorname{lgf} 2 \mathrm{r}^{\mathrm{fl} / \mathrm{+}} ; \mathrm{N} k \times 3.2^{+/ \mathrm{Cre}}\right)$. Importantly, deletion of Igf2 from the mesenchyme leads to a reduction in beta-cell mass ( $82 \% \mathrm{~N}$ at $\mathrm{P} 2)$, showing that the paracrine effects are not exclusive to the exocrine pancreas. Future studies will be necessary to identify the receptors that mediate the IGF2 actions in the acinar and beta cells.

The lack of mesenchymal IGF2 has important physiological consequences. It is well established that the pancreas size must match the physiological demands of the host organism to promote nutrient 
digestion and absorption in the gut and to maintain glucose homeostasis. In this study, we report that mesenchyme Igf2-deficient mice have a disproportionately smaller pancreas, with a $30 \%$ size reduction at $\mathrm{P} 2$, which is associated with a reduced output of secreted acinar enzymes, such as lipase. Our data suggests that nutrient malabsorption due to loss of exocrine mass and/or exocrine dysfunction might be causative of the postnatal growth restriction, which is first observed in these mice at the weaning stage and maintained throughout adulthood. Mouse models with perturbations of lipase genes such as colipase (Clps) and pancreatic-lipase related protein 2 (Pnliprp2) exhibit a similar body weight growth defect phenotype due to an inability to process fat from mother's milk $^{25,26}$. It has been suggested that the lipase deficiency can programme a "set-point" of body weight, with an inability to catch-up in body weight later on, due to the effects of poor weight gain during the suckling period ${ }^{25,26}$. Interestingly, RNA-seq shows that mesenchyme Igf2-deficient pancreases upregulate transcription of exocrine genes involved in the production of digestive enzymes. We suggest that these changes represent adaptive responses of the small exocrine pancreas to meet the demand for digestion and absorption of nutrients in early postnatal life. However, this compensatory mechanism might not be sufficient to match demand, and whole-body growth restriction ensues. The RNA-seq studies also showed increased expression of chemokines, which are normally up-regulated by pro-inflammatory stimuli and attract immune cells by inducing a response from the innate and adaptive immune system ${ }^{27,28}$. Whether a pre-pancreatitis state exists, linked to the premature activation of digestive enzymes in the interstitial space of the pancreas, and how such a state might contribute to putative nutrient absorption abnormalities require further investigation. We also observed that the loss of IGF2 paracrine effects from the mesenchyme results in a modest reduction of the beta-cell mass that does not impact on glucose homeostasis control in young mice under a normal diet and physiological state. However, induced metabolic stress, as it occurs naturally during pregnancy, leads to glucose intolerance. It remains to be established if pregnancy-related beta-cell mass expansion is impaired and the extent to which other metabolic stress states, such as aging, high fat diet, acute insulin resistance states, may also uncover mesenchymal IGF2 effects on beta-cell function. Finally, we found little evidence for an autocrine growth action of IGF2 in the beta-cell that would have an impact on glucose homeostasis regulation under normal physiology. Beta-cell mass is unaffected by beta-cell specific lgf2 deletion at 42 weeks in chow fed animals (Hammerle et al., unpublished). These results are largely similar to those recently reported in 24-26 weeks old beta-cell specific Igf2 knockout mice fed with normal chow $\operatorname{diet}^{18}$.

Our findings offer novel insights into mesenchymal factors that regulate pancreas organogenesis. Wnt, BMP, FGF and Hedgehog signalling pathways have been implicated as early mesenchymal 
factors regulating pancreas development and growth ${ }^{2,29,30,31,32}$, but for the majority of these studies the specific roles in the mesenchyme could not be assessed (only recently it has been possible to start interrogating the roles that genes play in the mesenchyme with the generation of specific Cre recombinases). To our knowledge, this study, using a combination of loss and gain-of-function conditional mouse models, is the first to identify a mesenchymal-specific paracrine growth signal of the developing pancreas. It also reveals that IGF signalling plays previously unappreciated roles in the mesenchyme function and in the epithelial-mesenchymal interactions during pancreas organogenesis. Igf1, like lgf2, is highly enriched in the mesenchyme compared to non-mesenchyme cells and paracrine release of IGF1 from fibroblasts, which derive from the primitive mesenchyme, stimulate acinar cell proliferation during regeneration from acute pancreatitis ${ }^{33}$. Interestingly, deletion of Igf 1 from the developing epithelium also results in normal exocrine pancreas growth ${ }^{34}$, similarly to the results reported here for $\lg f 2$. Further conditional knockout studies will be required to examine mechanistic aspects of the role of mesenchymal IGF1, and to establish which receptors are important as signalling transducers for IGF1 and IGF2. Our study has also highlighted a number of growth-related imprinted genes (including Plag/1/Zac1 a master regulator of an imprinting growth network $^{35}$ ) that are highly enriched in the mesenchyme, and raises the interesting hypothesis that genomic imprinting contributes significantly to mesenchymal-specific functions during pancreas development.

In summary, we report in this study that IGF2 growth actions in the pancreas are limited to the highly expressing mesenchyme, and that size-determining mechanisms are programmed in early life by the activity of this important growth factor in a paracrine fashion, with consequences for postnatal physiology. In general, this work provides novel insights into how growth factors control pancreatic architecture and is highly relevant to pancreas pathologies, from diabetes to cancer.

\section{Methods}

\section{Generation of the $\lg f 2^{\mathrm{fl} /+}$ mouse}

The Igf2 gene targeting vector carried a loxP site inserted 5 ' of exon 4 and a loxP-flanked neomycin resistance cassette (neoR) inserted 3' of exon 6 (Supplementary Fig. 1a). Details of the cloning procedures are available upon request. In brief, we used a 3.1-kb Sall-Pacl genomic fragment (from exon 2 to intron 3 of $\operatorname{lgf} 2$ ) as the $5^{\prime}$ region of homology $\left(5^{\prime}-\mathrm{ROH}\right)$, a 5.8-kb Pacl-Afel genomic fragment that includes the entire Igf2 coding sequence (exons 4 to 6 ) as internal ROH (Int-ROH), and a 3.1-kb Afel-Blpl genomic fragment ( $3^{\prime}$ of exon 6$)$ as $3^{\prime}-\mathrm{ROH}$. The Int-ROH was flanked by a $5^{\prime}$ loxP site and a 3' loxP-neoR-loxP sequence (Supplementary Fig. 1a). The targeting vector was linearized at a unique $S c a l$ site outside the area of homology and $50 \mu \mathrm{g}$ linearized vector were electroporated into 
passage 9, E14 129ola male ES cells, at $250 \mathrm{~V}$ and $950 \mu \mathrm{F}$. Transfected cells were plated onto 10 gelatinized $100-\mathrm{mm}$ dishes pre-seeded with fibroblast feeder cells. After $24 \mathrm{~h}$ in nonselective medium, cells were incubated for 8 days with $\mathrm{G} 418$ medium $(200 \mu \mathrm{g} / \mu \mathrm{l})$ to select for neomycin resistance. Resistant clones were picked at day 9 and expanded into 96-well plates pre-seeded with fibroblast feeder cells. We initially screened $384 \mathrm{G} 418$-resistant clones by Southern blotting analysis of genomic DNA (gDNA) digested with EcoRI and hybridized the blots with a unique $511 \mathrm{bp} 5$ ' probe (located external to 5'-ROH and obtained by PCR amplification using primers 5'Pr-F: 5'AACAACGCGGTGGTAGgGAA-3' and 5'Pr-R: 5'-TCAgCAGAAAAAGAAGCAGGGC-3'). Two correctly targeted clones at the $5^{\prime}$ end were then verified by Southern blot (EcoRI digested DNA) using a 590 bp 3' probe (located external to 3'-ROH and obtained by PCR amplification using primers 3'Pr-F: 5'ACAAAGCCCAAGACAACTCC-3' and 3'Pr-R: 5'-CTTCCACAGTTCAAGCAACC-3') and an additional check for multiple integrations elsewhere in the genome using a 583 bp Internal probe (located in Igf2 exon 6 and obtained by PCR amplification with primers Int-F: 5'-AGAACCCAAGAAGAAAGGAAG-3' and Int-R: 5'-AGAAAGACAGAACTAGCAGCC-3'). One clone with a single integration site and correctly targeted $5^{\prime}$ and $3^{\prime}$ loxP sites was thus identified (Supplementary Fig. 1b), with the loxP sequences further verified by Sanger sequencing (data not shown). The neoR cassette was excised by transiently transfecting this ES cell clone with Cre recombinase (pMC-Cre vector), followed by two rounds of subcloning. Correctly excised clones that carry a single $3^{\prime}$ loxP site were verified by PCR screening (480 ES subclones) and gDNA digestion with Sphl restriction enzyme, followed by Southern blot analysis using the same 583 bp Internal probe described above (Supplementary Figs. 1c-f). Primers used for PCR screening of in vitro neoR deletion were: F0 5'-TGACCTCAGCAATTCAAGTCC-3'; F1 5'-GGTAGTGGTCTTTGGCATCC-3' and R1 5'-CAATAACTGGGGAAAAGGAGC-3'. Two independent ES clones were then microinjected into $\mathrm{C57BL} / 6 \mathrm{~J}$ blastocysts and transferred into (C57BL/6J X $\mathrm{CBA} / \mathrm{Ca}$ )F1 pseudo-pregnant females to generate chimeric mice. 27 chimeras were born, all males. Germline transmitting mice were backcrossed into the $\mathrm{C} 57 \mathrm{BL} / 6 \mathrm{~J}$ genetic background for more than 10 generations before being used as experimental animals. Paternal transmission of the lgf2 floxed allele did not have any impact on fetal and placental growth kinetics (Supplementary Fig. 1g,h). Homozygous $\operatorname{lgf} 2^{\mathrm{fl} / \mathrm{fl}}$ mice were obtained by breeding heterozygous $\lg \mathrm{f}^{\mathrm{f} / \mathrm{+}}$ parents.

\section{Mouse strains}

Targeted ES cells for the miR-483 knock-out ${ }^{22}$ were generated and provided by Dr. Haydn Prosser (Sanger Institute and International Knockout Mouse Consortium Project). Details on the generation of the miR-483 knock-out mice (depicted in Supplementary Fig. 7; Sekita et al., manuscript in preparation) are available upon request. Rosa26YFP-stop $p^{\mathrm{fl} / \mathrm{fl}}$ mice $^{36}$ were kindly provided by $\mathrm{Dr}$. 
Martin Turner (The Babraham Institute, Cambridge). H19DMD ${ }^{f / f f}$ mice ${ }^{23}$ and $/ g f 2 r^{f 1 / f l}$ mice ${ }^{37}$ were generously provided by Prof. Bass Hassan (University of Oxford). $\lg f 1 \mathrm{r}^{\mathrm{fl} / \mathrm{fl}}$ mice ${ }^{38}$ were imported from the Jackson Laboratory (Maine, USA). CMV-Cre mice ${ }^{39}$ were obtained from the Babraham Institute, Cambridge. This Cre recombinase is expressed soon after fertilization and allows ubiquitous deletion of floxed alleles in all tissues, including the germline ${ }^{39}$. Nkx3.2-knock-in-Cre mice ${ }^{40}$ were kindly provided by Dr. Warren Zimmer (Texas A\&M University). Nkx3.2 expression occurs in the mesenchyme of the developing pancreas, stomach and gut, as well as in the forming somites, but not in the endoderm-derived cells of these organs. Nkx3.2 is expressed in the pancreatic mesenchyme as early as E9.5 and, by E12.5, its expression becomes restricted to the mesenchymal area, which will give rise to the splenic bud ${ }^{40}$. The Nkx3.2-knock-in-Cre, in which a Cre recombinase CDNA cassette and a PGK-NeoR cassette were inserted in frame within exon 1 of $N k x 3.2$ (Bapx1) gene, faithfully replicates endogenous $N k \times 3.2$ expression and directs Cre activity to the foregut mesenchyme and skeletal somites starting at E9.5 $5^{2,40}$. We verified the pancreatic cell-type specificity of Nkx3.2-Cre expression using the Rosa26YFP-stop ${ }^{\mathrm{f} / / \mathrm{fl}}$ reporter mice and demonstrated absence of recombinase activity in acinar cells, pancreatic endocrine cells (Fig. 1C), endothelial cells (Supplementary Fig. 4a) or duct cells (Supplementary Fig. 4b) at postnatal day P2. Tek-Cre transgenic mice, in which Cre expression is controlled by the endothelial-specific receptor tyrosine kinase Tek (Tie2) promoter/enhancer and therefore found uniformly in endothelial cells during embryogenesis (E7.5 onwards) and adulthood ${ }^{41}$, were imported from the Jackson Laboratory (Maine, USA). Ptf1aknock-in-Cre mice, in which the protein-coding region of Ptf1a (exon 1 and 2) was replaced with a Cre-cassette, express Cre in pancreatic ducts, exocrine and endocrine cells as early as E10.5 ${ }^{42}$. In newborn pups Ptf1a-Cre expression marks all acinar cells and roughly $95 \%$ of ductal and insulinproducing cells, as well as $75 \%$ of glucagon-producing cells ${ }^{42}$. RIP-Cre mice, carry a Cre transgene under the control of the rat Ins2 (insulin 2) promoter (RIP) that directs expression to insulin-positive beta-cells from approximately E8.5-9 onwards ${ }^{43}$. Ptf1a-Cre and RIP-Cre strains were obtained from Central Biomedical Services (CBS Transgenic Services, University of Cambridge). All lines were bred into an inbred C57BL/6J line for $>10$ generations or placed into a uniform $\mathrm{C} 57 \mathrm{BL} / 6 \mathrm{~J}$ genetic background using the advanced congenics program MaxBax ${ }^{\circledR}$ (The Jackson Laboratory, Maine, USA), until >98\% C57BL/6J genetic contribution was achieved.

\section{Mouse crosses and genotyping}

This research has been regulated under the Animals (Scientific Procedures) Act 1986 Amendment Regulations 2012 following ethical review by the University of Cambridge Animal Welfare and Ethical Review Body (AWERB). Mice were fed standard chow diet with 9\% of kcal from fat (SDS, Essex, UK) 
and housed with a 12 -h light/dark cycle in a temperature-controlled room $\left(22^{\circ} \mathrm{C}\right)$. For timed mating, the day of detection of a vaginal plug was noted as embryonic day 1 (E1) and the day of birth was noted as post-natal day 0 (PO). Mice were weaned at 3 weeks of age and ear notches were used for visual identification and to collect tissue for PCR genotyping.

Mouse crosses used for each experiment are listed in Supplementary Table 1. Throughout the paper, $\operatorname{lgf} 2^{+/ f l}$ represents genotype of offspring that inherited the floxed allele from father; $\operatorname{lgf} 2^{\mathrm{f} / /+}$ represents genotype of offspring that inherited the floxed allele from mother; $\operatorname{lgf} 2^{+/+}$represents genotype of offspring with wild-type alleles at the lgf2 locus; Nkx3.2-Cre represents genotype of offspring that are heterozygous Cre-carriers ( ${ }^{\mathrm{Cre} /+}$ or ${ }^{+/ \mathrm{Cre}}$ ); $\operatorname{lgf2^{+/fl}} ; \mathrm{Nk} \times 3.2^{\mathrm{Cre} /+}$ represents offspring with mesenchymal Igf2 deletion on the paternal allele, having inherited the floxed allele from father and the Cre allele from mother; $\lg f 2^{\mathrm{fl} /+} ; \mathrm{Nk} \times 3.2^{+/ / \mathrm{Cre}}$ represents offspring with mesenchymal $/ g f 2$ deletion on the maternal allele, having inherited the floxed allele from mother and the Cre allele from father; $H 19 D M D^{\mathrm{fl} /+} ; N k \times 3.2^{+/ C r e}$ represents offspring with mesenchymal H19DMD deletion on the maternal allele, having inherited the floxed allele from mother and the Cre allele from father. All strains were genotyped by standard PCR using DNA extracted from ear biopsies (adult mice) or tail DNA (embryos or post-terminal). PCR was performed using the Red Taq Ready PCR system (Sigma Aldrich) using primers described in Supplementary Table 2, followed by separation of PCR amplicons by agarose gel electrophoresis.

\section{Southern blotting screening of ES clones}

gDNA were digested with EcoRI or $S p h I$ restriction enzymes and electrophoresed on $0.8 \%$ agarose gels in 1×TBE buffer, alkaline blotted onto Hybond $\mathrm{N}+$ membranes (Amersham), and UV cross-linked (Stratalinker, Stratagene). Probes were obtained by PCR and radiolabeled ( $\alpha$-32P-CTP). Hybridisation and washing of Southern blots was performed as described ${ }^{44}$. Membranes were exposed overnight to MS film (Kodak).

\section{Northern blotting analysis of Igf2 mRNA}

Total RNA (10 $\mu \mathrm{g})$ extracted from E19 placenta and liver samples using RNeasy midi kits (Qiagen) according to manufacturer's protocol, was separated in low-percentage formaldehyde gels, blotted onto Nytran-plus membrane (Schleicher and Schuell), and UV cross-linked (Stratalinker, Stratagene). The RNA blots were hybridized with radiolabelled ( $\alpha-32 \mathrm{P}-\mathrm{UTP}$ ) Igf2 and Gapdh cDNA probes. We carried out hybridization and washing of northern blots as described ${ }^{45}$. Transcript levels were quantified by Phosphorlmager analysis (Molecular analyst software, Biorad). 


\section{Western blotting analyses}

For Western blot analysis of IGF2, $5 \mu$ l serum samples collected at E19 were loaded into Bis-Tris gels (NuPAGE Novex, Life technologies) and transferred to nitrocellulose membranes (Invitrogen). $4 \mathrm{ng}$ human recombinant IGF2 (292-G2-050, R\&D Systems) was used as positive control, and the Novex Sharp protein ladder (Life technologies) was used as marker. The membranes were initially stained with Ponceau red (Invitrogen) and imaged with the Biorad GelDoc system, the intensity of bands being used as internal control for protein loading. The membranes were then blocked with $5 \%$ skimmed milk in TBS-T for $1 \mathrm{~h}$ at $4^{\circ} \mathrm{C}$, after which were incubated overnight at $4^{\circ} \mathrm{C}$ with goat antihuman IGF2 antibody (R\&D systems AF-292) diluted 1: 1,000 in TBS-T containing 0.3\% skimmed milk. After $4 \times 10$ min washes with milliQ water, the blots were incubated for $1 \mathrm{~h}$ at room temperature with the secondary antibody (1:2,000 rabbit anti-goat IgG coupled to HRP, SantaCruz) in TBS-T containing $3 \%$ skimmed milk. Blots were washed $4 \times 10$ min with milliQ water, exposed to substrate (Clarity ECL Western Blotting Substrate, Biorad) for 5 minutes and imaged with the Biorad GelDoc system. Bands were quantified using the ImageLab software (Biorad), the output values being normalized to the corresponding Ponceau red loading control values.

For Western blot analysis of AKT phosphorylation, acinar cell pellets were lysed in $30 \mu$ l RIPA containing protease and phosphatase inhibitors. Protein concentration was determined by DC assay (Biorad) and $10 \mu \mathrm{g} / \mathrm{lane}$ total cell lysates were electrophoresed through 4-12\% Bis-Tris NuPAGE gels with MOPS running buffer. Proteins were transferred to nitrocellulose by iBlotll (P3 8:00 $\mathrm{min}$ ) prior to being blocked for an hour in 3\%BSA/TBST. Primary antibody to pAKT (S473) [Cell Signalling Technology (CST) 9271], total AKT (CST 2920), or Beta-actin (CST 4967) was incubated overnight at $4^{\circ} \mathrm{C}$. Membrane was washed 5 times before detection of bound antibody by detection of chemiluminescent signal associated with HRP-conjugated anti-rabbit or anti-mouse secondary antibody. Membrane was washed 5 times before detection of bound antibody by detection of chemiluminescent signal associated with HRP-conjugated secondary antibody.

\section{Pancreas immunostainings, imaging and stereology analysis}

Pancreata were dissected under microscope (for embryonic and early post-natal analyses), fixed in 4\% paraformaldehyde in PBS overnight, dehydrated and then embedded in paraffin. Paraffin blocks were cut at $5 \mu \mathrm{m}$ thickness, sections were then deparaffinised, rehydrated, stained and mounted with coverslips. Conditions used for antigen retrieval, blocking and combinations of primary and secondary antibodies used for each staining are described in Supplementary Table 3. Counterstaining was performed with haematoxylin for light microscopy stains or DAPI for fluorescent stains. 
Light microscopy stained slides were imaged using the NanoZoomer whole slide scanner (Hamamatsu). Fluorescent immunostainings were imaged with a LSM510 Meta confocal laser scanning microscope and the ZEN 2009 software (Carl Zeiss, Germany) or scanned using an Axio whole slide scanner. Whole slide scans of stained sections (seven sections spaced at $100 \mu \mathrm{m}$ distance for each P2 pancreas) were analysed using the Visiopharm automated image quantification software (Visiopharm, Denmark) to measure the area of positive cell-specific staining or to count individual nuclei. The mass of each cell-type was calculated using the formula:

(area of cell-specific stain $\left.\left(\mu \mathrm{m}^{2}\right)\right) \times($ pancreas weight $(\mathrm{mg}))=$ mass of cell type of interest $(\mathrm{mg})$ (overall tissue surface $\left(\mu \mathrm{m}^{2}\right)$ )

\section{mRNA in situ hybridization (ISH) for Igf2}

ISH was performed as described ${ }^{46}$, with minor modifications. Briefly, a region of 415 bp spanning coding Igf2 exons 4-6 was amplified by PCR using primers: F: 5'-CACGCTTCAGTTTGTCTGTTCG-3' and R: 5'-GCTGGACATCTCCGAAGAGG-3' and CDNA from whole P2 pancreata as template. The PCR product was cloned into a pCR2.1-TOPO plasmid (Invitrogen) containing M13 primers and a T7 RNA polymerase transcription initiation site. Sense (S) and antisense (AS) RNA probes were generated and labelled with Digoxigenin (DIG) by in vitro reverse transcription, according to manufacturer's instructions (Roche). Pancreata were dissected in cold phosphate buffered saline (PBS) and fixed overnight in $4 \%$ paraformaldehyde in $0.1 \%$ diethylpyrocarbonate (DEPC)-PBS at $4^{\circ} \mathrm{C}$. After rinsing in DEPC-PBS, tissues were dehydrated and then embedded in paraffin in RNase-free conditions. Pancreas sections ( $7 \mu \mathrm{m}$ thick) mounted on polysine slides (VWR) were de-waxed, rehydrated in PBS, post-fixed in $4 \%$ paraformaldehyde for 10 minutes, treated with proteinase $\mathrm{K}(30 \mathrm{\mu g} / \mathrm{ml}$ ) for $10 \mathrm{~min}$ at room temperature, acetylated for 10 minutes (acetic anhydride, 0.25\%) and hybridized overnight at $65^{\circ} \mathrm{C}$ in a humidified chamber with DIG-labeled probes diluted in hybridization buffer (containing $200 \mathrm{mM}$ sodium choride, $13 \mathrm{mM}$ tris, $5 \mathrm{mM}$ sodium phosphate monobasic, $5 \mathrm{mM}$ sodium phosphate dibasic, $5 \mathrm{mM}$ EDTA, $50 \%$ formamide, $10 \%$ dextran sulfate, $1 \mathrm{mg} / \mathrm{ml}$ yeast tRNA and $1 \times$ Denhardt's $[1 \% \mathrm{w} / \mathrm{v}$ bovine serum albumin, $1 \% \mathrm{w} / \mathrm{v}$ Ficoll, $1 \% \mathrm{w} / \mathrm{v}$ polyvinylpyrrolidone $]$ ). Two $65^{\circ} \mathrm{C}$ posthybridization washes ( $1 \times$ SSC, $50 \%$ formamide, $0.1 \%$ tween-20) followed by two room temperature washes in $1 \times$ MABT (150 mM sodium chloride, $100 \mathrm{mM}$ maleic acid, $0.1 \%$ tween-20, pH7.5) were followed by 30 minutes RNAse treatment ( $400 \mathrm{mM}$ sodium chloride, $10 \mathrm{mM}$ tris pH7.5, $5 \mathrm{mM}$ EDTA, $20 \mu \mathrm{g} / \mathrm{ml}$ RNAse A). Sections were blocked for 1 hour in $1 \times$ MABT, $2 \%$ blocking reagent (Roche), $20 \%$ heat inactivated goat serum and then incubated overnight with anti-DIG antibody (Roche; 1:2,500 dilution) at $4^{\circ} \mathrm{C}$. After 4×20 min washes in $1 \times$ MABT, slides were rinsed in $1 \times N T M T$ ( $100 \mathrm{mM} \mathrm{NaCl}, 50$ $\mathrm{mM} \mathrm{MgCl}, 100 \mathrm{mM}$ tris $\mathrm{pH} 9.5,0.1 \%$ tween-20) and incubated with NBT/BCIP mix in NTMT buffer, 
according to manufacturer's instructions (Promega). Slides were counterstained with nuclear fast red (Sigma), dehydrated and cleared in xylene and mounted in DPX mounting medium (Sigma). Pictures were taken with a camera attached to a light microscope.

\section{Fluorescence-activated cell sorting (FACS)}

Mice were sacrificed by decapitation (embryos and P2 neonates) or cervical dislocation (P5 neonates and older). Then, pancreata were dissected and dissociated into single cells using trypsin-EDTA (Sigma Aldrich) at $37^{\circ} \mathrm{C}$ for $20 \mathrm{~min}$. After one wash with ice-cold PBS, the cells were passed through $70 \mu \mathrm{m}$ strainers and single-cell suspensions were sorted into YFP-positive and YFP-negative fractions using an Aria-Fusion cell sorter (BD Bioscience). Dead cells were excluded based on forward and side scatter profiles and the uptake of 7AAD (7-Aminoactinomycin D dead cell stain, Life Technologies). Sorted YFP-positive and YFP-negative cells were pelleted by centrifugation and flash frozen in liquid nitrogen, then stored at $-80^{\circ} \mathrm{C}$ until use.

\section{Total RNA and microRNA extraction (pancreas and sorted cells)}

Total RNA was extracted from whole pancreata, cells isolated by FACS or cultured cells using the RNEasy Mini kit (Qiagen) or the RNEasy Micro kit (Qiagen), respectively, according to manufacturer's instructions, with additional removal of contaminating DNA using QIASpin DNA eliminator columns. microRNA was extracted using the miRNeasy kit (Qiagen), according to manufacturer's instructions with an additional step of DNasel treatment (Qiagen).

\section{Quantitative real-time PCR (qRT-PCR)}

Concentration and integrity of total RNA was verified by NanoDrop (Thermo Scientific) and agarose gel electrophoresis, respectively. For RNA extracted from whole pancreata, reverse transcription was performed using the RevertAid RT Reverse Transcription Kit (Life technologies), according to manufacturer's instructions. In the case of total RNA extracted from sorted cells, cDNA was produced using the QuantiTect Whole Transcriptome Kit (Qiagen) following manufacturer's instructions. Primers used for qRT-PCR are listed in Supplementary Table 4. Annealing temperatures were tested by gradient PCR using pancreas-cDNA as a template. qRT-PCR was performed using the SYBR Green JumpStart Taq Ready Mix (Sigma Aldrich) on an ABI Prism 7900 system (Applied Biosystems). Gene expression levels were normalized to the housekeeping gene Ppia (peptidylpropyl isomerase A or cyclophilin-A), which has previously been established as a good housekeeping gene for pancreas gene expression studies ${ }^{47}$ and is stably expressed between various developmental time points (data not shown). For microRNAs, reverse transcription was performed using the TaqMan 
Micro RNA Reverse Transcription kit (Applied Byosystems), according to manufacturer's protocol. qRT-PCR was performed using TaqMan assays (TM: 002560 for mmu-miR-483; TM: 001232 for snoRNA202 and TM: 001234 for snoRNA234) and TaqMan 2x Universal PCR Master Mix (Applied Byosystems). Levels of expression were calculated using the $2^{-\Delta \Delta C t}$ method $^{48}$.

\section{Complementary DNA library preparation and RNA-seq analysis}

Input RNA for genome-wide transcriptome analysis was verified for concentration and quality using Agilent RNA Pico chips, according to manufacturer's instructions. All RNA samples had RNA integrity numbers (RIN) >7.5. Total RNA ( $2 \mathrm{ng}$ ) was whole-transcriptome amplified using the Ovation RNA-seq System V2 (NuGEN). To prepare the RNA-seq libraries, the amplified CDNA ( 2 ug per sample) was fragmented to $200 \mathrm{bp}$ using a Bioruptor Sonicator (Diagenode), and barcode ligation and end repair were performed using the Ovation Rapid DR Library System (NuGEN). The barcoded libraries were combined and loaded onto an Illumina HiSeq 2500 system for single-end 50-bp sequencing at the Genomics Core Facility, Cambridge Institute, CRUK. The reads were aligned onto the mouse GRCm38 genome using TopHat 2.0.1199. Gene abundance and differential expression were determined with Cufflinks $2.2 .1^{50}$ and expressed in fragments per kilobase per million mapped reads (FPKM). The cut off for expression was set at $\geq 1$ FPKM. Genes with a linear fold expression change greater than 1.5 and a Benjamini-Hochberg false discovery rate $<5 \%$ were considered differentially expressed.

\section{Functional annotation and enrichment analysis}

DAVID (Database for Annotation, Visualization and Integrated Discovery; v6.8 http://david.abcc.ncifcrf.gov/, accessed March 2017) was performed to assess whether there was enrichment for genes implicated in particular biological processes within the differential expressed gene lists identified by RNA-seq. Enriched gene ontology (GO) terms with an FDR $\square<\square 0.05$ were considered significant. These terms were then clustered semantically using REViGO (Reduce and Visualize $\mathrm{GO})^{51}$, which removes redundancy. The results obtained by REViGO were ordered according to $\log 10 p$ values.

\section{Whole pancreas lipase content and amylase measurements}

For whole pancreas lipase measurements, frozen samples were removed from $-80^{\circ} \mathrm{C}$ and thawed on ice. $100 \mu \mathrm{L}$ TK lysis buffer with proteinase inhibitors (Calbiochem) was added to each pancreas and tissues were disrupted on ice with a homogenizer (Biospec Tissue Tearor). Lysates were spun at 3,000 rpm for $15 \mathrm{~min}$ at $4^{\circ} \mathrm{C}$ and supernatants were used for analysis. Lipase levels were measured using a lipase activity assay (Dimension RXL, Siemens). 
For amylase measurements, cultured acinar cells were lysed in $100 \mu \mathrm{L}$ RIPA buffer, spun at 3,000 $\mathrm{rpm}$ for $15 \mathrm{~min}$ at $4^{\circ} \mathrm{C}$ and the supernatants used for analysis. Amylase levels were measured in an autoanalyser (Siemens Dimension RXL) through a colorimetric reaction based on the ability of amylase to hydrolyse the chromogenic substrate 2-chloro-4-nitrophenol linked with maltotriose (CNPG3) into the coloured product 2-chloro-4-nitrophenol (CNP) plus CNPG2, maltotriose G3 and glucose. The absorbance increase at $405 \mathrm{~nm}$ is proportional to the amylase activity in the sample. Amylase levels were normalized to the total protein content determined by a BCA assay (Pierce BCA Protein Assay Kit, Thermo Fisher Scientific, 23225).

\section{Primary pancreatic acinar and mesenchymal cell isolation and culture}

Primary pancreatic cells were isolated as previously described ${ }^{52}$ and adapted here to $\mathrm{P} 2$ samples. Briefly, pancreata from an entire P2 litter were micro-dissected under microscope and sterile conditions and pooled in one tube containing HBSS, $0.25 \mathrm{mg} / \mathrm{ml}$ of trypsin inhibitor and $1 \%$ Penicillin-Streptomycin mix. After rinsing, pancreata were digested for $20-30 \mathrm{~min}$ at $37^{\circ} \mathrm{C}$ with a collagenase IA solution (HBSS containing 10mM HEPES, $200 \mathrm{U} / \mathrm{ml}$ of collagenase IA, and $0.25 \mathrm{mg} / \mathrm{ml}$ trypsin inhibitor). The digestion was stopped by placing the samples on ice and addition of FBS (fetal bovine serum) for a $2.5 \%$ final concentration. After additional washing steps, the cell suspension was passed through a $100 \mu \mathrm{m}$ cell strainer, allowing the passage of acini and mesenchymal cells, while retaining the non-digested fragments and larger pancreatic islets. The cells were placed in the culture media (basal Waymouth's media containing 2.5\% FBS, 1\% Penicillin-Streptomycin mix, 0.25 $\mathrm{mg} / \mathrm{ml}$ trypsin inhibitor, and $25 \mathrm{ng} / \mathrm{ml}$ of recombinant human EGF) and plated into six-well plates pre-coated with poly-L-lysine. After one hour incubation at $37^{\circ} \mathrm{C}$ under $5 \%(\mathrm{v} / \mathrm{v}) \mathrm{CO} 2$ atmosphere, the floating acini were transferred to a new well, while the mesenchyme cells remained attached. The cells were cultured under the above conditions for up to four days, with daily media changes.

\section{Measurement of IGF2 secretion by primary mesenchymal and acinar cells in vitro}

The primary mesenchymal and acinar cells were isolated and cultured as described above until reaching confluency. Media $(1 \mathrm{~mL})$ was collected $24 \mathrm{~h}$ post-confluency and freeze-dried using a Christ Gamma 2-16 LSC Freeze dryer. Dry pellets were re-dissolved in $50 \mu$ RIPA buffer and IGF2 measured by ELISA (Mouse IGF-II DuoSet ELISA kit, R\&D Systems - DY792) using an assay adapted for the MesoScale Discovery electrochemiluminescence immunoassay platform (MSD), as recently described $^{53}$.

\section{In vitro IGF2 treatments}


To assess the impact of exogenous IGF2 on intracellular signalling via AKT, freshly isolated acinar cells were starved for two hours in basal Waymouth's media, without FBS and EGF. IGF2 treatments (with vehicle or $1 \mathrm{nM}, 10 \mathrm{nM}$ or $50 \mathrm{nM}$ mouse recombinant IGF2) were performed for $10 \mathrm{~min}$ at $37^{\circ} \mathrm{C}$ under $5 \%(\mathrm{v} / \mathrm{v}) \mathrm{CO} 2$ atmosphere, then the cells were immediately placed on ice, washed two times in ice-cold PBS, pelleted and flash-frozen on dry-ice and stored at $-80^{\circ} \mathrm{C}$ until analysed by Western blotting.

To assess the impact of exogenous IGF2 on amylase production by acinar cells, subconfluent acinar cultures (48 hours after isolation) were placed in basal Waymouth's media containing $1 \%$ PenicillinStreptomycin mix and $0.25 \mathrm{mg} / \mathrm{ml}$ of trypsin inhibitor. FBS was replaced with Serum Replacement (Sigma Aldrich S0638) that does not contain any IGF2. The treated cells received $50 \mathrm{ng} / \mathrm{ml}$ mouse recombinant IGF2 for 48 hours, with new media added every day. After the treatment, cells were harvested and dissociated into single-cell suspension using trypsin, counted with a Cedex XS Analyser (Roche), washed, pelleted and stored at $-80^{\circ} \mathrm{C}$ until used for amylase measurement.

\section{Oral glucose tolerance test}

Conscious mice were used for an oral glucose tolerance test after 6 hours of fasting (from 8 am to $2 \mathrm{pm}$ ). Blood samples $(\leq 5 \mu \mathrm{L})$ were taken from the tail vein immediately before administration of glucose by oral gavage ( $20 \%$ weight for volume, $2 \mathrm{~g} / \mathrm{kg}$ body weight based on average body weights for each experimental group) and thereafter at the time points indicated, and used for glucose measurements with a glucose meter (AlphaTRAK).

\section{Statistical analysis}

Statistical analysis was performed using GraphPad Prism 7 software. For two groups with up to 6 samples, statistical analysis was performed using Mann-Whitney or the Wilcoxon matched-pairs signed rank test. For two groups with $\geq 6$ samples, to determine whether the data was of a Gaussian distribution, the Shapiro-Wilk test was first applied, followed by un-paired or paired Student's ttests, as appropriate. Where more than two groups exposed to the same treatment were analysed, 1-way ANOVA with Dunnett's post-hoc or Friedman's test with Dunn's correction tests were used, comparing every mean to a control mean. OGT data was analysed using two-way ANOVA with Sidak's multiple comparison tests, using the time from administration and the genotype as factors (two genotypes) or by repeated measures 1-way ANOVA with Dunnett's post hoc test for multiple comparisons against the controls (four genotypes). The area under the curve (AUC) was calculated by the trapezoidal rule and used for analyses by unpaired Student's t tests (two genotypes) or by 1-way ANOVA with Dunnett's post-hoc tests (four genotypes). Unless stated otherwise, data is 
shown as average values and error bars represent SEM or SD. N.S. $p>0.05 ;{ }^{*} p \leq 0.05 ;{ }^{* *} p \leq 0.01, * * *$ $\mathrm{p} \leq 0.001$.

\section{Data availability}

RNA-seq data have been deposited in the Gene Expression Omnibus (GEO) under the accession number GSE100981. Other data and materials are available upon request from the corresponding author.

\section{References}

1. Stanger, B.Z., Tanaka, A.J. \& Melton, D.A. Organ size is limited by the number of embryonic progenitor cells in the pancreas but not the liver. Nature 445, 886-891 (2007).

2. Landsman, L. et al. Pancreatic mesenchyme regulates epithelial organogenesis throughout development. PLoS Biol. 9, e1001143 (2011).

3. Hibsher, D., Epshtein, A., Oren, N. \& Landsman, L. Pancreatic Mesenchyme Regulates Islet Cellular Composition in a Patched/Hedgehog-Dependent Manner. Sci. Rep. 6, 38008 (2016).

4. Bendall, S.C. et al. IGF and FGF cooperatively establish the regulatory stem cell niche of pluripotent human cells in vitro. Nature 448, 1015-1021 (2007).

5. Ziegler, A.N., Levison, S.W. \& Wood, T.L. Insulin and IGF receptor signalling in neural-stem-cell homeostasis. Nat. Rev. Endocrinol. 11, 161-170 (2015).

6. Ferrón, S.R. et al. Differential genomic imprinting regulates paracrine and autocrine roles of IGF2 in mouse adult neurogenesis. Nat. Commun. 6, 8265 (2015).

7. Youssef, A. \& Han, V.K. Low Oxygen Tension Modulates the Insulin-Like Growth Factor-1 or -2 Signalling via Both Insulin-Like Growth Factor-1 Receptor and Insulin Receptor to Maintain Stem Cell Identity in Placental Mesenchymal Stem Cells. Endocrinology 157, 1163-1174 (2016).

8. Youssef, A., Aboalola, D. \& Han, V.K. The Roles of Insulin-Like Growth Factors in Mesenchymal Stem Cell Niche. Stem Cells Int. 2017, 9453108 (2017).

9. Ziegler, A.N. et al. Insulin-like Growth Factor II: An Essential Adult Stem Cell Niche Constituent in Brain and Intestine. Stem Cell Reports 12, 816-830 (2019).

10. DeChiara, T.M., Robertson, E.J. \& Efstratiadis, A. Parental imprinting of the mouse insulin-like growth factor II gene. Cell 64, 849-859 (1991).

11. Constância, M., Kelsey, G. \& Reik, W. Resourceful imprinting. Nature 432, 53-57 (2004). 
12. Ideraabdullah, F.Y., Vigneau, S. \& Bartolomei, M.S. Genomic imprinting mechanisms in mammals. Mutat. Res. 647, 77-85 (2008).

13. Gicquel, C. et al. Epimutation of the telomeric imprinting center region on chromosome $11 \mathrm{p} 15$ in Silver-Russell syndrome. Nat. Genet. 37, 1003-1007 (2005).

14. Weksberg, R., Shen, D.R., Fei, Y.L., Song, Q.L. \& Squire, J. Disruption of insulin-like growth factor 2 imprinting in Beckwith-Wiedemann syndrome. Nat. Genet. 5, 143-150 (1993).

15. Efstratiadis, A. Genetics of mouse growth. Int. J. Dev. Biol. 42, 955-976 (1998).

16. Devedjian, J.C. et al. Transgenic mice overexpressing insulin-like growth factor-Il in beta cells develop type 2 diabetes. J. Clin. Invest. 105, 731-740 (2000).

17. Casellas, A. et al. Insulin-like Growth Factor 2 Overexpression Induces $\beta$-Cell Dysfunction and Increases Beta-cell Susceptibility to Damage. J. Biol. Chem. 290, 16772-16785 (2015).

18. Modi, H. et al. Autocrine Action of IGF2 Regulates Adult $\beta$-Cell Mass and Function. Diabetes 64, 4148-4157 (2015).

19. Petrik, J. et al. Overexpression of insulin-like growth factor-II in transgenic mice is associated with pancreatic islet cell hyperplasia. Endocrinology 140, 2353-2363 (1999).

20. Hill, D.J., Strutt, B., Arany, E., Zaina, S., Coukell, S. \& Graham, C.F. Increased and persistent circulating insulin-like growth factor II in neonatal transgenic mice suppresses developmental apoptosis in the pancreatic islets. Endocrinology 141, 1151-1157 (2000).

21. Kido, Y., Nakae, J., Hribal, M.L., Xuan, S., Efstratiadis, A. \& Accili, D. Effects of mutations in the insulin-like growth factor signalling system on embryonic pancreas development and beta-cell compensation to insulin resistance. J. Biol. Chem. 277, 36740-36747 (2002).

22. Prosser, H.M., Koike-Yusa, H., Cooper, J.D., Law, F.C. \& Bradley, A. A resource of vectors and ES cells for targeted deletion of microRNAs in mice. Nat. Biotechnol. 29, 840-845 (2011).

23. Srivastava, M. et al. $\mathrm{H} 19$ and Igf2 monoallelic expression is regulated in two distinct ways by a shared cis acting regulatory region upstream of H19. Genes Dev. 14, 1186-1195 (2000).

24. Ghosh, P., Dahms, N.M. \& Kornfeld, S. Mannose 6-phosphate receptors: new twists in the tale. Nat. Rev. Mol. Cell Biol. 4, 202-212 (2003).

25. Lowe, M.E., Kaplan, M.H., Jackson-Grusby, L., D'Agostino, D. \& Grusby, M.J. Decreased neonatal dietary fat absorption and $\mathrm{T}$ cell cytotoxicity in pancreatic lipase-related protein 2-deficient mice. J. Biol. Chem. 273, 31215-31221 (1998).

26. D'Agostino, D., Cordle, R.A., Kullman, J., Erlanson-Albertsson, C., Muglia, L.J. \& Lowe, M.E. Decreased postnatal survival and altered body weight regulation in procolipase-deficient mice. J. Biol. Chem. 277, 7170-7177 (2002). 
27. Le, Y., Zhou, Y., Iribarren, P. \& Wang, J. Chemokines and chemokine receptors: their manifold roles in homeostasis and disease. Cell. Mol. Immunol. 1, 95-104 (2004).

28. Grady, T., Liang, P., Ernst, S. A. \& Logsdon, C. D. Chemokine gene expression in rat pancreatic acinar cells is an early event associated with acute pancreatitis. Gastroenterology 113, 19661975 (1997).

29. Apelqvist, A., Ahlgren, U. \& Edlund, H. Sonic hedgehog directs specialised mesoderm differentiation in the intestine and pancreas. Curr. Biol. 7, 801-804 (1997).

30. Kawahira, H., Scheel, D.W., Smith, S.B., German, M.S. \& Hebrok, M. Hedgehog signalling regulates expansion of pancreatic epithelial cells. Dev. Biol. 280, 111-121 (2005).

31. Jonckheere, N. et al. Analysis of mPygo2 mutant mice suggests a requirement for mesenchymal Wnt signalling in pancreatic growth and differentiation. Dev. Biol. 318, 224-235 (2008).

32. Ahnfelt-Rønne, J., Ravassard, P., Pardanaud-Glavieux, C., Scharfmann, R. \& Serup, P. Mesenchymal bone morphogenetic protein signalling is required for normal pancreas development. Diabetes 59, 1948-1956 (2010).

33. Ludwig, C.U., Menke, A., Adler, G. \& Lutz, M.P. Fibroblasts stimulate acinar cell proliferation through IGF-I during regeneration from acute pancreatitis. Am. J. Physiol. 276, G193-G198 (1999).

34. Lu, Y. et al. Pancreatic-specific inactivation of IGF-I gene causes enlarged pancreatic islets and significant resistance to diabetes. Diabetes 53, 3131-3141 (2004).

35. Varrault, A. et al. Zac1 regulates an imprinted gene network critically involved in the control of embryonic growth. Dev. Cell 11,711-722 (2006).

36. Srinivas, S. et al. Cre reporter strains produced by targeted insertion of EYFP and ECFP into the ROSA26 locus. BMC Dev. Biol. 1, 4 (2001).

37. Wylie, A.A. et al. Tissue-specific inactivation of murine M6P/IGF2R. Am. J. Pathol. 162, 321-328 (2003).

38. Dietrich, P., Dragatsis, I., Xuan, S., Zeitlin, S. \& Efstratiadis, A. Conditional mutagenesis in mice with heat shock promoter-driven cre transgenes. Mamm. Genome 11, 196-205 (2000).

39. Schwenk, F., Baron, U. \& Rajewsky, K. A cre-transgenic mouse strain for the ubiquitous deletion of loxP-flanked gene segments including deletion in germ cells. Nucleic Acids Res. 23, 50805081 (1995).

40. Verzi, M.P. et al. Role of the homeodomain transcription factor Bapx1 in mouse distal stomach development. Gastroenterology 136, 1701-1710 (2009).

41. Kisanuki, Y.Y. et al. Tie2-Cre transgenic mice: a new model for endothelial cell-lineage analysis in vivo. Dev. Biol. 230, 230-242 (2001). 
42. Kawaguchi, Y. et al. The role of the transcriptional regulator Ptf1a in converting intestinal to pancreatic progenitors. Nat. Genet. 32, 128-134 (2002).

43. Herrera, P.L. Adult insulin- and glucagon-producing cells differentiate from two independent cell lineages. Development 127, 2317-2322 (2000).

44. Feil, R., Walter, J., Allen, N.D. \& Reik, W. Developmental control of allelic methylation in the imprinted mouse lgf2 and H19 genes. Development 120, 2933-2943 (1994).

45. Constância, M. et al. Adaptation of nutrient supply to fetal demand in the mouse involves interaction between the Igf2 gene and placental transporter systems. Proc. Natl. Acad. Sci. USA 102, 19219-19224 (2005).

46. Simmons, D.G., Rawn, S., Davies, A., Hughes, M. \& Cross, J.C. Spatial and temporal expression of the 23 murine Prolactin/Placental Lactogen-related genes is not associated with their position in the locus. BMC Genomics 9, 352 (2008).

47. Feroze-Merzoug, F., Berquin, I.M., Dey, J. \& Chen, Y.Q. Peptidylprolyl isomerase A (PPIA) as a preferred internal control over GAPDH and beta-actin in quantitative RNA analyses. Biotechniques 32, 776-778 (2002).

48. Livak, K.J. \& Schmittgen, T.D. Analysis of relative gene expression data using real-time quantitative PCR and the 2(-Delta Delta C(T)) Method. Methods 25, 402-408 (2001).

49. Kim, D. et al. TopHat2: accurate alignment of transcriptomes in the presence of insertions, deletions and gene fusions. Genome Biol. 14, R36 (2013).

50. Trapnell, C. et al. Transcript assembly and quantification by RNA-seq reveals unannotated transcripts and isoform switching during cell differentiation. Nat. Biotechnol. 28, 511-515 (2010).

51. Supek, F., Bošnjak, M., Škunca, N. \& Šmuc, T. REVIGO summarizes and visualizes long lists of gene ontology terms. PLoS One 6, e21800 (2011).

52. Gout, J. et al. Isolation and culture of mouse primary pancreatic acinar cells. J. Vis. Exp. 13, 78 (2013).

53. Sandovici, I. et al. Fetus-derived IGF2 matches placental development to fetal demand. Preprint at https://www.biorxiv.org/content/10.1101/520536v1 (2019). 


\section{Acknowledgements}

This work was supported by Biotechnology and Biological Sciences Research Council (grant BB/H003312/1 to M.C., S.E.O., A.V.P.); the Medical Research Council ([MRC_MC_UU_12012/4 and MRC_MC_UU_00014/4] to M.C and S.E.O, [MRC 979241] to C.H., [MRC_MC_UU_12012/5] to Metabolic Diseases Unit), the Wellcome Trust ([Strategic Award 100574/Z/12/Z], [102355/Z/13/Z] to N.M.S.) and [098051] for miR-483 knockout production), the NIHR Cambridge BRC Cell Phenotyping Hub (in particular we wish to thank Natalia Savinykh for help with flow cytometry cell sorting) and the Spanish Ministry of Economy and Competitiveness (grants BFU2012-33594 and BFU2013-47384R to G. M.-G.). We thank Debbie Drage, Martin George and in particular Ted Saunders (The Babraham Institute Gene Targeting Facility) for help with generating the $\operatorname{lgf2^{+/fl}}$ mice; Adrian Wayman (West Forvie Phenomics Center) and Adriana Izquierdo-Lahuerta and Yurena Vivas (Universidad Rey Juan Carlos) for help with mouse husbandry; Keli Philips and Gregory Strachan (Imaging Core facility), for help with preparing tissue samples for histology and confocal microscopy imaging, respectively; Keith Burling (Biochemical Assay Laboratory) for performing lipase, amylase and IGF2 measurements; Dan Hart (MRL Disease Model Core) for performing oral glucose tolerance tests; Dr. Claire Stocker from the University of Buckingham for providing training on pancreas stereology; Dr. Allan Bradley for providing miR-483 knockout ES cells.

\section{Contributions}

C.M.H. performed most of the experiments, contributed to the design of the study and wrote the manuscript. I.S. generated the conditional Igf2 knock-out mouse, contributed experimentally to most of the experiments and their design and wrote the manuscript. G.V.B. contributed to the in vitro experiments on pancreatic acinar cells. N.M.S. contributed to the analysis of the mouse phenotypes (in particular imaging, stereological measurements and OGTT analyses during 
pregnancy). C.M.H., I.S., G.V.B., N.M.S., B.Y.H.L., W.N.C, G.M.-G. and M.C. analysed the data. W.E.Z. generated and provided the Nkx3.2-Cre mouse model and I.Z., H.M.P. and Y.S. contributed to the miR-483 mouse model study. M.M. prepared RNA-seq libraries. A.V.-P., S.E.O., G.M.-G., and M.C. discussed and initiated the study. M.C. designed and led the study, and wrote the manuscript, with contributions to the final version from all authors.

\section{Competing interests}

The authors declare no competing financial interests.

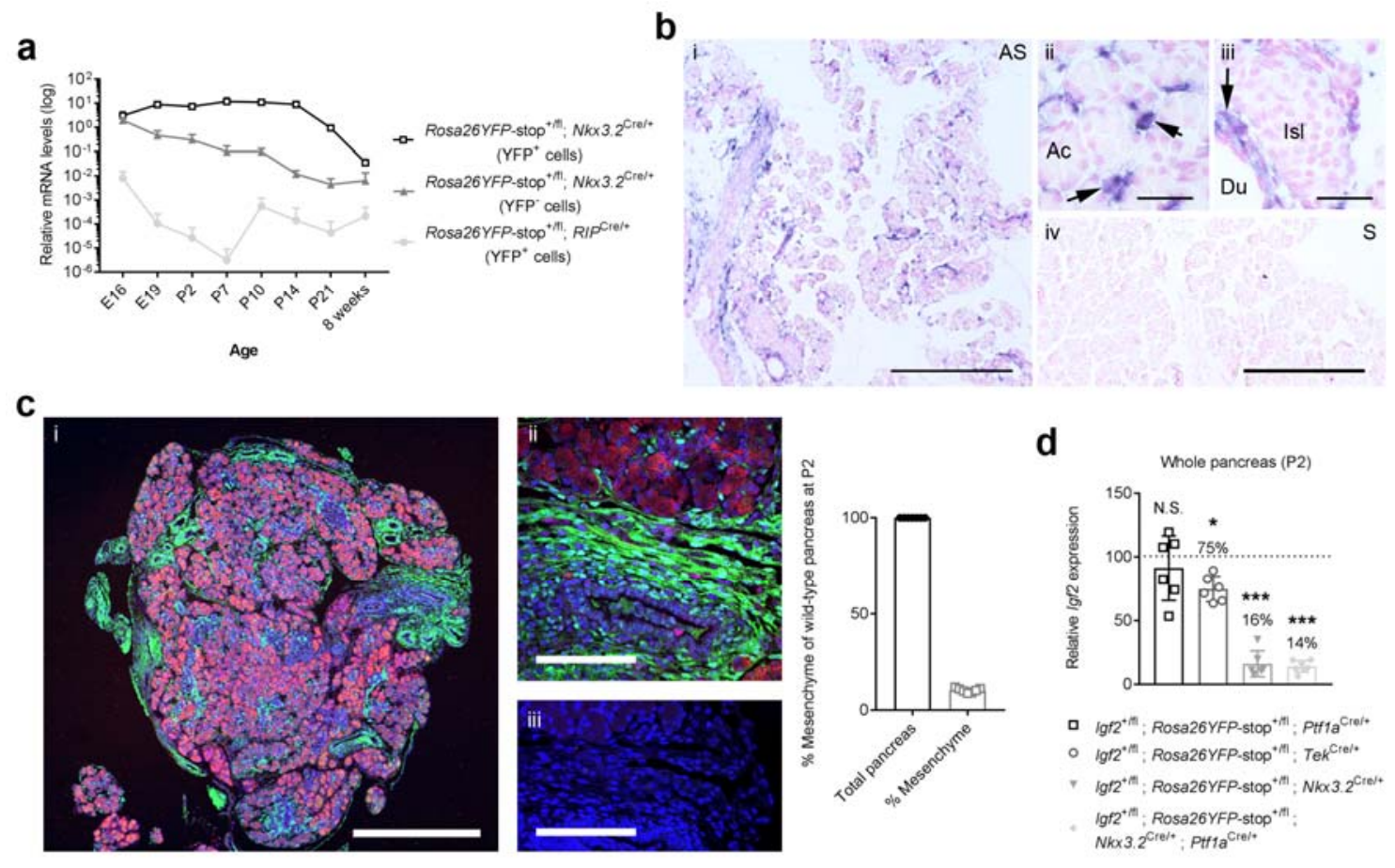

Figure 1: Developmental profiling of $I g f 2$ mRNA expression in mouse pancreas. (a) Timeline of $\lg f 2$ mRNA expression measured by qRT-PCR in YFP+ or YFP- FACS isolated cells from offspring of Nkx3.2Cre or RIP-Cre females mated with Rosa26YFP-stop ${ }^{\mathrm{fl} / f l}$ males (E - embryonic day; P - postnatal day). Highest levels of $I g f 2$ expression are observed in the mesenchyme fraction ( $N k \times 3.2-C r e$ YFP+ cells) throughout development. Expression data is normalized to Ppia, and is shown as average + SD ( $n=3-$ 5 per time point and cell fraction). (b) Igf2 mRNA analysis by in situ hybridization at P5 showing high levels of expression in mesenchymal cells (blue colour, see arrows). AS - antisense probe (in insets i, ii and iii); S - sense probe (negative control; in inset iv); Ac - acinar cells; Isl - pancreatic islet; Du pancreatic duct. Scale bars: $30 \mu \mathrm{m}$ and $300 \mu \mathrm{m}$ in higher and lower resolution insets, respectively. (c) 
Representative immunofluorescence of a P2 pancreatic section (i) stained for acinar cell amylase (red), Nkx3.2-Cre driven YFP expression (green) as marker of mesenchyme cells and DAPI (blue) for nuclei. Scale bar: $0.5 \mathrm{~mm}$. The insets show high levels of YFP in the connective tissue surrounding acinar cells (ii), and a negative control, without primary antibodies (iii). Scale bars for insets: $100 \mu \mathrm{m}$. The graph depicts the percentage of YFP+ pancreatic mesenchyme cells in wild-type pancreas $(n=7)$. Data is shown as individual values. (d) Cell-type contribution to whole pancreas Igf2 mRNA levels, measured by qRT-PCR in lysates at P2 from offspring of heterozygous Cre females mated with $/ g f 2^{+f f l}$ males. Data was normalized to Ppia and shown as individual values and averages \pm SD relative to levels in control littermates, which were arbitrarily set to 1 . Residual levels of Igf2 mRNA in each mutant are indicated as percentage values; ( $n=6-7$ samples per genotype; N.S. - non-significant; * $p<0.05 ;{ }^{* * *} p<0.001$ by unpaired Student's $t$-test). 

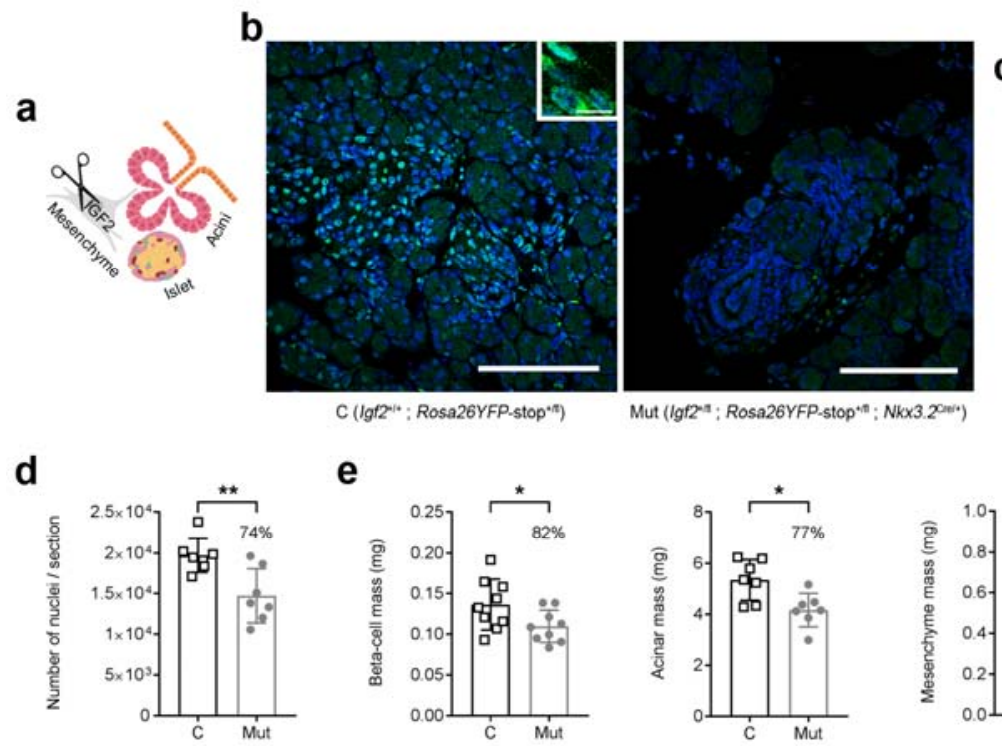

e
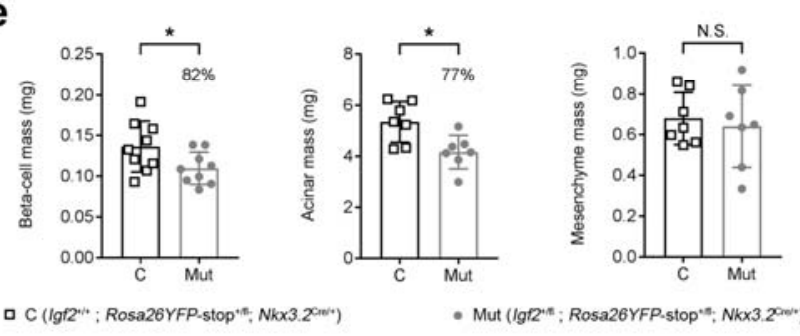

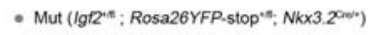

Figure 2: Pancreatic hypoplasia in mesenchyme-specific deletion of Igf2 at postnatal day 2 (P2). (a)

Schematic representation of conditional Igf2 deletion from the pancreatic mesenchyme. (b) Representative immunofluorescence confocal microscopy showing cytoplasmatic staining (inset) for IGF2 in pancreata of control mice $\left(C-\operatorname{lgf} 2^{+/+}\right)$and absence of signal in mutants (Mut $-\operatorname{lgf} 2^{+/ f l}$; $N k \times 3.2^{\text {Cre/ }}$ ) (green - IGF2; blue - DAPI staining of nuclei; scale bars - $100 \mu \mathrm{m}$ and $10 \mu \mathrm{m}$ for lower and higher magnification panels, respectively). (c) Pancreas weights are significantly reduced in mutants compared to littermate controls ( $n=23$ controls and $n=30$ mutants), with similar body weights between genotypes. (d) Stereological measurements showing significant reductions (shown as \%) in the total number of nuclei (measured in seven sections/sample). (e) Stereological measurements showing significant reductions in beta-cell mass and acinar mass, but not mesenchymal mass in mutants compared to littermate controls. (f) Reduced pancreatic lipase content in mutants compared to littermate controls. For all graphs, data is shown as average and individual values $\pm S D$; N.S. - non-significant, ${ }^{*} p<0.05,{ }^{* *} p<0.01$ and ${ }^{* * *} p<0.001$ by unpaired Student's $t$ tests. 
a

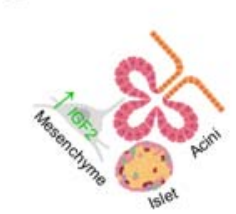

e

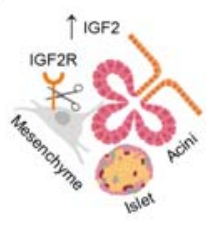

b

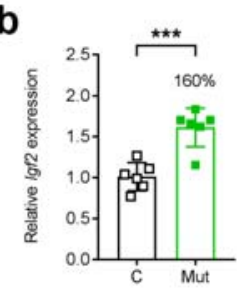

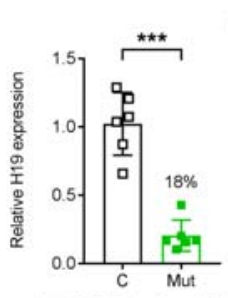

口 C (H190MD" "; Rosa26YFP-stop")

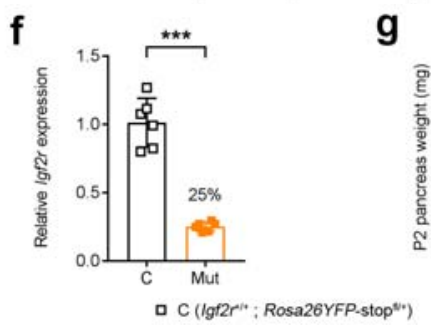

C

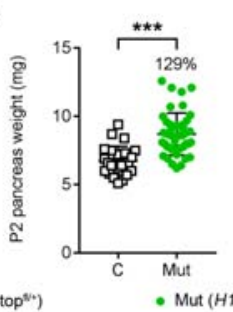

Mut (H19DMD*. C Mut

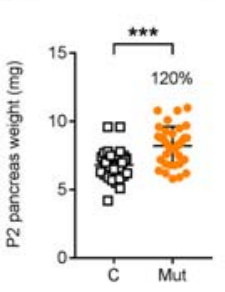

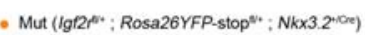

d
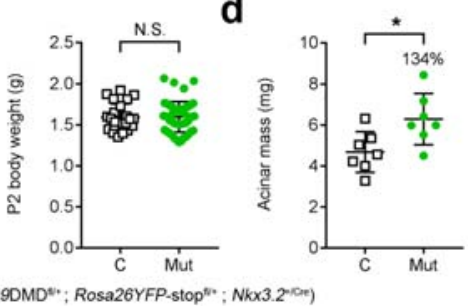

h
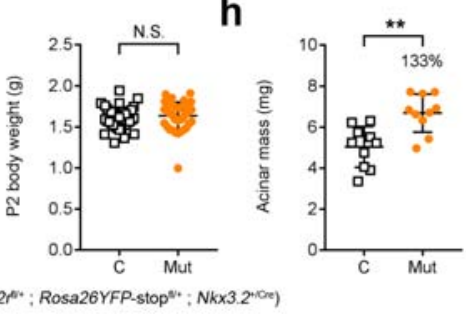

Figure 3: Pancreatic hyperplasia in two models of Igf2 gain-of-function, at postnatal day 2 (P2). (a)

Schematic representation of conditional lgf2 overexpression in pancreatic mesenchyme. (b) Increased Igf2 mRNA expression and reduced H19 mRNA levels in whole pancreata of mutant mice (Mut - H19DMD $D^{\mathrm{f} /+} ; N k \times 3.2^{+/ \mathrm{Cre}}$ ) compared to control littermates $\left(\mathrm{C}-H 19 D M D^{+/+}\right.$) measured by qRTPCR. Data was normalized to Ppia and is shown relative to levels in controls (arbitrarily set to 1). (c) Pancreas weights, shown as individual measurements, are significantly increased in mutants compared to littermate controls ( $n=24$ controls and $n=45$ mutants), with similar body weights between genotypes. (d) Stereological measurements revealed a significant increase (shown as \%) in the acinar-cell mass in mutants compared to littermate controls. Data is shown as individual measurements. (e) Schematic representation of conditional lgf2r deletion in pancreatic mesenchyme. (f) Reduced lgf2r mRNA levels in whole pancreata of mutant mice (Mut - $\lg f 2 \mathrm{fl}^{\mathrm{fl} / \mathrm{+}}$; $N k \times 3.2^{+/ C r e}$ ) compared to control littermates $\left(C-\lg f 2 r^{+/+}\right)$measured by qRT-PCR. Data was normalized to Ppia and is shown relative to levels in controls (arbitrarily set to 1). (g) Pancreas weights, shown as individual measurements, are significantly increased in mutants compared to littermate controls ( $n=39$ controls and $n=35$ mutants), with similar body weights between genotypes. (h) Stereological measurements revealed a significant increase (shown as \%) in the acinar-cell mass in mutants compared to littermate controls. Data is shown as individual measurements. For all graphs error bars represent SD, N.S. - non-significant, ${ }^{*} p<0.05,{ }^{* *} p<0.01$ and ${ }^{* * *} p<0.001$ by unpaired Student's $t$ tests. 
a

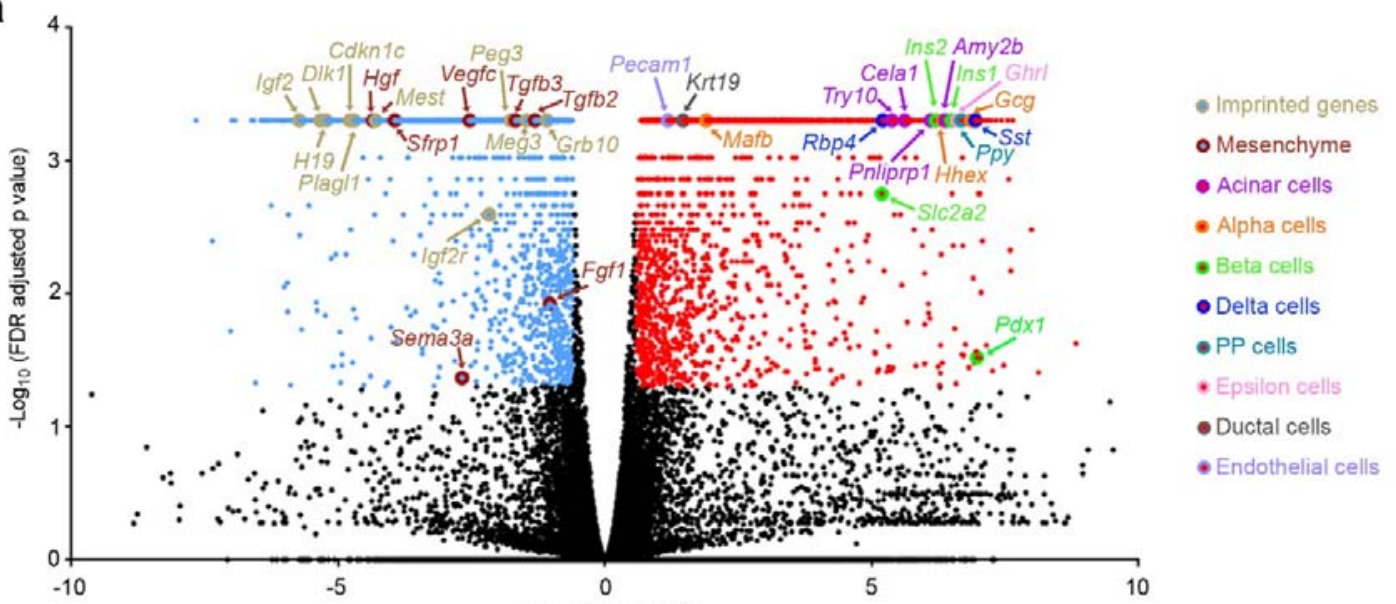

$\log _{2}$ (Fold change)

b Negative regulation of protein kinase activity Axon extension involved in axon guidance

Cell adhesion mediated by integrin Neural crest cell migration

Glycosaminoglycan biosynthetic process Planar cell polarity pathway involved in neural tube closure

Canonical Wnt signalling pathway Collagen catabolic process Negative regulation of JAK-STAT cascade
Vesicle-mediated transport

Vascular endothelial growth factor receptor signalling pathway
Retinoic acid metabolic process Retinoic acid metabolic process

Positive regulation of insulin-like growth factor receptor signalling pathway

Endocardial cushion morphogenesis

Insulin-like growth factor receptor signalling pathway SMAD protein signal transduction

C

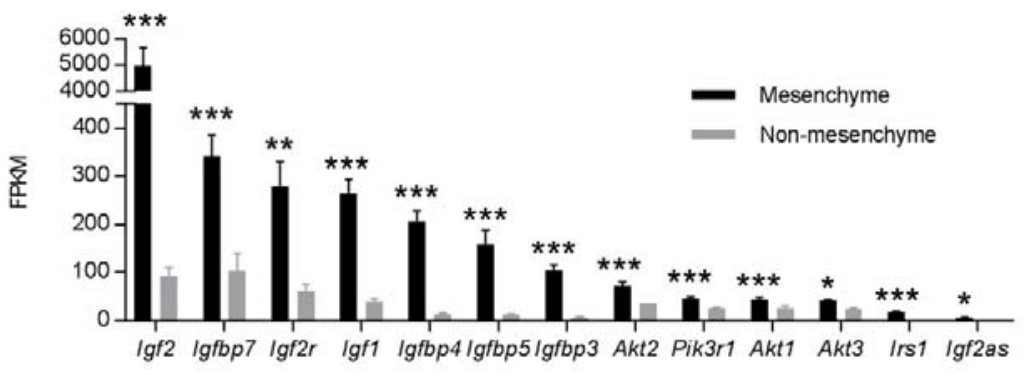

d

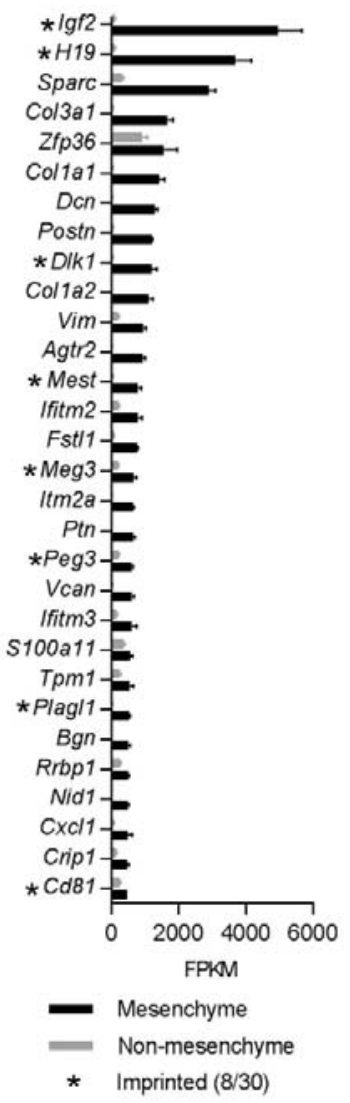

Figure 4: Distinct gene expression patterns of pancreatic mesenchyme identified by RNA-seq at postnatal day 2 (P2). (a) Volcano plot representing all expressed transcripts in pancreatic mesenchyme and non-mesenchyme cells (purified by FACS). For every transcript, the $\log _{2}$ fold change between mesenchyme and non-mesenchyme cells was plotted against the $-\log _{10} p$ value (FDR adjusted). Genes significantly enriched, with a fold change $>1.5$ and FDR adjusted $p$ value $<0.05$, in mesenchyme are depicted as blue dots ( $n=1,902$ genes), in non-mesenchyme as red dots 
$(n=2,212)$, and those not significantly enriched in either cell fraction are depicted as black dots (all genes are listed in Supplementary Data 1). Selected genes of interest, such as known mesenchymeexpressed genes, signature genes for the various non-mesenchyme cell-types and imprinted genes are grouped by colour. (b) Top scoring biological processes containing genes enriched in the pancreatic mesenchyme as identified by DAVID functional annotation include IGF receptor signalling (ranked $19^{\text {th }}$ and $22^{\text {nd }}$ ). The enriched genes involved in this pathway are highlighted in (c). The dotted line in panel (b) corresponds to a $\mathrm{p} \square$ value of 0.05 . For panel (c) data is shown as average FPKM + SEM $(n=4)$, ranked by levels of expression. FDR adjusted $p$ values: ${ }^{*} p<0.05,{ }^{* *} p<0.01$ and $* * *$ $p<0.001$. (d) Top 30 expressed genes with highest FPKM values in pancreatic mesenchyme cells (average FPKM + SEM in mesenchyme and non-mesenchyme cells with $n=4$ per group). Note that all 30 genes are significantly enriched in mesenchyme compared to non-mesenchyme (>1.5 fold, FDR adjusted $p$ value $<0.05$ ). Asterisks indicate imprinted genes, of which there are 8 amongst the top 30 . 
a

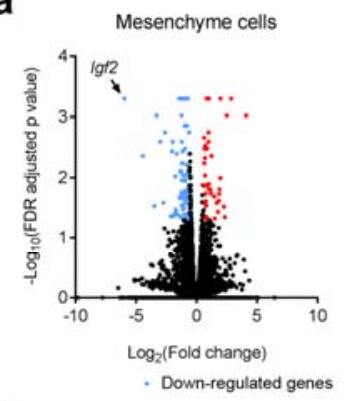

C

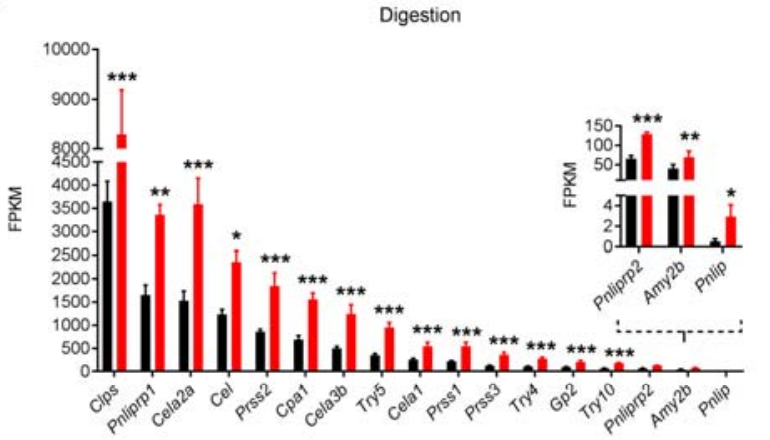

b

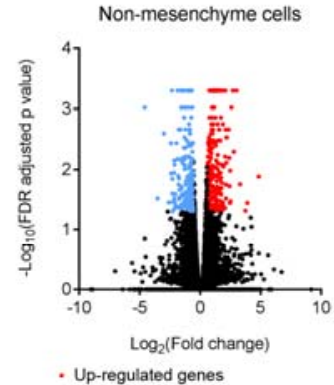

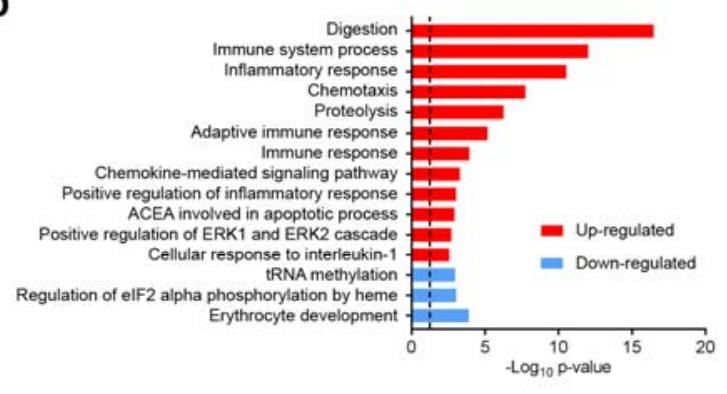

Immune response

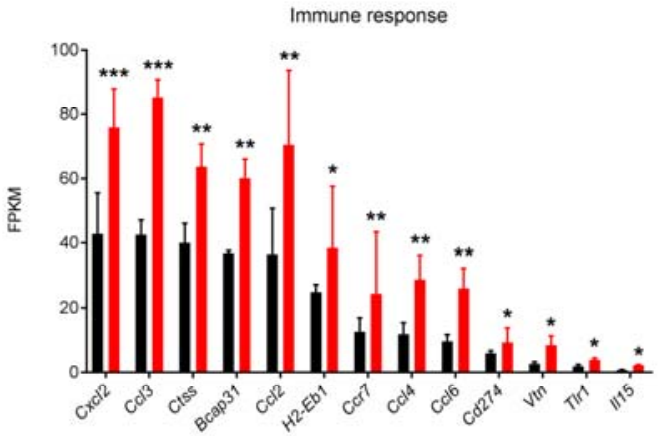

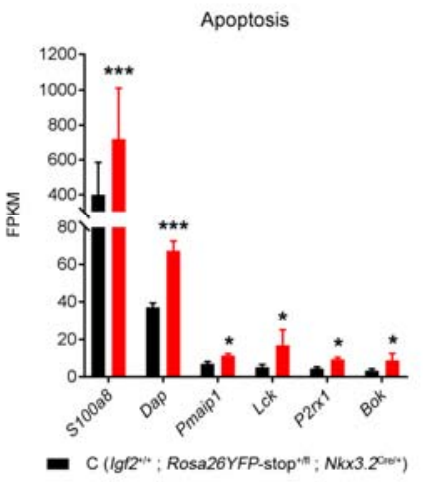
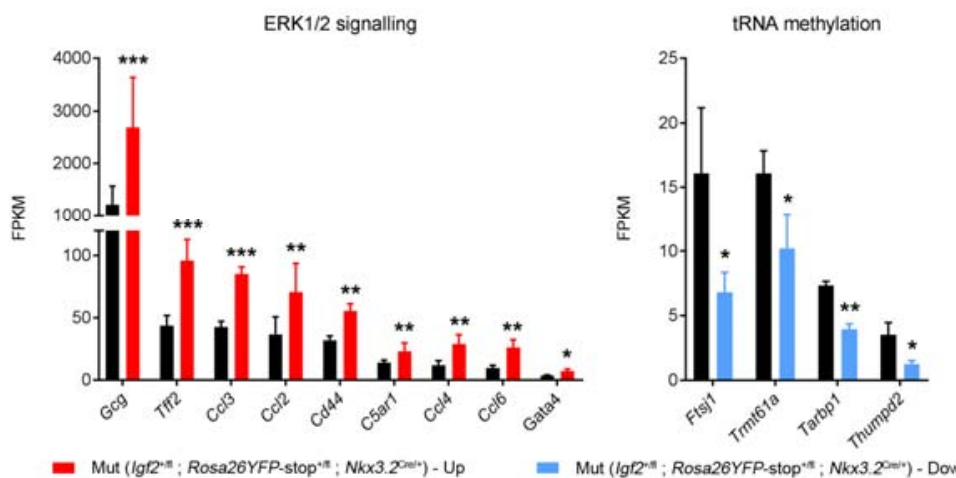

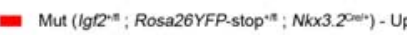

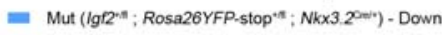

Figure 5: Loss of Igf2 in pancreatic mesenchyme causes significant transcriptional changes in nonmesenchymal cells in a paracrine manner. (a) Volcano plot representing all expressed transcripts (by RNA-seq) in Igf2-deficient pancreatic mesenchyme (lgf2 ${ }^{+/ f l} ; N k \times 3.2^{\mathrm{Cre} /+}$ ) (left panel) and in corresponding non-mesenchyme cell fraction (right panel), compared to mesenchyme and nonmesenchyme controls $\left(\operatorname{lgf} 2^{+/+} ; \mathrm{Nk} 3.2^{\mathrm{Cre} /+}\right)$, respectively. Expression changes detected in the right panel thus reflect changes caused by lack of lgf 2 from the mesenchyme on neighbouring nonmesenchymal cells. For every transcript, the $\log _{2}$ fold change of mutant versus control was plotted against the $-\log _{10} \mathrm{p}$ value (FDR adjusted). Blue and red dots depict statistically significant downregulated and up-regulated genes (fold change $>1.5$ fold FDR adjusted $p$ value $<0.05$ ), respectively, and black dots show genes that are not statistically different; $n=3$ mutants and $n=4$ controls per cellular fraction). There are more differentially expressed genes in the non-mesenchyme fraction (216 down-regulated and 282 up-regulated genes) than in the mesenchyme (109 down-regulated 
and 42 up-regulated genes) (all genes are listed in Supplementary Data 2 and 3). (b) Biological processes enriched in down-regulated (blue) and upregulated (red) genes between nonmesenchyme of $\operatorname{lgf} 2^{+/ f l} ; N k \times 3.2^{\text {Cre/+ }}$ mutants and $\operatorname{lgf} 2^{+/+} ; \mathrm{Nk} \times 3.2^{\mathrm{Cre} /+}$ controls as identified by DAVID. The horizontal axis shows $-\log _{10}$ of $p$ value; the dotted line corresponds to a FDR-corrected $p \square$ value

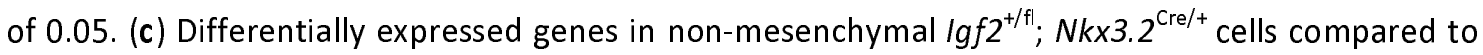

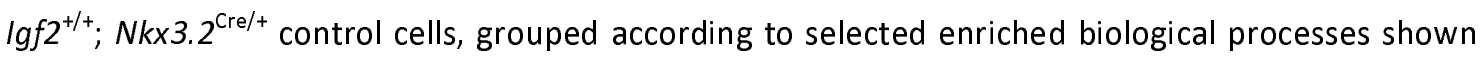
in b). Data is shown as average FPKM + SEM ( $\mathrm{n}=4 \mathrm{lgf2} 2^{+/+} ; \mathrm{Nk} \times 3.2^{\text {Cre/+ }}$ controls and $\mathrm{n}=3 \mathrm{lgf} 2^{+/ \mathrm{fl}}$; $N k \times 3.2^{\text {Cre/ }+}$ ), ranked by levels of expression (the inset depicts lower expressed genes related to "digestion", with a different scale bar). FDR adjusted $p$ values: ${ }^{*} p<0.05,{ }^{* *} p<0.01$ and $* * * p<0.001$. 
a

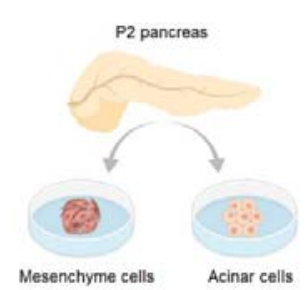

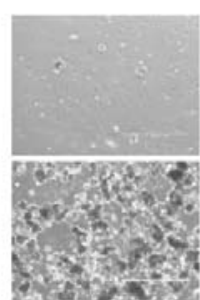

Day 1

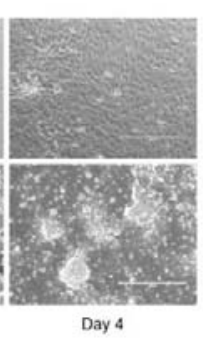

Sema5b
Mesenchyme cells

Acinar cells
C

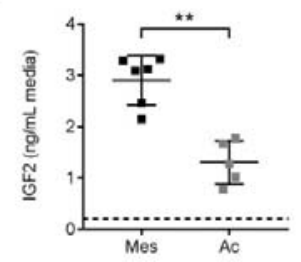

b
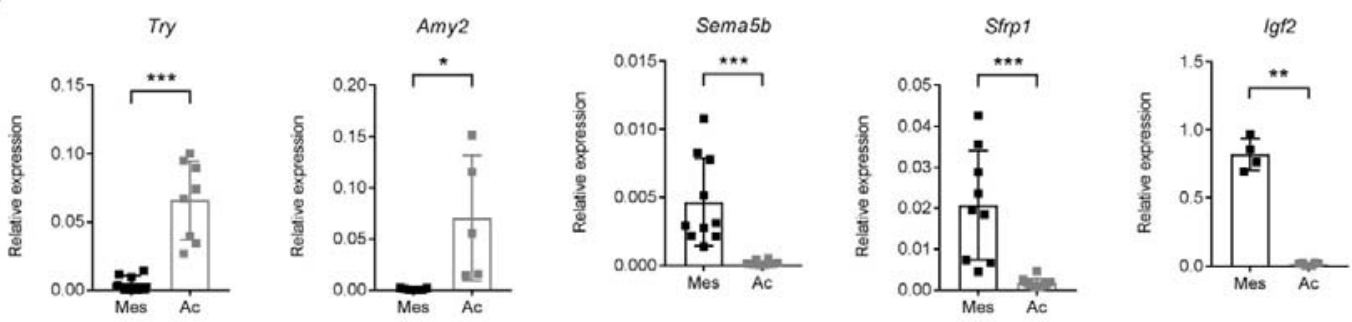

d

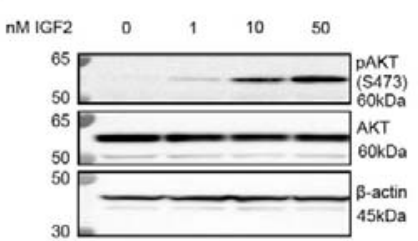

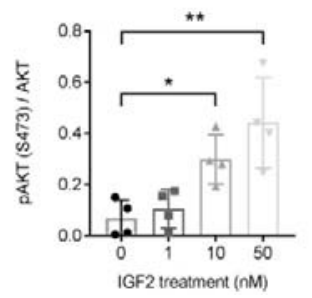

e

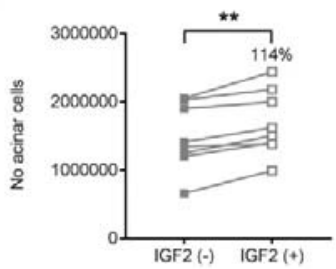

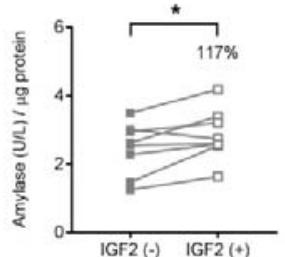

Figure 6: Paracrine effects of mesenchymal IGF2 on acinar cells using a primary cell culture model.

(a) Primary mesenchymal (Mes) and acinar cells (Ac) were isolated from P2 pancreata. Representative images are shown after one and four days in culture. (b) mRNA expression levels of acinar (Try, Amy2) and mesenchymal (Sema5b, Sfrp1, Igf2) signature genes measured by qRT-PCR after four days of culture, showing high purity of the primary cell cultures. (c) Measurement of IGF2 protein secreted by mesenchymal or acinar cells in the culture media. Dotted line corresponds to background readings in media only (d) Levels of AKT phosphorylation (pAKT-S473) after 10 minutes treatment of freshly isolated acinar cells with increasing doses of IGF2 (0nM to 50nM) by western blotting, and quantified against total AKT levels ( $n=4$ independent biological replicates). (e) Effect of IGF2 treatment (IGF2 +: $50 \mathrm{ng} I \mathrm{GF} 2 / \mathrm{ml}$ ) of primary acinar cells on total cell number (left panel) compared to non-treated cells [(IGF2 (-)], and amylase production normalized per protein content (right panel). For all graphs, the data is shown as individual values and averages, error bars represent SD. ${ }^{*} p<0.05,{ }^{* *} p<0.01,{ }^{* *} p<0.001$ by Mann-Whitney tests $(\mathbf{b}, \mathbf{c})$, Friedman's test with Dunn's correction for multiple comparisons (d) and the Wilcoxon matched-pairs signed rank test (e). 


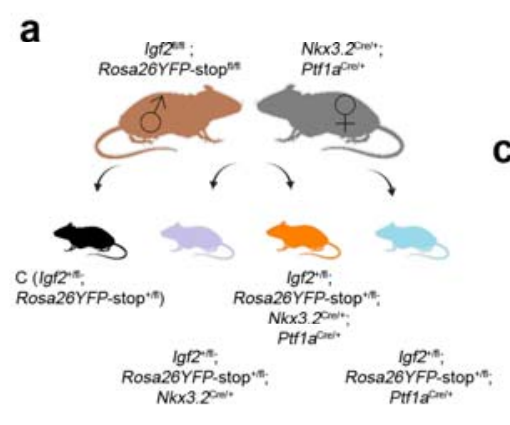

b
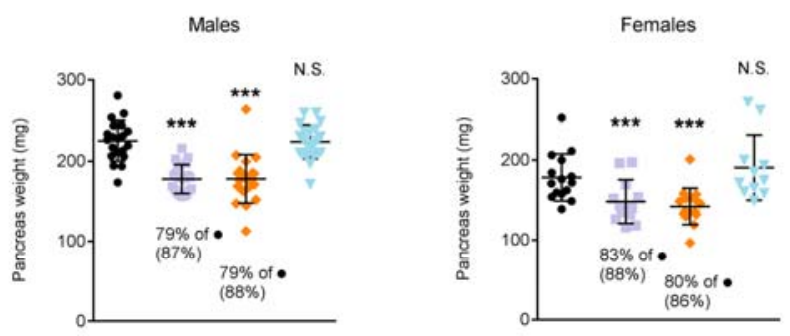

C
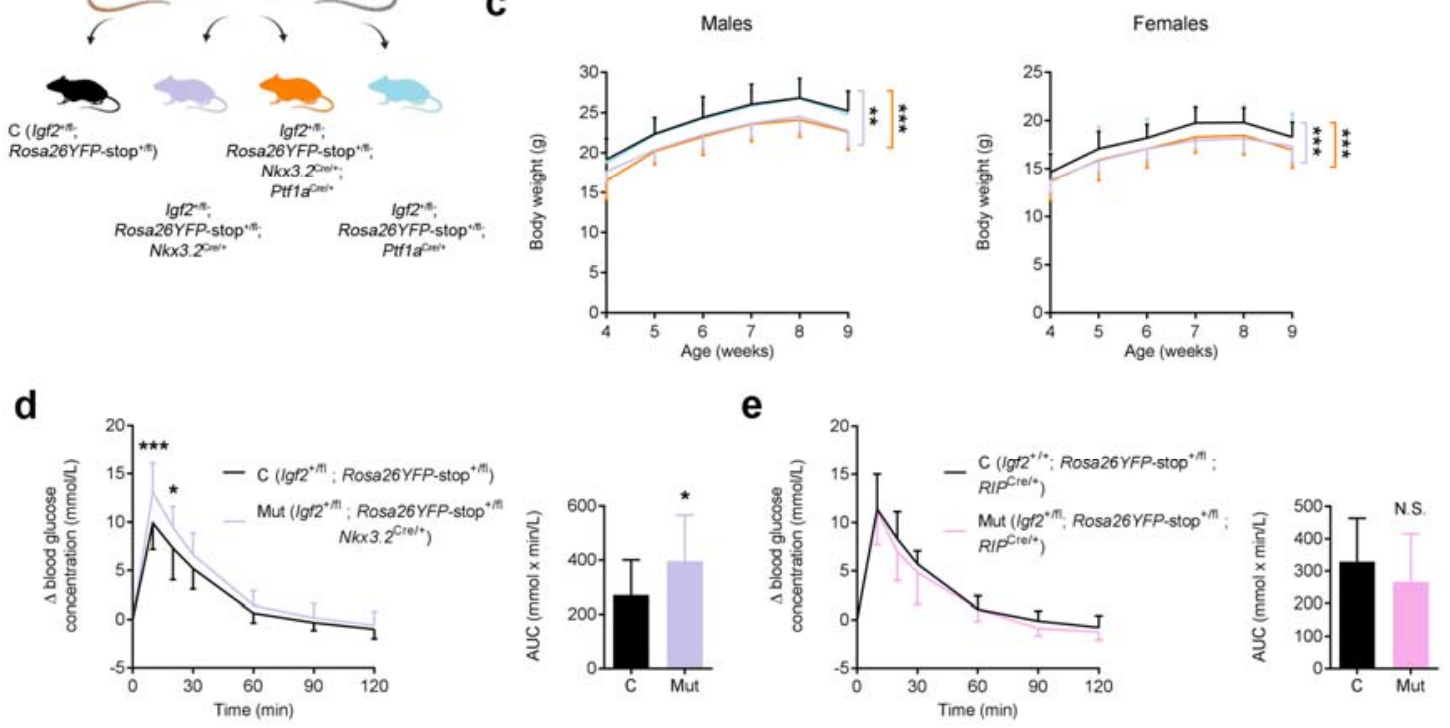

Figure 7: Growth and glucose homeostasis regulation in pancreas-cell type specific Igf2 knockout

mice in adulthood. (a) Schematic representation of the mating strategy used to generate control mice (black) and littermates with lgf2 deletion in the pancreatic mesenchyme only (purple), mesenchyme plus epithelium (orange) or epithelium only (blue). (b) Pancreas weights at 9 weeks of age for males ( $n=20-22$ per genotype) and females ( $n=11-15$ per genotype). Significant reductions in weight (shown as \%) are only observed in mice that carry a deletion of Igf2 in the mesenchyme (i.e.

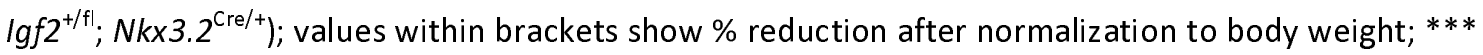
$\mathrm{p}<0.001$ by 1 -way ANOVA with Dunnett's multiple comparisons tests against controls $\left(\mathrm{C}-\operatorname{lgf2^{+/f1}}\right)$. (c) Growth kinetics from weaning to 9 weeks of age for males ( $n=20-22$ per genotype) and females ( $n=11-15$ per genotype). ${ }^{* *} p<0.01$ and $* * * p<0.001$ by repeated measures 1 -way ANOVA with Dunnett's post hoc test for multiple comparisons against the controls $\left(C-\operatorname{lgf} 2^{+/ f l}\right)$. Oral glucose tolerance tests performed in pregnant 8-week old females at E15 of gestation after six hours of fasting: (d) - Igf2 mesenchyme-specific deficient females ( $\mathrm{n}=16 \mathrm{lgf2^{+/fl }}$ controls and $\mathrm{n}=15 \mathrm{lgf2} \mathrm{f}^{+/ \mathrm{fl}}$; $N k \times 3.2^{\text {Cre/t}}$ mutants) and (e) $\operatorname{lgf} 2$ beta-cell specific deficient females ( $\mathrm{n}=15 \mathrm{lgf2^{+/+ }} ; R^{\mathrm{C}} \mathrm{P}^{\mathrm{Cre} /+}$ controls and $\mathrm{n}=14 \mathrm{Igf2^{+/fl }} ; R I P^{\mathrm{Cre} /+}$ mutants). For both (d) and (e), changes in blood glucose concentrations (y-axis) from basal pre-treatment values with time ( $x$-axis) after glucose administration are shown. ${ }^{*} p<0.05$ 
bioRxiv preprint doi: https://doi.org/10.1101/714121; this version posted July 31,2019. The copyright holder for this preprint (which was not certified by peer review) is the author/funder, who has granted bioRxiv a license to display the preprint in perpetuity. It is made available under aCC-BY-NC-ND 4.0 International license.

and ${ }^{* * *} p<0.001$ by two-way ANOVA with Sidak's multiple comparison tests. The graphs on the right side indicate area under curve (AUC) calculated using the trapezoid rule; * $\mathrm{p}<0.05$ by unpaired Student's $t$ test. For all panels, data is shown as average values \pm SD; N.S. - non-significant. 


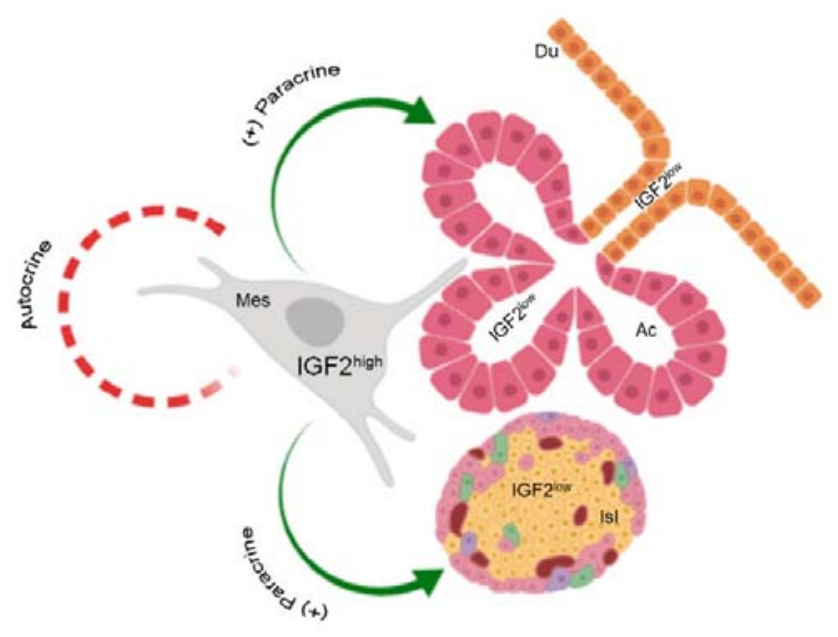

Figure 8: Suggested model of mesenchymal IGF2 actions in the developing pancreas. IGF2 expression is high (IGF2 ${ }^{\text {high }}$ ) in the mesenchymal cells (Mes) of the pancreas and low (IGF2 ${ }^{\text {low }}$ ) in other pancreatic cell types (Ac - acinar cells, Isl - pancreatic islet cells, Du - pancreatic duct cells). IGF2 produced by the mesenchymal cells exerts paracrine effects (green arrows) on pancreatic acinar cells and pancreatic islets. However, we found little evidence (red dotted line) for an autocrine role of mesenchymal IGF2 (see text). Therefore, we propose that the main function of IGF2 in the developing pancreas resides within the mesenchyme as a growth signal to the neighbouring cell types. 
a

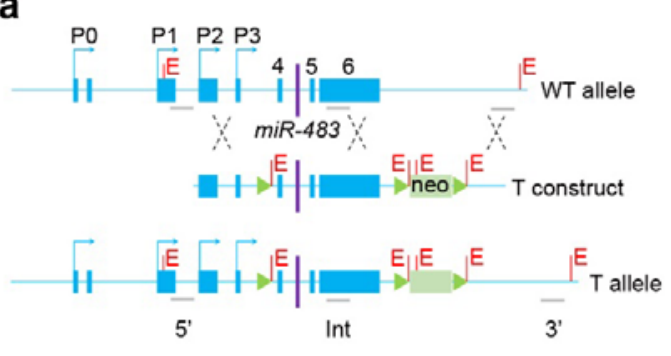

C

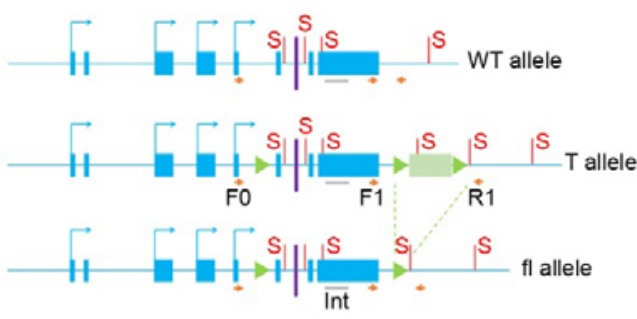

b

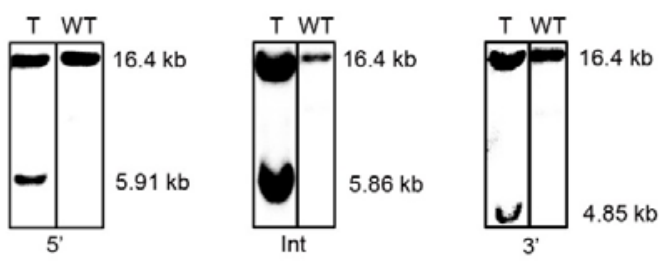

d

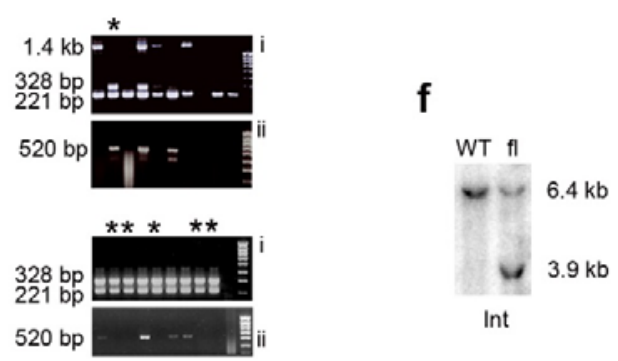

g

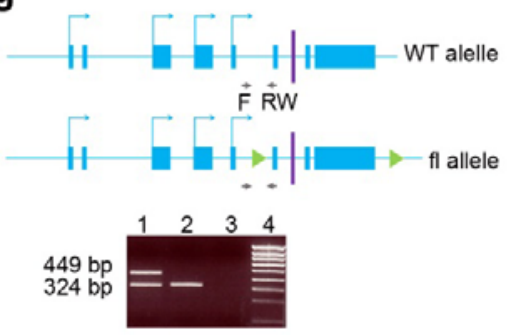

h
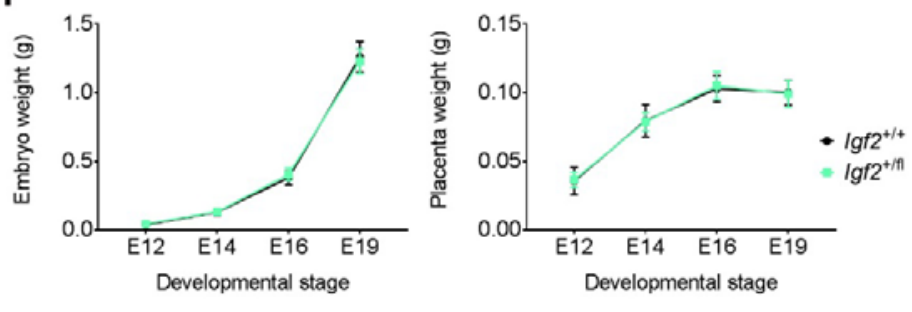

Supplementary Figure 1: Generation of Igf2 conditional knockout mice (see Methods for further details). (a) Targeting strategy to generate an Igf2 allele with coding exons 4 to 6 flanked by loxP sites (not drawn to scale). Blue boxes - exons; P0-P3 - alternative promoters; green triangles - loxP sites; neo - neomycin cassette; WT - wild-type; T - targeting (construct); E - EcoRI restriction sites; $5^{\prime}$, Int, $3^{\prime}$ : location of 5', internal and $3^{\prime}$ Southern blotting probes, respectively (b) Southern blot confirmation of homologous recombination between targeting vector and endogenous lgf 2 sequences in genomic ES cell DNA, digested with EcoRI and hybridized with 5', Int or 3' probes. Diagnostic molecular weights $(\mathrm{kb})$ are indicated in each panel. T and WT - targeted and wild-type clones, respectively. (c) Screening strategy for loxP recombination events (not drawn to scale). Correctly targeted ES clones (as shown in (b)) that are transiently exposed to Cre recombinase in vitro will undergo three possible independent recombination events involving the loxP sites, which can be discriminated by PCR and Southern blotting. F0, F1, R1 - PCR screening primers; S - SphI restriction sites; Int - Internal Southern probe (d) Five 96-well plates containing targeted ES cells transfected with Cre recombinase were screened by F1+R1 primer PCR (panel i) or F0+R1 primer PCR (panel ii). F1+R1 PCR products of $221 \mathrm{bp}, 1.4 \mathrm{~kb}$ and $328 \mathrm{bp}$ are diagnostic of the wild-type allele, neomycin cassette, and neomycin cassette deletion, respectively (panel i). F0+R1 PCR products of 
$520 \mathrm{bp}$ are diagnostic of a deletion that includes the neomycin cassette and exon4-6 region (in panel (ii)). Since all clones that had deletion of the neomycin cassette (i.e. $328 \mathrm{bp}$ ) also had cells with deletion of exon4-6 region (520 bp), the clone indicated with a star in panel (i) was subsequently subcloned for selection of cells with neomycin cassette excision events only. (e) Representative ES subclones (starred) with deletion of the neomycin cassette only (i.e. 328 bp in panel (i) but absence of 520 bp PCR product in panel ii). (f) Southern blot confirmation of deletion of the neomycin cassette in ES subclones identified in (e). DNA was digested with Sphl and hybridized with the internal probe: $6.4 \mathrm{~kb}$ - wild-type allele (WT); $3.9 \mathrm{~kb}$ - floxed allele (fI), resulting from Cre-induced deletion of the neomycin cassette. (g) PCR genotyping of $/ g \mathrm{f}^{+/ f \mid}$ mice was performed using primers $\mathrm{F}$ and RW flanking the $5^{\prime}$ loxP site (primer sequences are shown in Supplementary Table 2). A representative example of tail DNA PCR is shown for mice carrying one floxed lgf2 allele (lane 1) wild-type littermate (lane 2); lane 3 - no template PCR control; lane 4-100 bp DNA ladder. (h) Carriers of an Igf 2 floxed allele that was inherited paternally show identical embryonic and placental weights as littermate controls (E12: $n=8$ wild-type and $n=3$ floxed; E14: $n=16$ wild-type and $n=7$ floxed; E16 $n=12$ wild-type and $n=10$ floxed; E19: $n=29$ wild-type and $n=24$ floxed). Data is shown as average weight; error bars represent standard deviation (SD). 
a
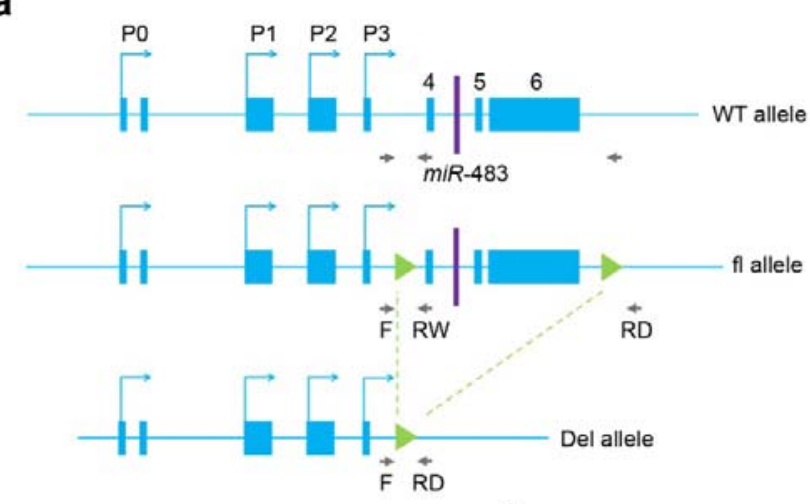

C

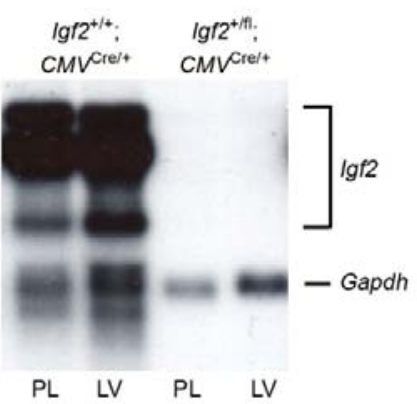

f

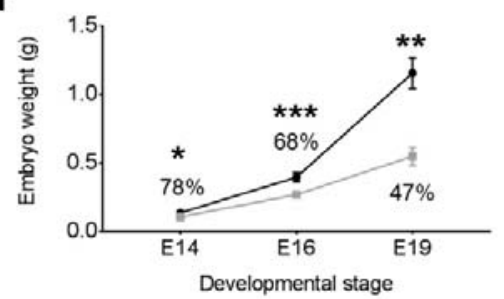

g b

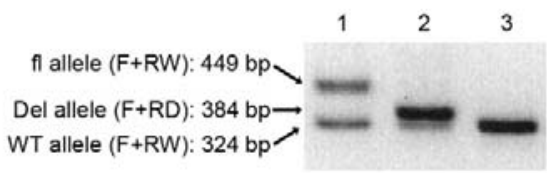

e
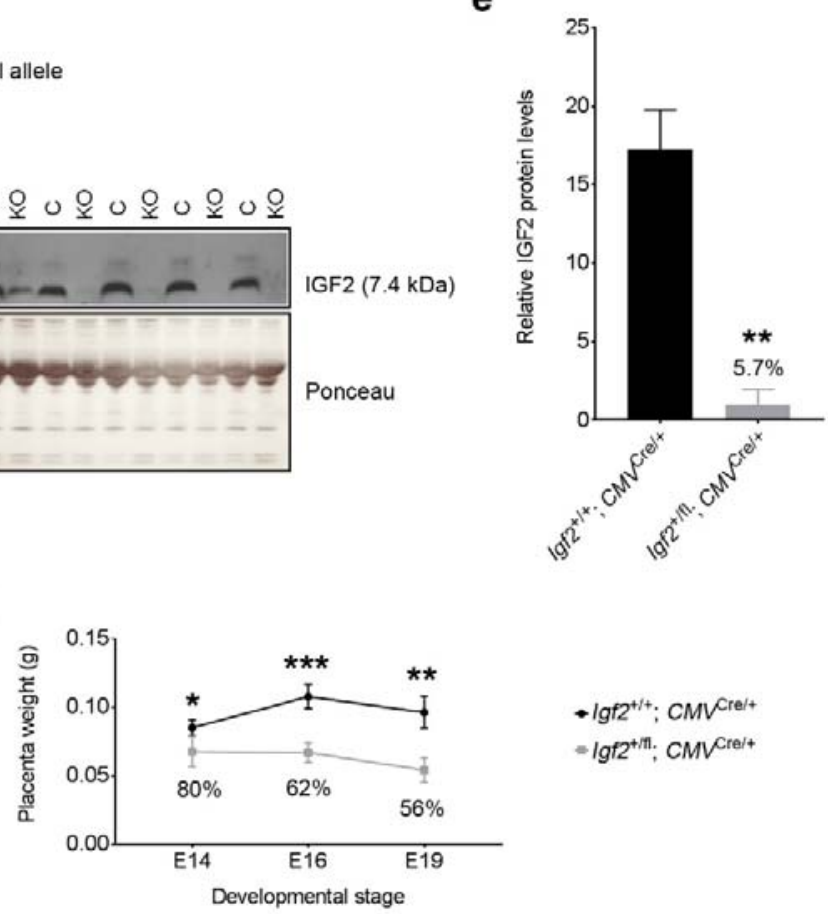

$+\operatorname{lgf} 2^{+/+} ; \mathrm{CMV}^{\mathrm{Cr} /+}$

$=\lg 2^{+/ \pi t} ; C M V^{\text {Crei+ }}$

Supplementary Figure 2: Cre-mediated deletion of the Igf2 floxed allele. (a) PCR strategy to identify deletion events at DNA level. PCR products obtained in a tri-primer (F+RW+RD) PCR are diagnostic of the wild-type allele (WT: 324bp), floxed allele (fl: $449 \mathrm{bp}$ ) and deleted allele (Del: 384bp). Representative tail DNA PCR examples are shown in (b) for $/ g \mathrm{f}^{+/ f 1}$ mice that carry floxed and wild-

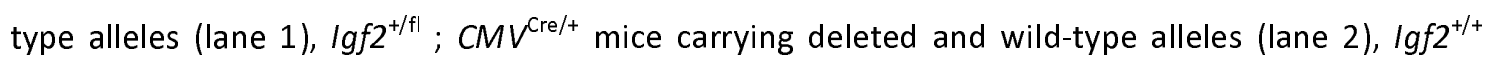
control littermates with wild-type alleles only. (c) to (g) CMV-Cre mediated deletion of the Igf2 floxed allele in vivo. Heterozygous floxed Igf2 males were mated with females homozygous for CMVCre (active in all cells of embryos and placentae), and offspring analysed for levels of Igf2 deletion by northern blotting (c), Western blotting (d) and (e), and growth curves from E14 to E19 of gestation $((\mathbf{f})$ and $(\mathbf{g}))$. (c) Northern blot analysis of Igf2 mRNA levels, showing wild-type levels of expression in controls $\left(\mathrm{lgf2} 2^{+/+} ; \mathrm{CMV}^{\mathrm{Cre} /+}\right)$ in both placenta (PL) and liver (LV) at E19, and absence of all Igf2 transcripts upon CMV-Cre mediated deletion of the paternally inherited floxed allele $\left(/ g f 2^{+/ f l}\right.$; 
$\mathrm{CMV}^{\text {(re/t+}) . G a p d h-i n t e r n a l ~ c o n t r o l ~ f o r ~ R N A ~ l o a d i n g . ~(d) ~ W e s t e r n ~ b l o t t i n g ~ a n a l y s i s ~ o f ~ t h e ~ m a t u r e ~ f o r m ~}$ of IGF2 in serum samples collected from E19 controls (C: $\operatorname{lgf} 2^{+/+} ; \mathrm{CMV}^{\mathrm{Cre} /+}$ ) and mutant (KO: $\operatorname{lgf} 2^{+/ f 1}$; $C \mathrm{MV}^{\mathrm{Cr} / \mathrm{f}}$ ) embryos. Normalisation of IGF2 expression across samples was performed against Ponceau-stained protein band (arrow), and the relative quantification of IGF2 levels for the two genotypes is shown in (e). Data is shown as average values; error bars represent SEM; ${ }^{* *} p<0.01$ by Mann-Whitney test. (f) and (g) Mice with a CMV-Cre mediated deletion of the paternally inherited Igf2 floxed allele (Igf2 $\left.{ }^{+/ f l} ; \mathrm{CMV}^{\mathrm{Cre/+}}\right)$ show a similar embryonic (f) and placenta (g) growth phenotype to Igf2 null mice, i.e. $\sim$ half of the weight of littermate controls $\left(\operatorname{lgf} 2^{+/+} ; \mathrm{CMV}^{\mathrm{Cre} /+}\right)$ at the end of gestation (E14: $n=3$ litters; E16: $n=9$ litters; E19: $n=4$ litters). Data is shown as average values; error bars represent SD; ${ }^{*} p<0.05 ;{ }^{* *} p<0.01 ;{ }^{* * *} p<0.001$ using paired student $t$ tests. 
a

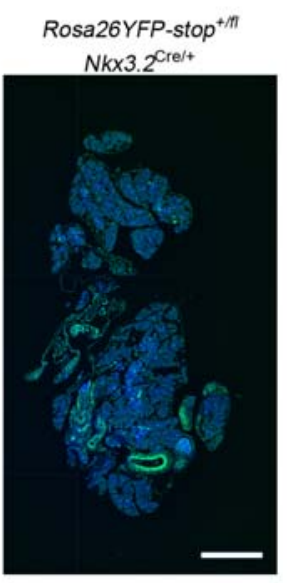

d
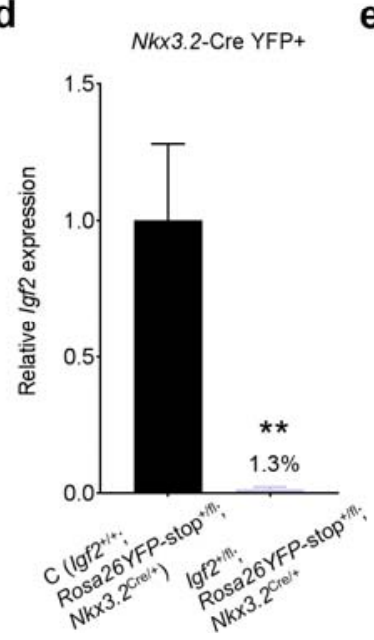

b

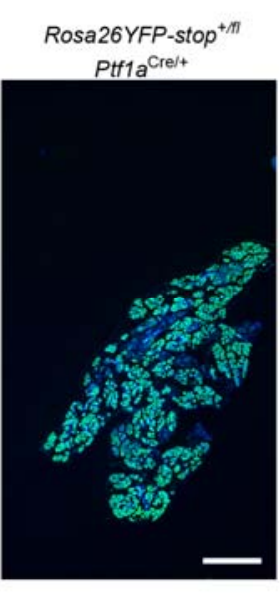

e

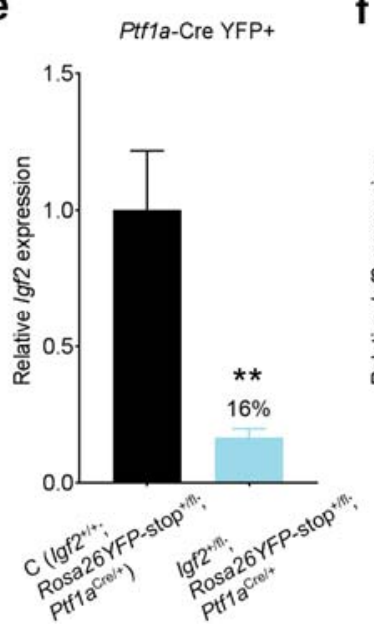

C

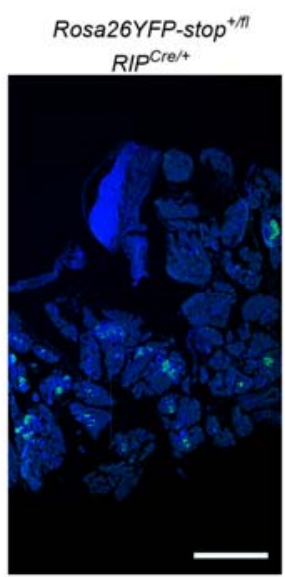

$\mathbf{f}$

RIP-Cre YFP+

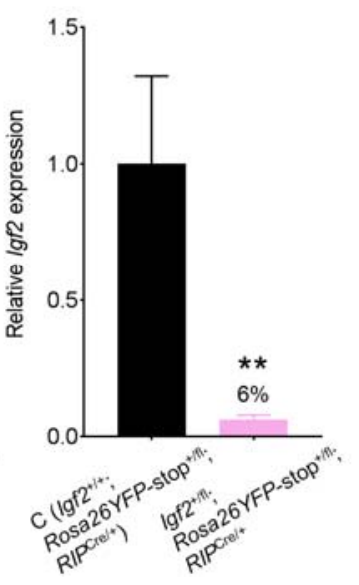

g

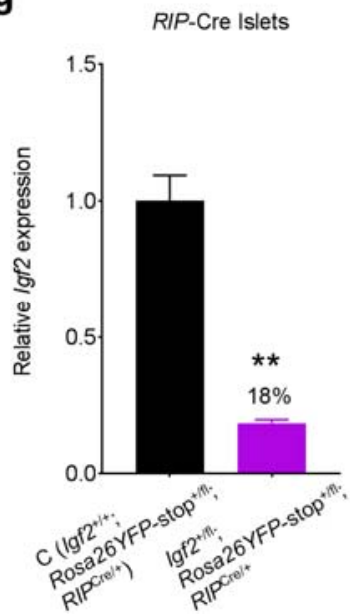

Supplementary Figure 3: Assessment of specificity and efficiency of pancreas-expressing Cre lines using the Rosa26YFP-stop ${ }^{\mathrm{fl} / \mathrm{fl}}$ reporter mouse, at postnatal day 2 (P2). (a), (b) and (c) Confocal fluorescence microscopy images of sections stained for the YFP protein (green) and nuclei (DAPI, blue). Upon Cre-mediated deletion of the loxP-Stop-loxP cassette, the YFP protein is expressed in the pancreatic mesenchyme ( $N k \times 3.2-\mathrm{Cre}$ ), pancreatic epithelial cells (Ptf1a-Cre) and pancreatic beta cells (RIP-Cre). Scale bar: $500 \mu \mathrm{m}$. (d), (e) and (f) Igf2 mRNA expression measured by qRT-PCR in YFP+ cells collected from offspring with the genotypes indicated. (g) Igf2 mRNA expression measured by qRTPCR in pancreatic islets isolated from 11-week old mice with the genotypes indicated. For panels (d) to $(\mathbf{g})$ expression data was normalized to Ppia and shown as averages + SEM relative to levels measured in control (C) littermates, arbitrarily set to 1 . Percentage values indicate the level of Igf2 mRNA reduction relative to controls ( $n=4-6$ samples/genotype; ${ }^{* *} p<0.01$ by Mann-Whitney tests). 


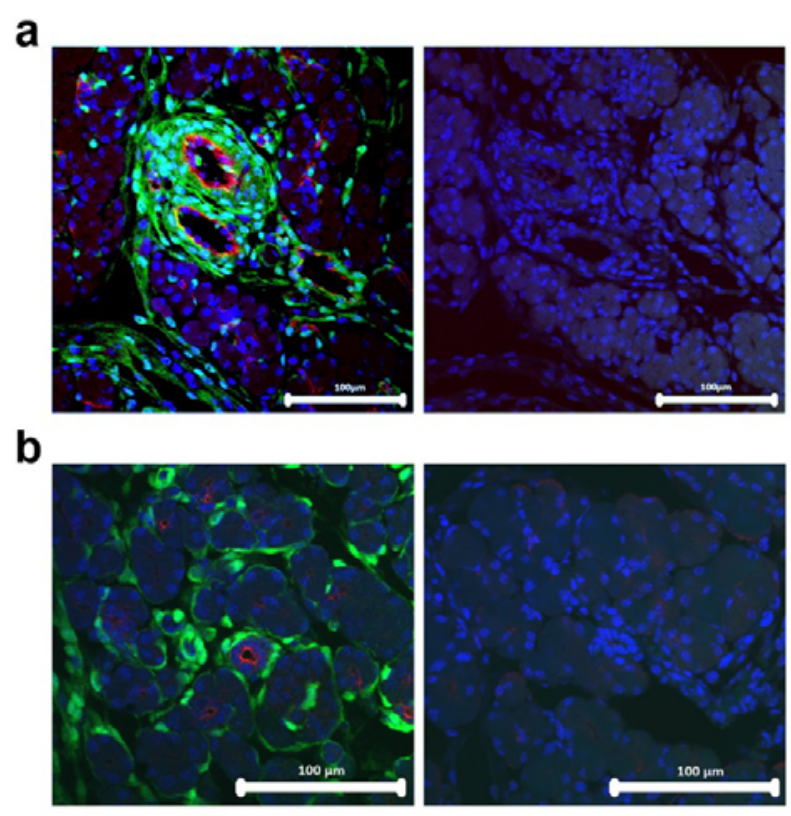

Supplementary Figure 4: Assessment of mesenchyme-specific activity of Nkx3.2-Cre at postnatal day 2 (P2). Representative immunofluorescence for (a) endothelial cell marker CD31 (red) and (b) duct cell marker pan-cytokeratin (red) showing no stain overlap with the $N k \times 3$.2-Cre driven YFP expression as a marker of mesenchyme cells (green). DAPI (blue) stains the nuclei. $N k \times 3.2-C r e$ is therefore not expressed in endothelial and duct cells, being confined to mesenchymal cells surrounding other cell types, as reported before by others. Panels on the right show negative controls performed in consecutive sections, without primary antibodies. Scale bars: $100 \mu \mathrm{m}$. 
a

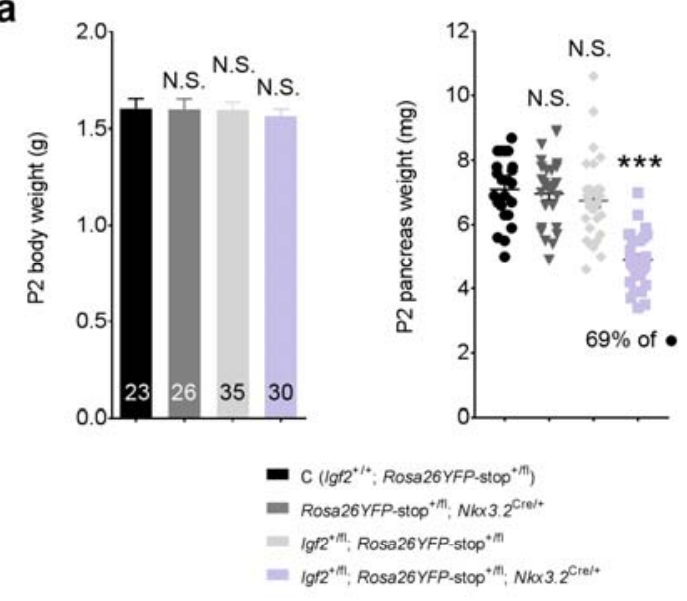

b

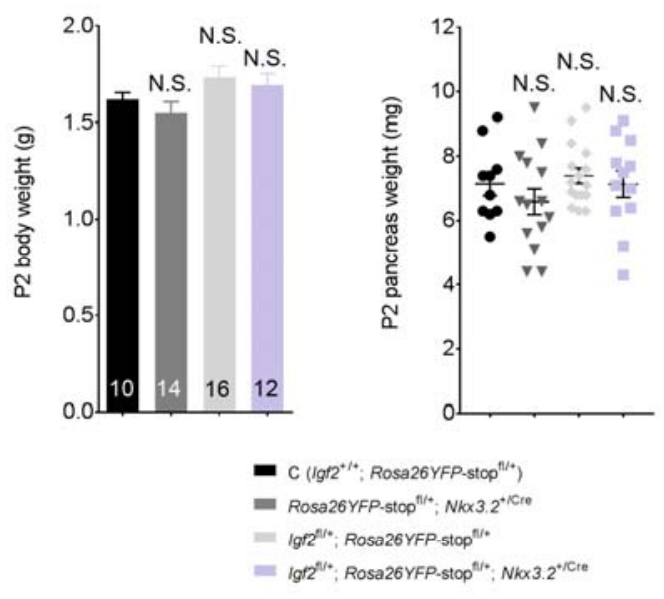

C

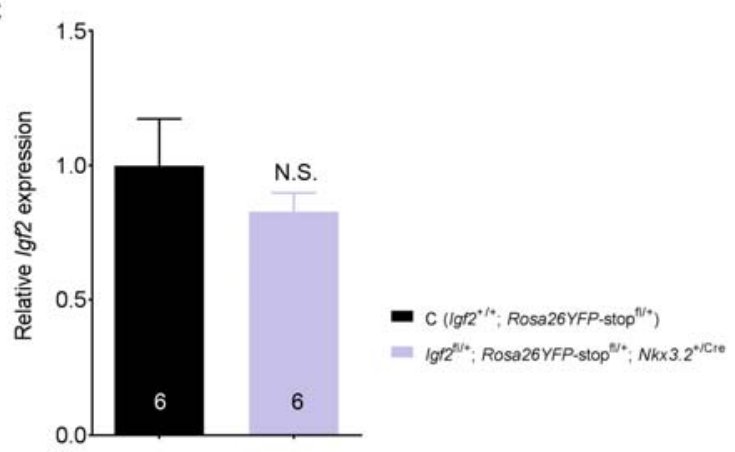

Supplementary Figure 5: The presence of $\mathbf{N k x 3 . 2 - C r e ~ o r ~ I g f 2 ~ f l o x e d ~ a l l e l e s , ~ o r ~ d e l e t i o n ~ o f ~ m a t e r n a l ~}$ Igf2 alleles do not affect total body or pancreas weights at postnatal day 2 (P2). (a) body and pancreas weights in offspring obtained from a cross between heterozygous $N k \times 3.2-C r e$ females and heterozygous Igf2 floxed males (b) body and pancreas weights in offspring obtained from a cross between heterozygous Igf2 floxed females and heterozygous Nkx3.2-Cre males (c) Igf2 mRNA levels measured by qRT-PCR in pancreases with a deletion of the maternal Igf2 allele in the mesenchyme. Data is normalized to Ppia and shown relative to average lgf2 levels in controls $\left(\mathrm{C}-\operatorname{lgf} 2^{+/+}\right)$, set to 1 . Data is shown as averages or individual values; error bars represent SEM. Numbers shown indicate numbers of animals for each genotype. Data was analysed using one-way ANOVA with Dunnett's multiple comparison test against the control group for panels (a) and (b) and by unpaired Student's t test in panel (c); N.S. - non-significant; ${ }^{* * *} p<0.001$. 
a

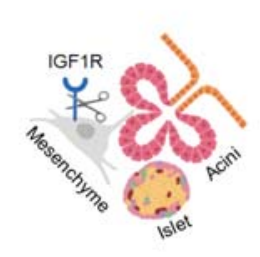

b

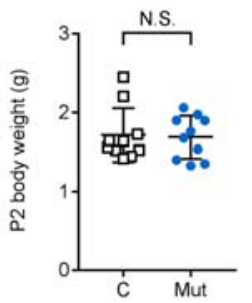

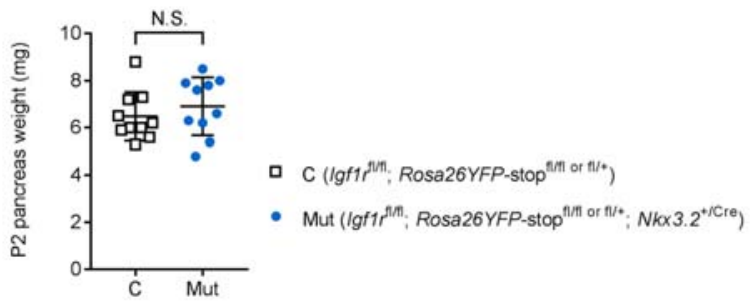

Supplementary Figure 6: Normal pancreas growth upon mesenchyme-specific deletion of Igf1r. (a)

Schematic representation of the conditional Igfir deletion from the pancreatic mesenchyme. (b) Pancreas weights and total body weights are similar in mutants compared to littermate controls at postnatal day P2 ( $n=10$ controls and $n=10$ mutants). Data is presented as individual values with averages \pm SD; N.S. - non-significant by unpaired Student's $t$ tests. 
a

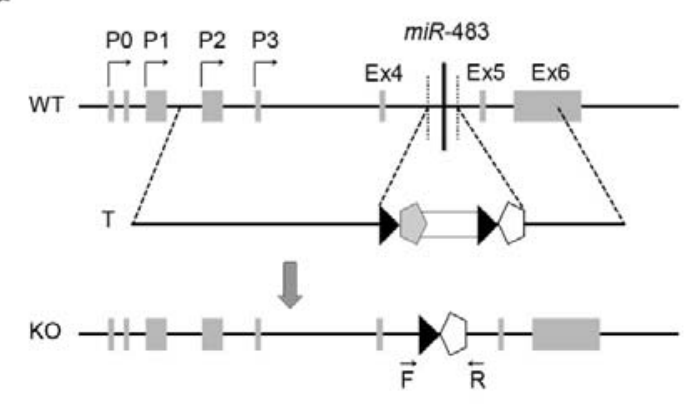

C

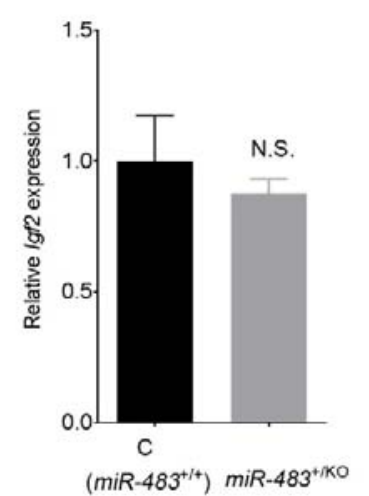

d b
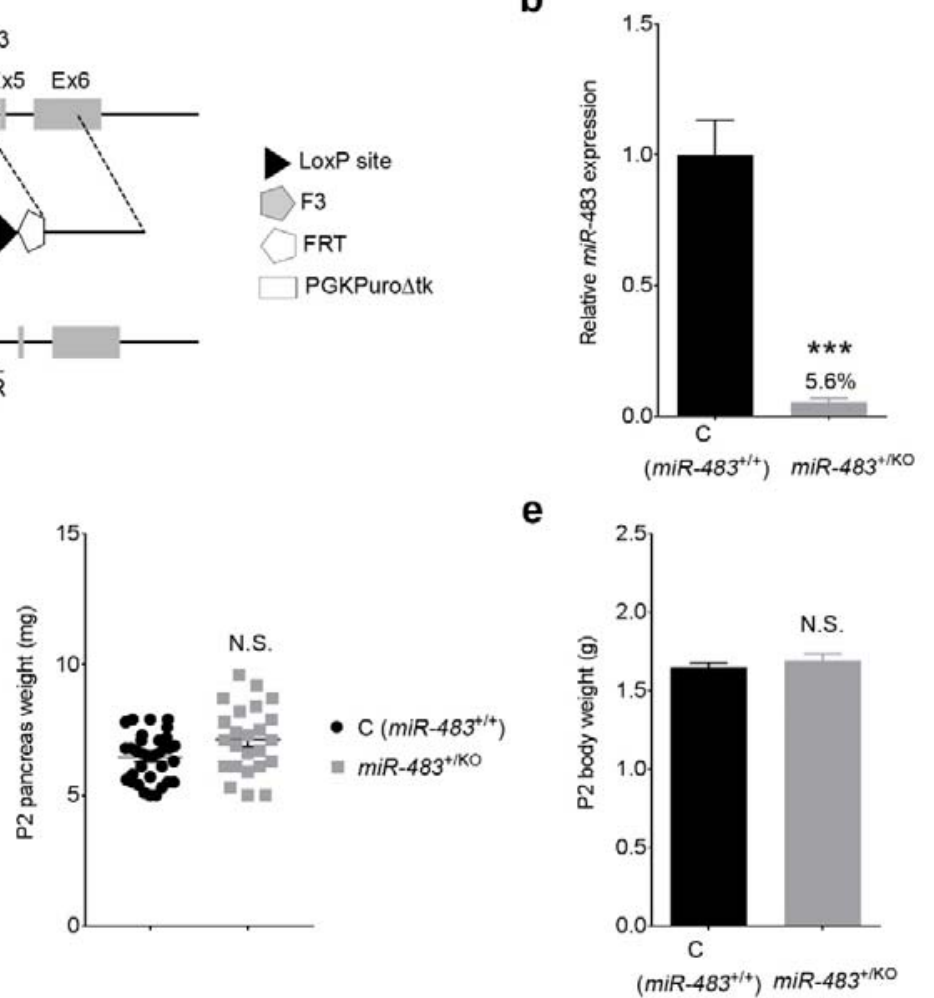

LoxP site

$\mathrm{F3}$

FRT

J PGKPuroAtk

e

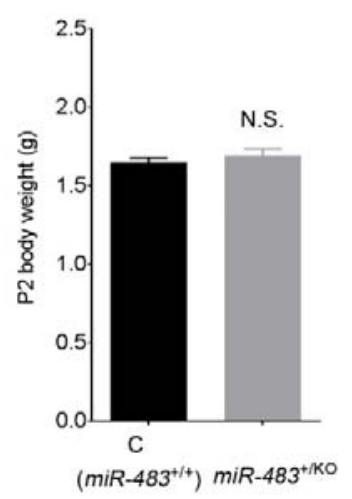

Supplementary Figure 7: Paternally inherited miR-483 deletion does not lead to reduction in pancreas size. (a) Gene targeting strategy to delete the intronic lgf2 miR-483. In brief, a targeting vector was used to replace the miR-483 sequence in intron 4 of the $\operatorname{lgf2}$ gene with a PGKPuro $\Delta$ tk selection cassette in ES cells. Removal of the selection marker was achieved by Cre-recombination between loxP sites. Germline transmitting miR-483 KO chimeric mice were generated by ES cell injection into blastocysts (Sekita, Prosser, Zvetkova et al., manuscript in preparation). (WT - wildtype allele, T - targeted allele, KO - knock-out allele, PO - P3 are alternative Igf2 promoters, Ex4 Ex6 are the Igf 2 coding exons, $\mathrm{F}$ and $\mathrm{R}$ indicate the position of the forward and reverse primers used for PCR genotyping). (b) miR-483 expression levels measured by qRT-PCR in postnatal day 2 (P2) whole pancreas from offspring of heterozygous miR-483 KO males mated with wild-type females and shown relative (\%) to littermate controls $\left(C-m i R-483^{+/+}\right)$set to 1 . Expression data was normalized to snoR-202 and snoR-234 and is shown as average + SEM ( $n=10 \mathrm{C}$ and $\mathrm{n}=10 \mathrm{KO})$. ${ }^{* * *} \mathrm{p}<0.001$ by unpaired Student's $t$ test. (c) Igf2 mRNA expression is unaltered in $m i R-483^{+/ K O}$. Data was normalized to Ppia and is shown relative to controls set to 1 ( $n=10 \mathrm{C}$ and $n=10 \mathrm{KO}$ ); error bars: SEM. N.S. - nonsignificant differences between genotypes by unpaired Student's $t$ test. Total pancreas weights (d) shown as individual values and population average \pm SEM and corresponding body weights (e) at P2. 
bioRxiv preprint doi: https://doi.org/10.1101/714121; this version posted July 31, 2019. The copyright holder for this preprint (which was not certified by peer review) is the author/funder, who has granted bioRxiv a license to display the preprint in perpetuity. It is made available under aCC-BY-NC-ND 4.0 International license.

Data is shown as averages ( $n=33 \mathrm{C}$ and $n=24$ KO); error bars represent SEM; N.S. - non-significant differences by two-way ANOVA using genotype and litter as factors. 
a

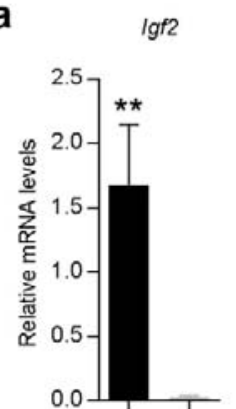

b
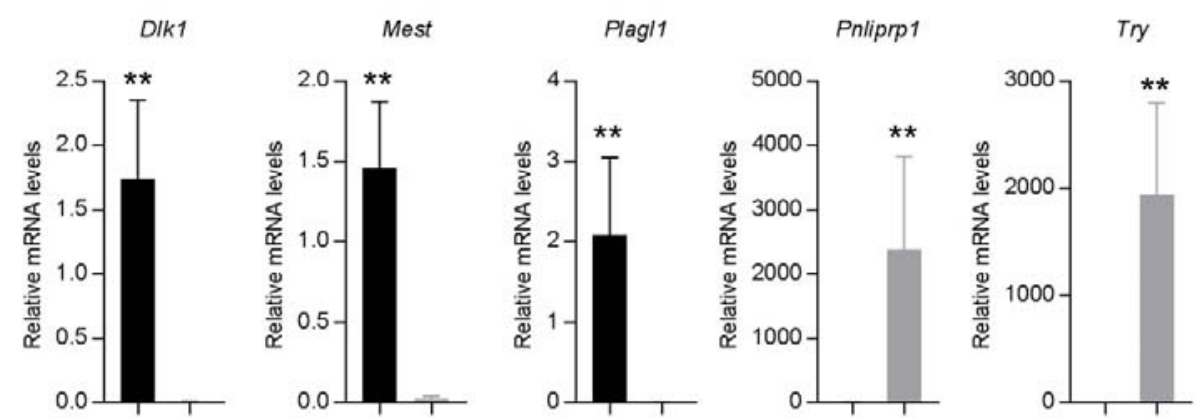

邁

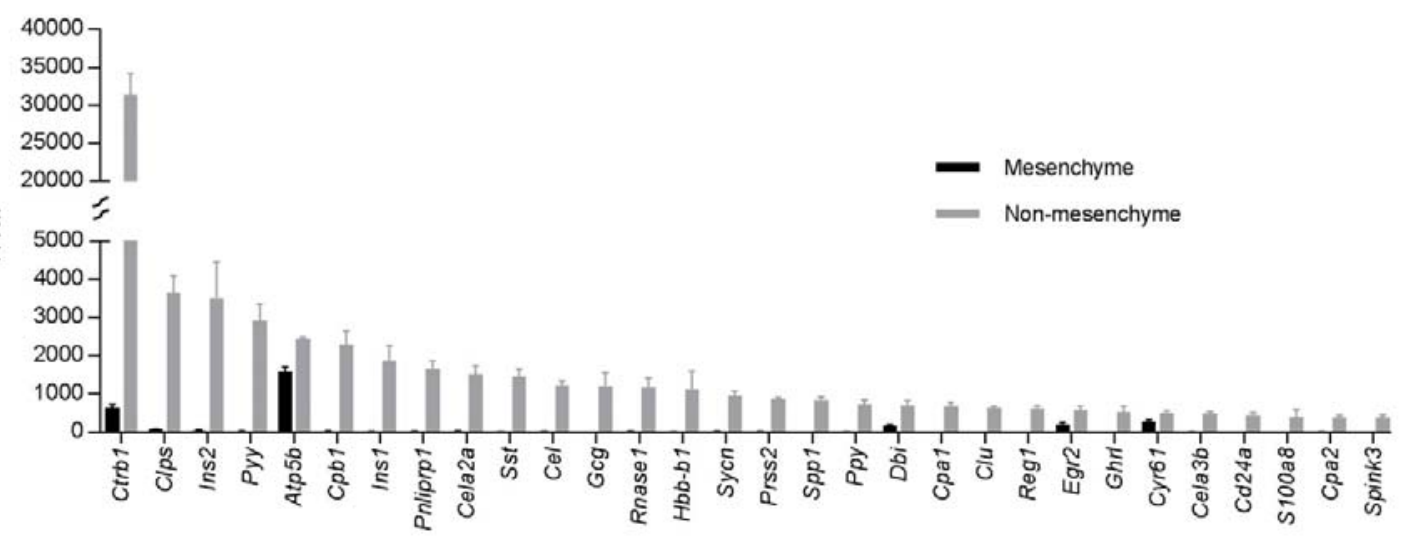

Supplementary Figure 8: Gene expression analysis in pancreatic mesenchyme and nonmesenchyme cells at postnatal day 2 (P2). (a) Biological validation by qRT-PCR of differentially expressed genes between mesenchyme and non-mesenchyme, identified by RNA-seq ( $n=5-6$ samples per group). Expression levels were normalized to Ppia. Data is shown are average values; error bars represent SEM; ** $p<0.01$ by Mann-Whitney tests. (b) Top 30 expressed genes with highest average FPKM values in pancreatic non-mesenchyme cells, and corresponding expression in mesenchyme $(n=4$; error bars represent SEM). Note that all 30 genes are significantly enriched in non-mesenchyme cells ( $>1.5$ fold, FDR adjusted $p$ value $<0.05$ ) compared to mesenchyme. 
a

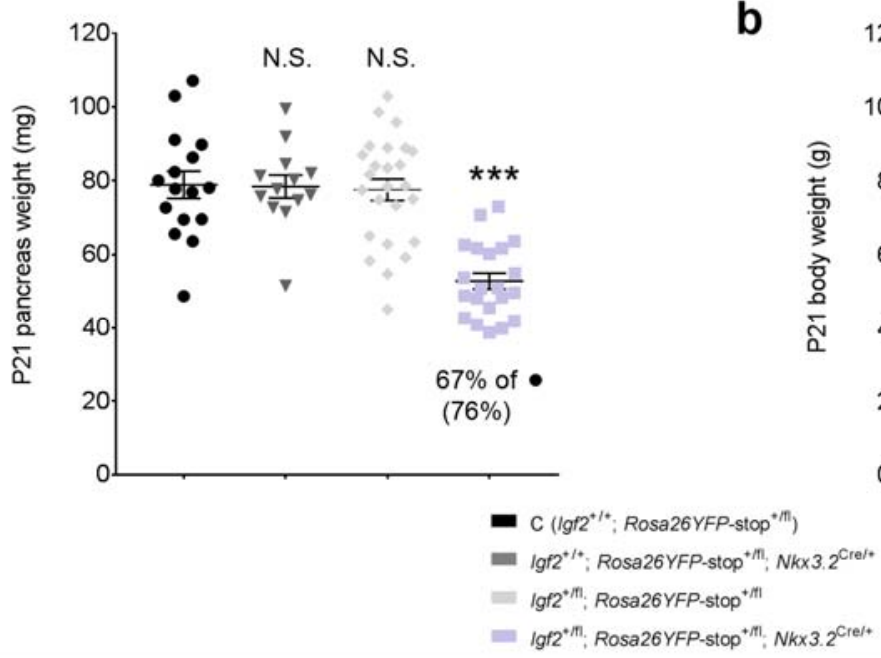

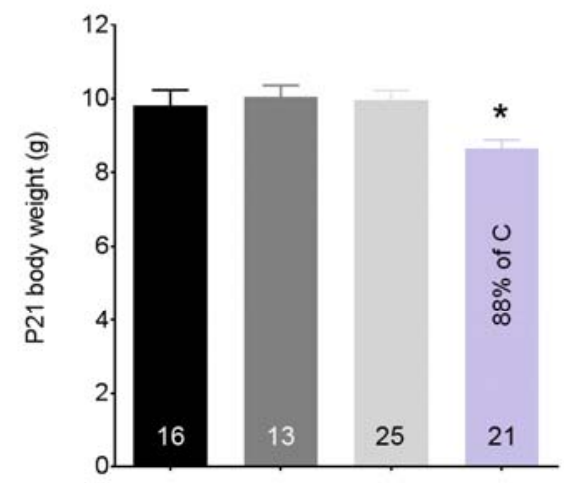

Supplementary Figure 9: Deletion of paternal Igf2 in pancreatic mesenchyme leads to reduced body and pancreas weights at weaning (P21). Total pancreas weight (a) and body weight (b) in offspring obtained from a cross between heterozygous Nkx3.2-Cre females and Igf2 floxed males. The value within brackets in (a) shows \% pancreas weight reduction after normalization to body weight. Data is shown as averages or individual values; error bars represent SEM. Numbers of mice for each genotype are shown. Data was analysed using one-way ANOVA with Dunnett's multiple comparison tests against the control group (C $\left.-\operatorname{lgf} 2^{+/+}\right)$; N.S. - non-significant; ${ }^{*} \mathrm{p}<0.05$; ${ }^{* * *}$ $\mathrm{p}<0.001$. 
a

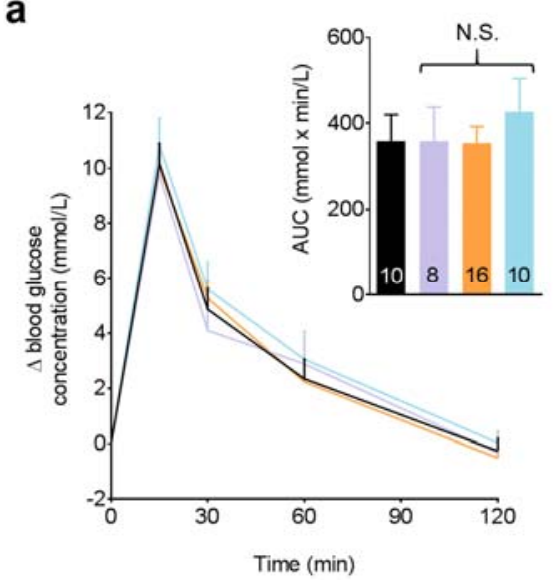

C

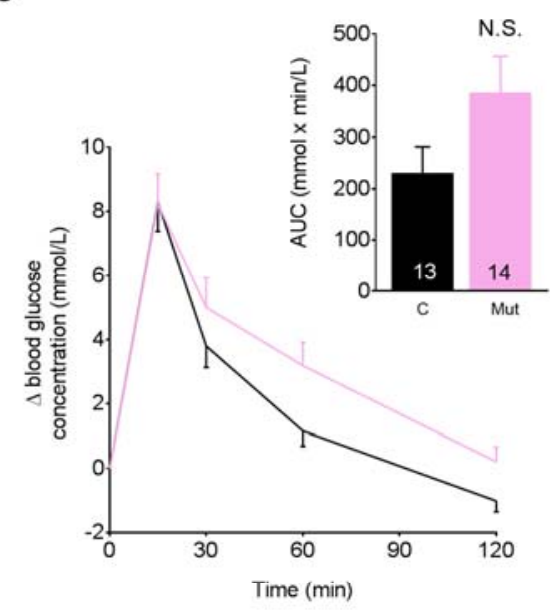

b

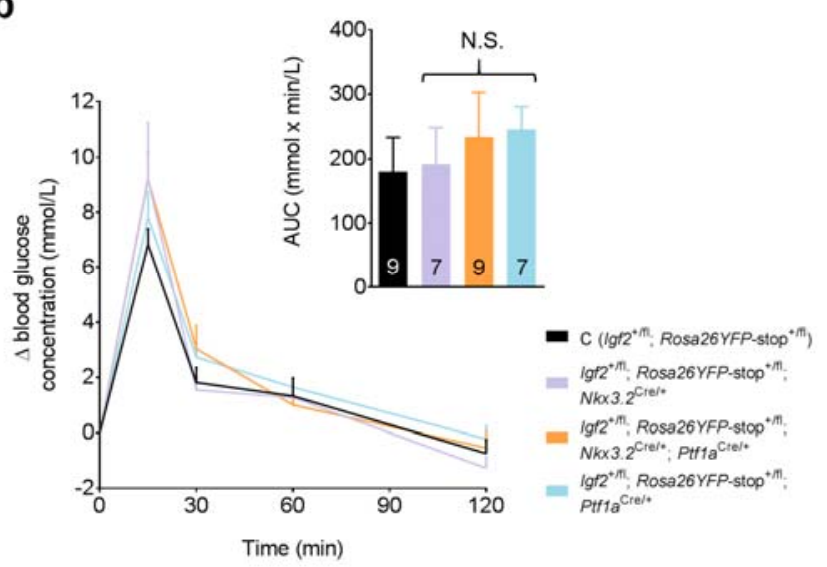

d

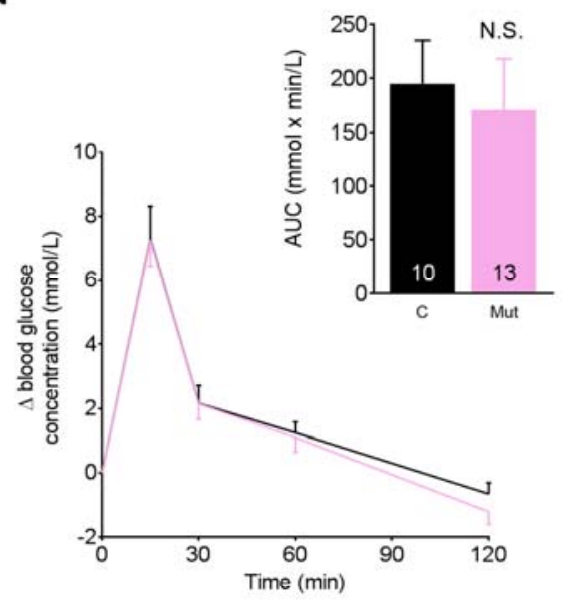

e

Females

Males

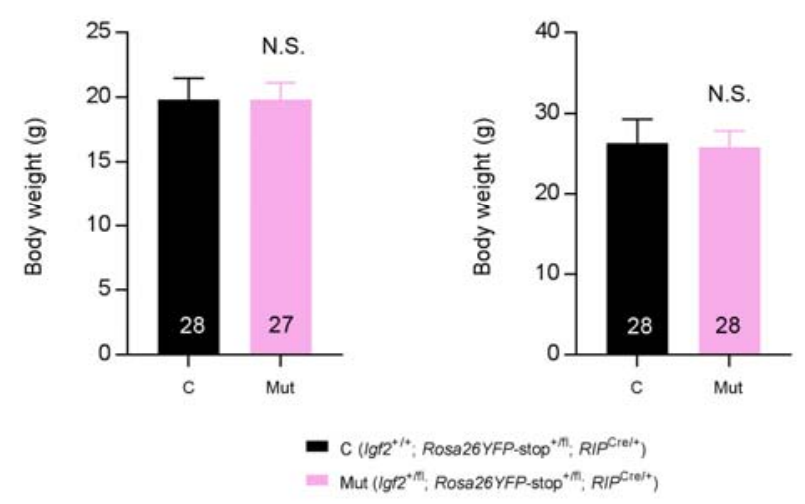

Supplementary Figure 10: Glucose homeostasis and body weights in lgf2 pancreas-cell type specific knockouts at $\mathbf{8}$ weeks of age. Oral glucose tolerance tests (OGTTs) in male mice (a) and (c), and female mice (b) and (d), with pancreas cell-type specific deletions of Igf2 mediated by Nkx3.2Cre: mesenchyme, Ptf1a-Cre: epithelium in (a) and (b) or RIP-Cre: beta-cells in (c) and (d). Panels (a) to (d) depict changes in blood glucose concentrations from basal pre-treatment values ( $\mathrm{Y}$ axis) with 
time ( $X$ axis) after glucose administration. The insets indicate area under curve (AUC) calculated using the trapezoid rule. OGTT data was analysed statistically by repeated measures 1-way ANOVA with Dunnett's multiple comparison tests against controls $\left(\mathrm{C}-\operatorname{lgf} 2^{+/ f \mid}\right)$ for panels (a) and (b) and by two-way ANOVA with Sidak's multiple comparison tests for panels (c) and (d). AUC data was analysed statistically by 1-way ANOVA with Dunnett's post-hoc tests for panels (a) and (b) and by unpaired Student's t tests in panels (c) and (d). (e) Body weights in mice with beta-cell specific deletion of Igf2. Data was analysed using unpaired Student's $t$ tests. For all panels, data is shown as average values and the error bars represent SEM; N.S. - non-significant. Numbers of mice are shown within data columns (per genotype). 
bioRxiv preprint doi: https://doi.org/10.1101/714121: this version posted July 31, 2019. The copyright holder for this preprint (which was not certified by peer review) is the author/funder, who has granted bioRxiv a license to display the preprint in perpetuity. It is made available under aCC-BY-NC-ND 4.0 International license.

\section{Supplementary Table 1: Mouse strains and crosses}

\begin{tabular}{|c|c|c|c|}
\hline $\begin{array}{l}\text { Paternal } \\
\text { genotype }\end{array}$ & $\begin{array}{l}\text { Maternal } \\
\text { genotype }\end{array}$ & Offspring/embryo genotypes & Related to Figure \\
\hline $\operatorname{lgf2} 2^{1++}$ & $\operatorname{lgf2}^{+1+}$ & $\lg f 2^{+/+}$ & Fig. 1b; Fig. 6 \\
\hline \multirow[b]{2}{*}{$\operatorname{lgf} 2^{+/ f \mid}$} & \multirow[b]{2}{*}{$\operatorname{lgf} 2^{+/+}$} & $\lg f 2^{+/ \pi}$ & \multirow[t]{2}{*}{ Supplementary Fig. 1} \\
\hline & & $\lg 2^{+/+}$ & \\
\hline \multirow[b]{2}{*}{$\operatorname{lgf} 2^{+/ f l}$} & \multirow[b]{2}{*}{$C M V^{\text {Cre/Cre }}$} & $\operatorname{lgf} 2^{+/ f l} ; C M V^{\mathrm{Cre} /+}$ & \multirow[t]{2}{*}{ Supplementary Fig.2 } \\
\hline & & $\operatorname{lgf} 2^{+++} ; C M V^{\mathrm{Cre} /+}$ & \\
\hline \multirow{4}{*}{$\begin{array}{l}\operatorname{lgf2} 2^{+/ f l} ; \\
\text { Rosa26 YFP- } \\
\text { stop }^{\mathrm{fl} / \mathrm{fl}}\end{array}$} & \multirow{4}{*}{$N k \times 3.2^{+/ C r e}$} & $\operatorname{lgf2}^{+f t /} ;$ Rosa26YFP-stop ${ }^{+/ f l} ; N k x 3.2^{\mathrm{Cre} /+}$ & \multirow{4}{*}{$\begin{array}{l}\text { Fig. 2; Fig. 4; Fig. 5, Fig. 7d } \\
\text { Supplementary Fig. 3d } \\
\text { Supplementary Fig. } 4 \\
\text { Supplementary Fig. } 5 \mathrm{a} \\
\text { Supplementary Fig. } 8 \\
\text { Supplementary Fig. } 9\end{array}$} \\
\hline & & Igf2 $^{+/+} ;$Rosa26YFP-stop ${ }^{+/ f l} ; N k x 3.2^{\mathrm{Cre} /+}$ & \\
\hline & & $\operatorname{lgf}^{+/ t+} ;$ Rosa26YFP-stop ${ }^{+/ f l}$ & \\
\hline & & $\operatorname{lgf2}^{+/+} ;$Rosa26YFP-stop $^{+/ t l}$ & \\
\hline \multirow{4}{*}{$N k \times 3.2^{+/ C r e}$} & \multirow{4}{*}{ 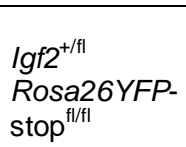 } & $\operatorname{lgf2}^{\mathrm{t} /+} ;$ Rosa26YFP-stop ${ }^{\mathrm{t} /+} ; N k \times 3.2^{+/ \mathrm{Cre}}$ & \multirow[t]{4}{*}{ Supplementary Fig. 5b,c } \\
\hline & & Igf2 $^{+/+} ;$Rosa26YFP-stop ${ }^{\mathrm{t} /+} ; N k \times 3.2^{+/ C r e}$ & \\
\hline & & $\operatorname{lgf}^{\mathrm{t} / 1++} ;$ Rosa26YFP-stop ${ }^{\mathrm{t} /+}$ & \\
\hline & & $\operatorname{lgf}^{t /+} ;$ Rosa26YFP-stop $^{\mathrm{tl}+}$ & \\
\hline \multirow{2}{*}{$\begin{array}{l}\text { Rosa26YFP- } \\
\text { stop }^{f / / 1}\end{array}$} & \multirow[t]{2}{*}{$N k \times 3.2^{+/ C r e}$} & Rosa26YFP-stop $^{+/ t /} ; N k \times 3.2^{\mathrm{Cre} /+}$ & \multirow{2}{*}{$\begin{array}{l}\text { Fig. 1a,c } \\
\text { Supplementary Fig. } 3 a \\
\text { Supplementary Fig. } 4\end{array}$} \\
\hline & & Rosa26YFP-stop ${ }^{+/ t}$ & \\
\hline \multirow{4}{*}{$N k \times 3.2^{+/ C r e}$} & \multirow{4}{*}{$\begin{array}{l}\text { H19DMD } \\
\text { Rosa26 } \\
\text { stop }^{\mathrm{fl} / \mathrm{+l}}\end{array}$} & H19DMD $^{\mathrm{t} /+} ;$ Rosa26YFP-stop ${ }^{\mathrm{t} /+} ;$ Nkx3.2 ${ }^{+/ C r e}$ & \multirow{4}{*}{ Fig. 3a-d } \\
\hline & & $H_{19 D M D^{+/+}} ;$Rosa26YFP-stop ${ }^{\text {t/l+t}} ; N k x 3.2^{+/ C r e}$ & \\
\hline & & $H_{19 D M D^{\mathrm{t} /++} ; \text { Rosa26YFP-stop }}{ }^{\mathrm{t} /+}$ & \\
\hline & & H19DMD $^{+/+} ;$Rosa26YFP-stop ${ }^{\mathrm{fl} /+}$ & \\
\hline \multirow{4}{*}{$N k \times 3.2^{+/ C r e}$} & \multirow{4}{*}{ 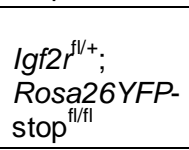 } & 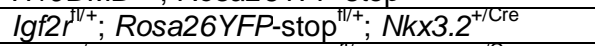 & \multirow{4}{*}{ Fig. 3e-h } \\
\hline & & $\operatorname{lgf2r}^{+/+} ;$Rosa26YFP-stop ${ }^{\text {t//+}} ; N k \times 3.2^{+/ C r e}$ & \\
\hline & & 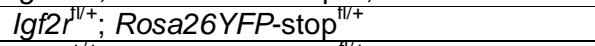 & \\
\hline & & $\operatorname{lgf2r}^{+/+} ;$Rosa26YFP-stop ${ }^{\mathrm{t} / /+}$ & \\
\hline \multirow{10}{*}{ 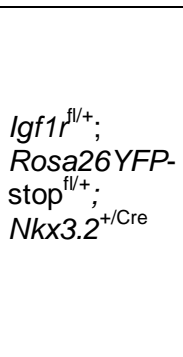 } & \multirow{10}{*}{ 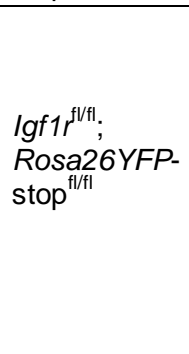 } & $\operatorname{lgf1r}^{\mathrm{fl} / \mathrm{fl}} ;$ Rosa26YFP-stop $^{\mathrm{fl} / \mathrm{fl}} ; N k \times 3.2^{+/ \mathrm{Cre}}$ & \\
\hline & & lgf1 $1^{\mathrm{fl} / \mathrm{t}} ;$ Rosa26YFP-stop ${ }^{\mathrm{tl}+} ; N k \times 3.2^{+/ \mathrm{Cre}}$ & \\
\hline & & $\operatorname{lgf1}^{\mathrm{t} / /+} ;$ Rosa26YFP-stop ${ }^{\mathrm{t} / / 1 \mathrm{t}} ; N k \times 3.2^{+/ \mathrm{Cre}}$ & \\
\hline & & $\operatorname{lgf1} \mathrm{f}^{\mathrm{fl}+} ;$ Rosa26YFP-stop ${ }^{\mathrm{t} / /+} ; N k \times 3.2^{+/ \mathrm{Cre}}$ & \\
\hline & & $\operatorname{lgf1r^{\mathrm {fl}/\mathrm {t}};\text {Rosa26YFP-stop}}$ & Supplementary Fig. 6 \\
\hline & & $\operatorname{lgf1r}^{\mathrm{fl/fl}} ;$ Rosa26YFP-stop $^{\mathrm{t} / \mathrm{+}}$ & \\
\hline & & $\operatorname{lgf1r}^{\mathrm{fl}+} ;$ Rosa26YFP-stop $\mathrm{p}^{\mathrm{t} / \mathrm{t}}$ & \\
\hline & & $\operatorname{lgf1r}^{\mathrm{fl}+} ;$ Rosa26YFP-stop ${ }^{\mathrm{tl}++}$ & \\
\hline & & $\operatorname{lgf}^{+/+} ;$Rosa26YFP-stop ${ }^{+/ f l} ; N k \times 3.2^{+/ C r e}$ & \\
\hline & & $\lg 2^{+/+}$ & \\
\hline $\begin{array}{l}\text { Rosa26YFP- } \\
\text { stop }^{\mathrm{fl} / \mathrm{fl}}\end{array}$ & $R I P^{\text {Cre/Cre }}$ & Rosa26YFP-stop ${ }^{+/ f l} ; R I P^{\text {Cre/+ }}$ & $\begin{array}{l}\text { Fig.1a; Supplementary Fig. } \\
3 \mathrm{c}\end{array}$ \\
\hline $\lg 2^{+/ f t}$ & $R I P^{\text {Cre/Cre }}$ & $\operatorname{lgf}^{+f f l} ;$ Rosa26YFP-stop ${ }^{+f f l} ; R I P^{C r e /+}$ & Fig. $7 e$ \\
\hline $\begin{array}{l}\text { Rosa26YFP- } \\
\text { stop }^{\mathrm{fl} / \mathrm{fl}}\end{array}$ & & $\operatorname{lgf}^{+/+} ;$Rosa26YFP-stop ${ }^{+/ t} ; R I P^{\text {Cre/+ }}$ & $\begin{array}{l}\text { Supplementary Fig. 3f,g } \\
\text { Supplementary Fig. } 10 \mathrm{c}, \mathrm{d}, \mathrm{e}\end{array}$ \\
\hline 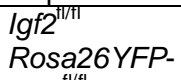 & $\begin{array}{l}\text { Nkx3.2//Cre; } \\
\text { Ptf1a }\end{array}$ & $\begin{array}{l}\text { lgf2 } 2^{+/ f l} \text {; Rosa26YFP-stop }{ }^{+/ f l} ; \quad N k \times 3.2^{\mathrm{Cre} /+} ; \\
\text { Ptf1a }\end{array}$ & $\begin{array}{l}\text { Fig. 1d } \\
\text { Fig. } 7 a-c\end{array}$ \\
\hline $\operatorname{stop}^{\mathrm{fl} / \mathrm{fl}}$ & & $\operatorname{lgf2^{+/tl}} ;$ Rosa26YFP-stop ${ }^{+/ f l} ; N k x 3.2^{\text {Cre/+ }}$ & Supplementary Fig. 10a,b \\
\hline & & lgf2 $^{+f f l} ;$ Rosa26YFP-stop ${ }^{+f f l} ; P t f 1 a^{\text {Cre/+ }}$ & \\
\hline & & $\operatorname{lgf}^{+/ f 1} ;$ Rosa26YFP-stop ${ }^{+/ f t}$ & \\
\hline $\operatorname{lgf} 2^{\mathrm{t} / \mathrm{tI}}$ & $\operatorname{Tek}^{+/ \mathrm{Cre}}$ & $\operatorname{lgf} 2^{+/ 1 \mathrm{I}} ; \operatorname{Tek}^{\mathrm{Cre} /+}$ & Fig.1d \\
\hline $\begin{array}{l}\text { Rosa26 YFP- } \\
\text { stop }^{\mathrm{fl} / \mathrm{fl}}\end{array}$ & & $\operatorname{lgf2^{+fti}}$ & \\
\hline $\lg 2^{+t+t}$ & Ptf1a ${ }^{+/ \mathrm{Cre}}$ & lgf2 $^{+f f l} ;$ Rosa26YFP-stop ${ }^{+f f l} ; P t f 1 a^{\text {Cre/+ }}$ & Supplementary Fig. 3b,e \\
\hline Rosa26YFP- & & $\operatorname{lgf2}^{+/ f t} ;$ Rosa26YFP-stop ${ }^{+f f}$ & \\
\hline $\operatorname{stop}^{f / f l}$ & & 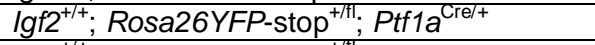 & \\
\hline & & $\operatorname{lgf}^{+/+} ;$Rosa26YFP-stop ${ }^{+/ f 1}$ & \\
\hline$m i R-483^{+/ k o}$ & $m i R-483^{+/+}$ & $m i R-483^{+/ k o}$ & Supplementary Fig. 7 \\
\hline & & $m i R-483^{+/+}$ & \\
\hline
\end{tabular}

+ wild-type allele; fl - floxed allele; ko - knockout 


\section{Supplementary Table 2: Primers used for genotyping by PCR}

\begin{tabular}{|c|c|c|c|c|c|}
\hline Strain & Primer & Sequence $\left(5^{\prime}\right.$ to $\left.3^{\prime}\right)$ & Primer & Sequence $\left(5^{\prime}\right.$ to $\left.3^{\prime}\right)$ & $\begin{array}{l}\text { Amplicon } \\
\text { (bp) }\end{array}$ \\
\hline $\lg 2^{+/ f l}$ & $\mathrm{~F}$ & TTACAGTTCAAAGCCACCACG & $\begin{array}{l}\text { RW } \\
\text { RD }\end{array}$ & $\begin{array}{l}\text { GCCAAAGAGATGAGAAGCACC } \\
\text { GCCAAACACAGTAAAAAGAAA } \\
\text { TGC }\end{array}$ & $\begin{array}{l}\text { WT: } 324 \\
\text { fl: } 449 \\
\text { del: } 384\end{array}$ \\
\hline$H 19 D M D^{H /+}$ & $\mathrm{F}$ & CAGGCCTGTCCTCACCTGAAC & $R$ & $\begin{array}{l}\text { GCCAGCTTGCCTTGGCAACCCC } \\
\text { TT }\end{array}$ & $\begin{array}{l}\text { WT: } 387 \\
\text { fl: } 520\end{array}$ \\
\hline $\lg 2 r^{\mathrm{fl} /+}$ & $\mathrm{F}$ & CCTTCCCTCCAGGCCGTTAC & $\mathrm{R}$ & $\begin{array}{l}\text { GGTGAGGTCTCCATCTGAGTAC } \\
\mathrm{C}\end{array}$ & $\begin{array}{l}\text { WT: } 225 \\
\text { fl: } 259\end{array}$ \\
\hline $\operatorname{lgf} 1 r^{+/ f l}$ & $\mathrm{~F}$ & $\begin{array}{l}\text { CTTCCCAGCTTGCTACTCTAG } \\
\mathrm{G}\end{array}$ & $R$ & $\begin{array}{l}\text { CAGGCTTGCAATGAGACATGG } \\
\mathrm{G}\end{array}$ & $\begin{array}{l}\text { WT: } 124 \\
\text { fl: } 220\end{array}$ \\
\hline $\operatorname{miR}-483^{+/ k o}$ & $\mathrm{~F}$ & $\begin{array}{l}\text { TACCTGCCTGTGAACTGCTCT } \\
\mathrm{G}\end{array}$ & $\mathrm{R}$ & ATCTGGTGCCTCCTGTCTGGTA & $\begin{array}{l}\text { WT: } 440 \\
\text { KO: } 457\end{array}$ \\
\hline Nkx3.2-Cre & $\mathrm{F}$ & $\begin{array}{l}\text { CCAGGCGATCCTCAACAAGA } \\
\text { AGAGGG }\end{array}$ & $\begin{array}{l}\text { R-Cre } \\
\text { R-WT }\end{array}$ & $\begin{array}{l}\text { CTCGTTCTCTTCGCTCAGGGCT } \\
\text { GAG } \\
\text { GCCGCATAACCAGTGAAACAG } \\
\text { CATTGC }\end{array}$ & $\begin{array}{l}\text { Cre: } 420 \\
\text { WT: } 264\end{array}$ \\
\hline Ptf1a-Cre & $\mathrm{F}$ & ACCTTTGCCTTCCCCAAC & $\begin{array}{l}\text { R-WT } \\
\text { R-Cre }\end{array}$ & $\begin{array}{l}\text { TGGTGGCTGAGGAACTCTAC } \\
\text { TGAGTGAACGAACCTGGTCG }\end{array}$ & $\begin{array}{l}\text { WT: } 286 \\
\text { Cre: } 590\end{array}$ \\
\hline RIP-Cre & $\begin{array}{l}\text { F-WT } \\
\text { F-Cre }\end{array}$ & $\begin{array}{l}\text { ATGTCTCCAATCCTTGAACAC } \\
\text { TG } \\
\text { CGAGTGATGAGGTTCGCAAG }\end{array}$ & $\begin{array}{l}\text { R-WT } \\
\text { R-Cre }\end{array}$ & $\begin{array}{l}\text { GCAGTGGGAGAAATCAGAACC } \\
\text { TGAGTGAACGAACCTGGTCG }\end{array}$ & $\begin{array}{l}\text { WT: } 254 \\
\text { Cre: } 390\end{array}$ \\
\hline $\begin{array}{l}\text { Rosa26YFP- } \\
\text { stop }^{+f l}\end{array}$ & $\mathrm{~F}$ & TGTTATCAGTAAGGGAGCT & $\begin{array}{l}\text { R-WT } \\
\text { R-fl }\end{array}$ & $\begin{array}{l}\text { CACACCAGGTTAGCCTTTA } \\
\text { AAGACCGCGAAGAGTTTGT }\end{array}$ & $\begin{array}{l}\text { WT: } 239 \\
\text { fl: } 301\end{array}$ \\
\hline Tek-Cre & $\mathrm{F}$ & TGTAAACAAGAGCGAGTGGA & $\begin{array}{l}\text { R-WT } \\
\text { R-Cre }\end{array}$ & $\begin{array}{l}\text { AGAGAATGGCGAGAAGTCAC } \\
\text { TGAGTGAACGAACCTGGTCG }\end{array}$ & $\begin{array}{l}\text { WT: } 240 \\
\text { Cre: } 610\end{array}$ \\
\hline Sry & $\begin{array}{l}\text { F-WT } \\
\text { F-M }\end{array}$ & $\begin{array}{l}\text { ATGTCTCCAATCCTTGAACAC } \\
\text { TG } \\
\text { CCCAGCATGCAAAATACAGA }\end{array}$ & $\begin{array}{l}\text { R-WT } \\
\text { R-M }\end{array}$ & $\begin{array}{l}\text { GCAGTGGGAGAAATCAGAACC } \\
\text { TCAACAGGCTGCCAATAAAA }\end{array}$ & $\begin{array}{l}\text { WT: } 254 \\
M: 350\end{array}$ \\
\hline CMV-Cre & $\begin{array}{l}\text { F-WT } \\
\text { F-Cre }\end{array}$ & $\begin{array}{l}\text { ATGTCTCCAATCCTTGAACAC } \\
\text { TG }\end{array}$ & $\begin{array}{l}\text { R-WT } \\
\text { R-Cre }\end{array}$ & GCAGTGGGAGAAATCAGAACC & $\begin{array}{l}\text { WT: } 254 \\
\text { Cre: }\end{array}$ \\
\hline
\end{tabular}

+ wild-type allele; $\mathrm{fl}$ - floxed allele; ko - knockout 
bioRxiv preprint doi: https://doi.org/10.1101/714121; this version posted July 31, 2019. The copyright holder for this preprint (which was not certified by peer review) is the author/funder, who has granted bioRxiv a license to display the preprint in perpetuity. It is made available under aCC-BY-NC-ND 4.0 International license.

\section{Supplementary Table 3: Conditions used for pancreas immunostaining}

\begin{tabular}{|c|c|c|c|c|}
\hline Staining & Antigen retrieval & Blocking & Primary antibody & Secondary antibody \\
\hline Amylase & $\begin{array}{l}\text { Autoclaving for } 15 \\
\text { min at } 121^{\circ} \mathrm{C} \text { in citric } \\
\text { acid buffer (10 mM } \\
\text { citric acid, pH } 6.0 \text {, } \\
0.05 \% \text { tween) }\end{array}$ & $\begin{array}{l}5 \% \text { Donkey } \\
\text { serum } \\
\text { (Sigma) }\end{array}$ & $\begin{array}{l}\text { Rabbit polyclonal to } \\
\text { amylase }(1: 100, \text { Sigma } \\
\text { A8273) overnight at } 4^{\circ} \mathrm{C}\end{array}$ & $\begin{array}{l}\text { Donkey anti-rabbit } \\
(1: 200, \text { Jackson labs, } \\
\text { Alexa Fluor 594) } 1 \text { hour } \\
\text { at room temperature }\end{array}$ \\
\hline YFP & $\begin{array}{l}\text { Autoclaving for } 15 \\
\text { min at } 121^{\circ} \mathrm{C} \text { in citric } \\
\text { acid buffer (10 } \mathrm{mM} \\
\text { citric acid, pH } 6.0 \text {, } \\
0.05 \% \text { tween) }\end{array}$ & $\begin{array}{l}5 \% \text { Donkey } \\
\text { serum } \\
\text { (Sigma) }\end{array}$ & $\begin{array}{l}\text { Goat polyclonal to GFP } \\
(1: 200, \text { Abcam ab6673) } \\
\text { overnight at } 4^{\circ} \mathrm{C}\end{array}$ & $\begin{array}{l}\text { Donkey anti-goat (1:200, } \\
\text { Jackson labs, Alexa Fluor } \\
488) 1 \text { hour at room } \\
\text { temperature }\end{array}$ \\
\hline IGF2 & $\begin{array}{l}\text { Digestion with } 1 \% \\
\text { pronase (Protease } \\
\text { from Streptomyces } \\
\text { griseus, Sigma } \\
\text { Aldrich P6911) in } \\
1 \times \text { PBS for } 10 \mathrm{~min} \text { at } \\
37^{\circ} \mathrm{C}\end{array}$ & $\begin{array}{l}15 \% \text { Donkey } \\
\text { serum } \\
\text { (Sigma) }\end{array}$ & $\begin{array}{l}\text { Goat anti-human IGF2 } \\
\text { (1:50, R\&D systems AF- } \\
\text { 292) overnight at } 4^{\circ} \mathrm{C}\end{array}$ & $\begin{array}{l}\text { Donkey anti-goat (1:200, } \\
\text { Jackson labs, Alexa Fluor } \\
488) 1 \text { hour at room } \\
\text { temperature }\end{array}$ \\
\hline Cytokeratin & $\begin{array}{l}\text { Autoclaving for } 15 \\
\text { min at } 121^{\circ} \mathrm{C} \text { in citric } \\
\text { acid buffer (10 mM } \\
\text { citric acid, pH } 6.0 \text {, } \\
0.05 \% \text { tween) }\end{array}$ & $\begin{array}{l}15 \% \text { Donkey } \\
\text { serum } \\
\text { (Sigma) }\end{array}$ & $\begin{array}{l}\text { Rabbit anti-cytokeratin } \\
(1: 500 \text {, Dako) overnight at } \\
4^{\circ} \mathrm{C}\end{array}$ & $\begin{array}{l}\text { Donkey anti-rabbit } \\
(1: 200, \text { Jackson labs, } \\
\text { Alexa Fluor 594) } 1 \text { hour } \\
\text { at room temperature }\end{array}$ \\
\hline CD31 & $\begin{array}{l}\text { Autoclaving for } 15 \\
\text { min at } 121^{\circ} \mathrm{C} \text { in citric } \\
\text { acid buffer (10 mM } \\
\text { citric acid, pH 6.0, } \\
0.05 \% \text { tween) }\end{array}$ & $\begin{array}{l}15 \% \text { Donkey } \\
\text { serum } \\
\text { (Sigma) }\end{array}$ & $\begin{array}{l}\text { Rabbit anti-CD31 (1:50, } \\
\text { Abcam ab28364) } \\
\text { overnight at } 4^{\circ} \mathrm{C}\end{array}$ & $\begin{array}{l}\text { Donkey anti-rabbit } \\
(1: 200, \text { Jackson labs, } \\
\text { Alexa Fluor 594) } 1 \text { hour } \\
\text { at room temperature }\end{array}$ \\
\hline Insulin & Not needed & $\begin{array}{lr}5 \% & \text { Rabbit } \\
\text { serum (Dako) }\end{array}$ & 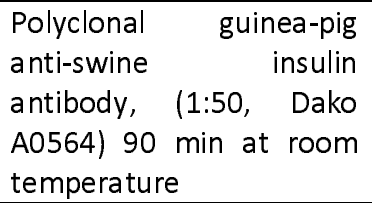 & $\begin{array}{l}\text { Rabbit anti-guinea pig } \\
\text { HRP coupled (1:100, } \\
\text { Abcam ab6771) } 1 \text { hour } \\
\text { at room temperature, } \\
\text { then DAB for } 2 \text { min }\end{array}$ \\
\hline
\end{tabular}




\section{Supplementary Table 4: Primers/assays used for qRT-PCR}

\begin{tabular}{|c|c|c|c|}
\hline Gene & Forward primer ( $5^{\prime}$ to $\left.3^{\prime}\right)$ & Reverse primer ( $5^{\prime}$ to $\left.3^{\prime}\right)$ & Amplicon (bp) \\
\hline Ppia & AAGGGTTCCTCCTTTCACAGAA & GATGCCAGGACCTGTATGCTT & 146 \\
\hline $\lg 2$ & AGTCCGAGAGGGACGTGTCTA & CGGACTGTCTCCAGGTGTCAT & 102 \\
\hline H19 & GTGTCACCAGAAGGGGAGTG & AGTGCCTCATGGGAATGGTG & 110 \\
\hline $\lg 1 r$ & GTTATCCACGACGATGAGTGC & AGTCACCGAATCGATGGTTTTC & 150 \\
\hline $\lg 2 r$ & GGAAGACACCAGAACCAGACA & TGACACTCATCCTCTGGAAGC & 103 \\
\hline DIk1 & GGACGGGAAATTCTGCGAAAT & TTTCCAGAGAACCCAGGTGTG & 126 \\
\hline Plag/1 & CTGGCTTTCCTGCTCTCACA & AGCCCAGACAGAAAGAAGGTG & 127 \\
\hline Mest & GCTCTGCACTCATGGAAGACT & AGCACAACTATCTCAGGGCTT & 107 \\
\hline Pnliprp1 & CCTTGGAGCCCTGAGAAGATC & CCTCAATGGTCGATGGGTCAG & 103 \\
\hline Try & GATTCCTGCCAGGGTGACTC & TAGTTGCAGACCTTGGTGT & 125 \\
\hline Amy2 & GCAAGTGGAATGGCGAGAAG & TCGCTGATTATCATGGTTGTCC & 110 \\
\hline Sema5b & GTGTTCGGCCTATCATAGC & CAGGTTGTGATGTTCTGGATCC & 139 \\
\hline Sfrp1 & GTCAGAGGCCATCATTGAACAT & TGTCACCGTTTTCCTTCTTCAC & 86 \\
\hline$m m u-m i R-483-3 p$ & \multicolumn{3}{|c|}{ TM002560 (Applied Biosystems) } \\
\hline SNORNA202 & \multicolumn{3}{|c|}{ TM001232 (Applied Biosystems) } \\
\hline SnORNA234 & \multicolumn{3}{|c|}{ TM001234 (Applied Biosystems) } \\
\hline
\end{tabular}

Supplementary Data 1: List of genes significantly enriched (fold change $>1.5$; FDR adjusted $p$ value $<0.05)$ in mesenchyme and non-mesenchyme pancreatic cells at P2 in wild-type mice $\left(\right.$ Igf $2^{+/+}$; Rosa26YFP-stop ${ }^{+/ f l} ; N k \times 3.2^{\text {Cre/t+}}$ ) and associated functional pathway analyses (DAVID).

Supplementary Data 2: List of differentially expressed genes (fold change $>1.5$; FDR adjusted $p$ value $<0.05$ ) in non-mesenchymal cells between Igf2 $^{+/ f l} ;$ Rosa26YFP-stop ${ }^{+/ f l} ; N k \times 3.2^{\text {Cre/+ }}$ knockouts and

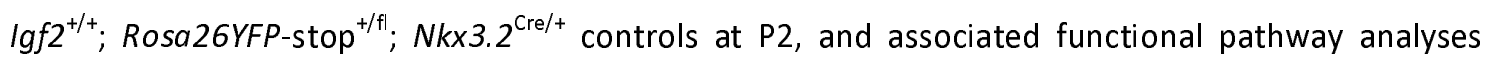
(DAVID).

Supplementary Data 3: List of differentially expressed genes (fold change $>1.5$; FDR adjusted $p$ value $<0.05$ ) in mesenchymal cells between Igf $2^{+/ f l} ;$ Rosa26YFP-stop ${ }^{+/ f l} ; N k \times 3.2^{\text {cre/+ }}$ knockouts and $/ g f 2^{+/+}$; Rosa26YFP-stop ${ }^{+/ f l} ; N_{k \times 3.2} 2^{\text {Cre/t }}$ controls at $\mathrm{P} 2$, and associated functional pathway analyses (DAVID). 